\title{
2 Heiligkeit und Heidentum im 13. Jahrhundert
}

\subsection{Heiligkeit und legendarisches Erzählen}

Das Heilige, verstanden als ein Bereich des Göttlichen, Vollkommenen und Absoluten, stellt gerade in seiner personifizierten Form als der oder die Heilige einen zentralen Bezugspunkt religiöser Identitätsbildung dar. Denn in heiligen Figuren manifestiert sich das Heilige als höchstes zu erstrebendes ,Gut' in menschlicher Gestalt im irdischen Leben und wird solchermaßen für die Gläubigen rezipierbar. Christliche Heiligenlegenden vermitteln diese Manifestation des Heiligen in der Welt auf narrative Weise. Im Folgenden werde ich daher die narrative Konstruktion von Heiligkeit im legendarischen Erzählen sowie ihre Funktion im Hinblick auf die dabei entworfenen Rezeptionspotentiale herausarbeiten. Dabei geht es mir darum, Heiligkeit als relationale Größe zu beschreiben, die gerade darin ihr Identifikationspotential erweist, dass sie das vertraute Eigene übersteigt und ein In-Bezug-Setzen des Innerweltlichen zur fremden Transzendenz erfordert, mithin die Aushandlung von Zugehörigkeit und Nichtzugehörigkeit befördert - und damit, wie ich dann im folgenden Unterkapitel zeigen werde, in struktureller Entsprechung zum Heidentum steht.

\subsubsection{Legendarisches Erzählen zwischen Transzendenz und Immanenz}

Wenn mit dem Begriff ,Legende` im engeren Sinn Lebensgeschichten von Heiligen bezeichnet werden, so fehlt ihm dennoch die Eindeutigkeit einer Übereinstimmung von Inhalt und Form, wie sie im klassischen Sinn eine Gattung konstituiert. Auf dieses grundlegende Problem weist schon die Etymologie des Begriffs selbst hin: Lateinisch legendum meint „das zu Lesende“, ist also eine Funktionszuweisung und spiegelt zunächst lediglich den Gebrauchszusammenhang dieser Textsorte wider, ohne mögliche formale Merkmale oder ihren inhaltlichen Kern $\mathrm{zu}$ benennen. ${ }^{1}$ Gemeint ist die

1 Vgl. Marina Münkler: Sündhaftigkeit als Generator von Individualität. Zu den Transformationen legendarischen Erzählens in den Faustbüchern des 16. und 17. Jahrhunderts. In: Literarische und religiöse Kommunikation in Mittelalter und Früher Neuzeit. DFG-Symposion 2006. Hrsg. von Peter Strohschneider. Berlin/New York 2009 (Germanistische Symposien. Berichtsbände), S. 25-61, hier S. 28. - Die gattungstheoretische Diskussion wird zudem dadurch erschwert, dass die ,Legende“ in der Forschung sowohl als universale Erzählform wie auch als spezifisch mittelalterliche und christlichreligiöse Gattung verstanden wird. Vgl. ebd., S. 35, Anm. 31. Für ersteren Ansatz vgl. vor allem HansPeter Ecker: Die Legende. Kulturanthropologische Annäherung an eine literarische Gattung. Stuttgart [u. a.] 1993 (Germanistische Abhandlungen. 76), für zweiteren in der älteren Forschung besonders Theodor Wolpers: Die englische Heiligenlegende des Mittelalters. Eine Formgeschichte des Legendenerzählens von der spätantiken lateinischen Tradition bis zur Mitte des 16. Jahrhunderts. Tübingen 1964 (Anglia. 10) und Siegfried Ringler: Zur Gattung Legende. Versuch einer Strukturbestimmung der christlichen Heiligenlegende des Mittelalters. In: Würzburger Prosastudien II. Untersuchungen zur 
liturgisch-kultische Praxis der religiösen Verehrung von Heiligen, deren Lebensbeschreibungen schon in der frühen Kirche zu bestimmten Tagen und Festen des Kirchenjahres sowie später besonders im Klosteralltag gelesen und vor allem vorgelesen wurden. ${ }^{2}$ Der Begriff der ,Legende“ ist aber auch insofern nicht eindeutig, als sich im mittelalterlichen Sprachgebrauch eine Vielzahl unterschiedlicher Bezeichnungen für Heiligenerzählungen findet, wie etwa vita, passio oder historia, die mitunter völlig willkürlich und austauschbar nebeneinander erscheinen können, zum Beispiel gerade auch in einem so systematisch und auf inhaltliche Kontingenz hin angelegten Legendar wie der Legenda aurea. Die forschungspragmatische Einengung auf den einzelnen Begriff ,Legende“ stellt also eine nicht unbegründete, aber eben doch diachron typologisierende Interpretation dar, die offenbar nicht den erzählerischen Kern dieser Texte bezeichnet.

Dazu kommt schließlich noch, dass Legendenstoffe in den mittelalterlichen Volkssprachen vielfältig bearbeitet wurden und daher in sehr unterschiedlichen Formen auftreten können. Es gibt also, so ließe sich resümieren, „keine literarischen Ausprägungen des Legendenerzählens, die kanonische Geltung beanspruchen könnten, sondern nur mehr oder weniger gelungene Versuche, mit den Mitteln der Literatur auch von dem Heiligen und den Heiligen zu erzählen“. ${ }^{3}$ Das ist freilich nicht als Hybridisierung zu verstehen, bei der die Legende in literarische Formen getragen würde, mit denen sie als im Kern religiöses Phänomen eigentlich nichts zu tun habe. Vielmehr zeigt sie sich darin als eine grundsätzlich transformatorische Gattung, die „aus ihrer Erzählhaltung heraus“, die in der Funktion der Narrativierung von Heiligkeit gründet, „das Spiel mit unterschiedlichen Erzählformen schon immer erlaubt“. ${ }^{4}$ Wenn es dennoch so etwas wie ,typische‘ Formen des legendarischen Erzählens gibt, so lassen sich diese weniger vom Stoff als von der Funktion der Legende her bestimmen, die im „religiösen Bedürfnis des Heiligenkults“ zu finden ist - die sich daraus ergebenden ,hagiographischen Konstanten‘, um einen Begriff der älteren Forschung aufzugreifen, können sich dann wiederum unterschiedlichen Rezeptions-

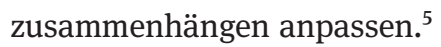

\footnotetext{
Literatur und Sprache des Mittelalters. Kurt Ruh zum 60. Geburtstag. Hrsg. von Peter Kesting. München 1975 (Medium Aevum. Philologische Studien. 31), S. 255-270.

2 Zum komplexen religiösen Gebrauchszusammenhang der Legende vgl. Arnold Angenendt: Heilige und Reliquien. Die Geschichte ihres Kultes vom frühen Christentum bis zur Gegenwart. 2., überarbeitete Aufl. München 1997.

3 Ulrich Wyss: Legenden. In: Epische Stoffe des Mittelalters. Hrsg. von Volker Mertens, Ulrich Müller. Stuttgart 1984, S. $40-60$, hier S. 40.

4 Julia Weitbrecht: Aus der Welt. Reise und Heiligung in Legenden und Jenseitsreisen der Spätantike und des Mittelalters. Heidelberg 2011 (Beiträge zur älteren Literaturgeschichte), S. 116, Anm. 15.

5 So zumindest der Ansatz von Wolpers, Die englische Heiligenlegende des Mittelalters, S. 36 - 37, Zitat S. 33. Auch Siegfried Ringler bestimmt die ,christliche Heiligenlegende des Mittelalters' auf diese Weise von ihrem religiösen Gehalt her, berücksichtigt aber ihre außerliterarische Einbindung nur insofern, als der Glaube die Grundlage für diesen Inhalt bildet, vgl. Ringler, Zur Gattung Legende.
} 
Eine Bestimmung des legendarischen Erzählens hat daher immer von zwei ineinander verschränkten Phänomenen auszugehen, die diese Textsorte konstituieren: Das Erzählen von außerliterarisch verbürgter Heiligkeit sowie die Konstruktion von Heiligkeit durch das Erzählen. Denn die Textgeltung von Legenden beruht zunächst einmal auf religiösen Legitimationsmechanismen, wie sie in der lateinischen Christenheit im Laufe des Mittelalters im kirchlichen Heiligsprechungsverfahren immer stärker formalisiert und institutionalisiert und besonders im 13. Jahrhundert auf den Papst und die römische Kurie hin zentralisiert werden. Zum anderen verfügen Legenden über narrative Muster und einen Kanon entsprechender Motive, die geeignet sind, die Heiligkeit des Protagonisten im Erzählprozess weniger zu beweisen als vielmehr sogar ,herzustellen'. Heiligkeit wird in der Legende also immer zugleich postuliert und prozessualisiert - sie wird als Heiligung narrativiert. ${ }^{6}$

Dabei greift es zu kurz, die Legende als Beschreibung eines Heiligenlebens zu verstehen, denn ihr Grundproblem reicht tiefer: Sie soll das Heilige in der Welt repräsentieren, das nicht als solches, sondern nur in seinen Wirkungen und damit nur auf vermittelnde Weise darstellbar ist. ${ }^{7}$ Die Schwierigkeit der Narrativierung von Heiligkeit besteht demnach im Erzählen vom per definitionem als unverfügbar angenommenem Transzendenten. Legenden, so die einflussreiche Definition von Peter Strohschneider, erzählen „nicht von der Transzendenz selbst, sondern sie erzählen vom Hineinragen der Transzendenz in die Immanenz, von ihrem Wirksamwerden in der Geschichte“. ${ }^{8}$ Damit stellt legendarisches Erzählen einen exemplarischen Fall religiöser Kommunikation im Sinne Niklas Luhmanns dar, deren Logik die grundsätzliche Unterscheidung von Immanenz und Transzendenz zugrunde liegt. Beide Bereiche bleiben aber aufeinander bezogen, denn erst durch die Wiedereinführung der Unterscheidung auf der einen Seite der Unterscheidung wird die Differenz überhaupt „denkbar und sagbar“. 9

Das Besondere der binären Codierung von Transzendenz und Immanenz besteht dabei in ihrer Asymmetrie, darin also, dass nicht beide Seiten der Unterscheidung der Beobachtung zugänglich sind. Gerade die Aussonderung eines nicht mehr unmittelbar zugänglichen Anderen als Transzendenz aus dem Bereich des Vorfindlichen der Immanenz aber ermöglicht Sinngebung und zwar in der „Einschränkung von Kommunikation durch die Form des Geheimnisvollen“, wodurch sich das Sakrale „distinguiert“ und sich selbst „gegen Trivialisierung“ schützt. ${ }^{10}$ Dabei existiert die

6 Vgl. Weitbrecht, Aus der Welt, S. 11.

7 Vgl. Peter Strohschneider: Textheiligung. Geltungsstrategien literarischen Erzählens im Mittelalter am Beispiel von Konrads von Würzburg Alexius. In: Geltungsgeschichten. Über die Stabilisierung und Legitimierung institutioneller Ordnungen. Hrsg. von Gert Melville, Hans Vorländer. Köln 2002, S. 109147, hier S. 113.

8 Ebd., S. 114.

9 Niklas Luhmann: Die Religion der Gesellschaft. Hrsg. von André Kieserling. Frankfurt a. M. 2000, Kap. 2: Codierung (S. 53-114), hier S. 77.

10 Ebd., S. 60-61. 
Transzendenz aber nicht unabhängig von der Immanenz, sondern findet in ihr mit der Sinngebung ihre spezifische Funktion, beide Werte setzen einander wechselseitig voraus: „Erst von der Transzendenz aus gesehen erhält das Geschehen in dieser Welt einen religiösen Sinn. “11 Auf eine einfache Formel gebracht hieße das, „daß eine Kommunikation immer dann religiös ist, wenn sie Immanentes unter dem Gesichtspunkt der Transzendenz betrachtet“. ${ }^{12}$

Man kann dieser ,Differenzlogik‘, wie sie Strohschneider für die Analyse und Interpretation mittelalterlicher Heiligenlegenden zuerst fruchtbar gemacht und zuletzt noch einmal systematisch herausgearbeitet hat, ${ }^{13}$ die ,Identitätsbehauptung ' der Legende entgegenhalten, derzufolge sich in ihr gerade die Transzendenz selbst darstellen, also unmittelbar zugänglich werden soll: Wunder, Bekenntnis oder Martyrium des Heiligen wären demnach, so Hartmut Bleumer, in ,jener Art mythischer Konnektivität“, wie sie charakteristisch für symbolisches Denken ist, „nicht das Gleiche wie das biblische göttliche Wirken oder das Leiden Christi, sie sind das Selbe“. ${ }^{14}$

Diese beiden unterschiedlichen narratologischen Ansätze entsprechen unterschiedlichen religionswissenschaftlichen Modellen: Die Unterscheidung von Transzendenz und Immanenz geht auf den schon älteren religionssoziologischen und funktionalistischen Ansatz von Émile Durkheim zurück, wonach Religion die Welt in zwei Bereiche, in ,sakral' und ,profan', aufteilt und die vor allem soziale Funktion hat, gesellschaftliche Identität und Zusammenhalt zu stiften. ${ }^{15}$ Das Problem lässt sich aber mit Mircea Eliade auch religionsphänomenologisch und substanzialistisch beschreiben, der ausgehend von der Trennung der beiden Sphären den Begriff der ,Hierophanie' einführt, um die Manifestation des Heiligen im Profanen zu beschreiben. Alles kann dabei durchsichtig werden für das Heilige, welches vom Profanen zwar völlig unterschieden, dem Menschen aber nur in ihm zugänglich ist. ${ }^{16}$

11 Ebd., S. 77.

12 Ebd.

13 Zuerst in Peter Strohschneider: Inzest-Heiligkeit. Krise und Aufhebung der Unterschiede in Hartmanns Gregorius. In: Geistliches in weltlicher und Weltliches in geistlicher Literatur des Mittelalters. Hrsg. von Christoph Huber, Burghart Wachinger, Hans-Joachim Ziegeler. Tübingen 2000, S. 105-133, besonders S. 105-109. Abschließend in: Ders.: Höfische Textgeschichten. Über Selbstentwürfe vormoderner Literatur. Heidelberg 2014 GRM. Beihefte. 55), Kap. D. 3. (S. 170-190).

14 Hartmut Bleumer: ,Historische Narratologie‘? Metalegendarisches Erzählen im Silvester Konrads von Würzburg. In: Historische Narratologie. Mediävistische Perspektiven. Hrsg. von dems. [u. a.]. Berlin [u. a.] 2010, S. 231-261, hier S. 239. Zur Kritik an Strohschneider und der Gegenüberstellung von „Identitätslogik“ und „Differenzlogik“ vgl. ebd., Anm. 21.

15 Émile Durkheim: Les formes élémentaires de la vie religieuse. Paris 1912. Wenngleich Luhmann sich von Durkheim absetzt, denn dieser ,sieht nicht in der Unterscheidung selbst die Form der Religion, sondern fragt den Bereich des Sakralen nach spezifisch religiösen Formen ab“ (Luhmann, Die Religion der Gesellschaft, S. 9), während Luhmann die Unterscheidung von sakral und profan als spezifische Codierung - als Einführung einer Unterscheidung in die Kommunikation, die Sinn prozessiert (herstellt und vermittelt) - religiöser Kommunikation beschreibt.

16 Vgl. Mircea Eliade: Das Heilige und das Profane. Vom Wesen des Religiösen [1957]. Frankfurt a. M. 1984, S. 14-15. Phänomenologisch ist auch der Ansatz von Rudolf Otto, der gegen die einseitige Be- 
Diese spezifisch religionswissenschaftlich-methodische Fragestellung läuft demnach letztlich auf zwei Ebenen der Betrachtung hinaus; die des unbeteiligten, nicht metaphysisch, sondern wissenschaftlich rationalen Beobachters und die des Gläubigen, dessen religiöses Erleben Grundlage seines Erkennens ist. ${ }^{17}$ Beides sind unterschiedliche Beschreibungsmodelle, die nicht gegeneinander stehen müssen: Die Identitätsbehauptung des symbolischen lässt sich durchaus mittels der Differenzlogik des konstruktivistischen Denkens beschreiben, wenn nur die Ebenen von Objekt und Beobachtung, von Selbst- und Fremdbeobachtung nicht miteinander vermischt werden. ${ }^{18}$

Strohschneider erhebt aber gerade nicht den Anspruch, das ,Wesen“ der Legende oder des Heiligen zu erfassen. Sein Ansatz ist gerade kein essentialistischer, sondern beruht auf der Grundlage einer strukturellen wie funktionalen Unterscheidung von

tonung des Rationalen in der christlichen Theologie den Begriff des ,Numinosen' einführt, um das ,Heilige ' jenseits einer allein moralischen Deutung zu fassen, dessen Erfahrung er als mysterium tremendum und mysterium fascinans beschreibt, vgl. Rudolf Otto: Das Heilige. Über das Irrationale in der Idee des Göttlichen und sein Verhältnis zum Rationalen [1917]. München 1963, Nachdruck 2004.

17 Das bemerkt Luhmann, Die Religion der Gesellschaft, S. 11, Anm. 8, für Rudolf Otto, der seinen Ausführungen vorausschickt: „Wir fordern auf, sich auf einen Moment starker und möglichst einseitiger religiöser Erregtheit zu besinnen. Wer das nicht kann oder wer solche Momente überhaupt nicht hat, ist gebeten nicht weiter zu lesen.“ Otto, Das Heilige, S. 8.

18 So Strohschneider, Höfische Textgeschichten, S. 180 in Replik auf Bleumer, Metalegendarisches Erzählen, S. 259, der letztlich selbst gerade zeigt, wie die Legende die Differenz von Transzendenz und Immanenz bearbeitet, auch wenn er darin ein spezifisch „metalegendarisches Erzählen“ sieht, weil er mit dem Silvester Konrads von Würzburg in einer meines Erachtens höchst problematischen Unterscheidung nur die „weltlichen Erzählformen vom Heiligen“ im Blick hat, „die das Problem der Heiligkeit diskursiv ausstellen, ohne deshalb selbst schon legendarisch zu wirken“. Dagegen lässt sich zeigen, dass auch das ,eigentliche“ legendarische Erzählen, als Erzählen vom Einbruch der unverfügbaren Transzendenz in die Immanenz, die Ebene des ,Metalegendarischen immer schon verhandelt, sei es bewusst oder unbewusst, ohne dass damit der Anspruch ,legendarischer Wirkung' eingeschränkt würde. Vielmehr werden in der Legende „,ihr eigene Wirkung und Reichweite stets benannt und im Erzählen produktiv gemacht“, so Julia Weitbrecht: Imitatio und Imitabilität. Zur Medialität von Legende und Legendenspiel. In: PBB 134, 2 (2012), S. 204-219, hier S. 219. Auf noch grundsätzlicherer theoretischer Ebene zeigt Susanne Köbele: Die Illusion der ,einfachen Form'. Über das ästhetische und religiöse Risiko der Legende. In: PBB 134, 3 (2012), S. 365 - 404, ebenfalls anhand von Konrads Silvester und in kritischer Absetzung von Bleumer, dass Legenden entgegen der Illusion der ,einfachen Form immer schon von einem religiösen und ästhetischen Risiko bestimmt sind: „Legenden müssen so tun, als wüssten sie nicht, dass ,schlicht und gläubig die gattungstypischen Paradoxien nicht zu bewältigen, sondern allenfalls zu überspringen sind angesichts eines Erzählens, das von der Evidenz des Wunders ausgeht, im Wissen, dass diese Evidenz nicht verfügbar ist. Das implizite Risiko der Legende, zugleich ihre religiöse Dringlichkeit besteht [...] in eben dieser Illusion der ,einfachen Form،.“ (Ebd., S. 395) Die Rede von der ,einfachen Form‘ bezieht sich auf André Jolles, der die Legende in einer substantialistischen Bestimmung in einer elementaren Symbolfunktion aufgehen lässt - der Darstellung ,des Guten', die in der gläubig-schlichten Nachahmung (imitatio) durch die Rezipienten ihre Entsprechung finde - und damit gattungstheoretisch lange bestimmend war. Vgl. Einfache Formen [1930]. 6., unveränderte Aufl. Tübingen 1982 (Konzepte der Sprach- und Literaturwissenschaft. 15), S. 35. Zur Kritik an Jolles siehe auch unten S. 33-34. 
Transzendenz und Immanenz, deren wechselseitiges Verhältnis immer wieder auf verschiedene Weise bearbeitet, also in Kommunikation überführt werden muss, weil sie schon in rein formalem Sinn nicht zu trennen sind, sondern in ihrer Einheit die „elementare Struktur unseres Weltverhältnisses“19 bilden. Ein solcher „formaler Prozessbegriff der ,Heiligung “ “20 hebt sich von herkömmlichen gattungstheoretischen Kategorien zur Bestimmung der Legende ab, indem er nicht literarische Themen und Motive in den Mittelpunkt stellt, sondern das Heilige und die Figur des Heiligen selbst. Damit ist er geeignet, die Geltungsbedingungen und Geltungsstrategien legendarischen Erzählens zu beschreiben. ${ }^{21}$ Denn aus der grundlegenden Unterscheidung von Transzendenz und Immanenz sowie der Bearbeitung dieser Differenz ergibt sich, dass Heiligkeit keine ontologische, sondern notwendigerweise eine relationale Kategorie ist. ${ }^{22}$ Das ist bedeutsam im Hinblick auf ihre religiösen Geltungsansprüche, die ich im folgenden Unterkapitel noch näher darstellen werde, zugleich aber aufschlussreich für die Funktionsweise und Muster legendarischen Erzählens, die ebendiese Geltungsansprüche entwerfen und transportieren.

Denn es geht im legendarischen Erzählen letztlich um die retrospektive, narrative Repräsentation von strukturell wie zeitlich abwesender Transzendenz, die im Leben eines nun verstorbenen Heiligen immanent wirksam geworden ist. ${ }^{23}$ Damit rückt die Legende in strukturelle Nähe zur Reliquie, unterscheidet sich von dieser aber kategorisch darin, dass sie die gnadenhaft gewährte Heilsgegenwart nicht zu realisieren vermag, sondern „bloß im Modus der symbolischen Verweisung“ repräsentiert, als Zeichen, das den Heiligen wie das Heil gegenwärtig scheinen lässt. ${ }^{24}$ Legendarisches Erzählen erweist sich mithin als narrative Bearbeitung einer spezifischen Grenze, eben der zwischen Transzendenz und Immanenz.

Ausgehend von den „narrative[n] Leerstellen, Paradoxien und Ambivalenzen“, die ein solches Erzählen mit sich bringt, hat Andreas Hammer den Ansatz von Strohschneider jüngst weiterentwickelt und nach den spezifischen Erzählstrategien und damit eben Funktionsweisen legendarischen Erzählens gefragt. ${ }^{25}$ Neben der

19 Strohschneider, Höfische Textgeschichten, S. 171.

20 Ebd.

21 Vgl. in diesem Zusammenhang auch meinen Beitrag: Die Wahrheit der Legende. Geltungsbedingungen und Geltungsstrategien legendarischen Erzählens am Beispiel der Legenda aurea. In: DIEGESIS. Interdisziplinäres E-Journal für Erzählforschung / Interdisciplinary E-Journal for Narrative Research 7, 2 (2018), S. 90 -110, hier S. 91-94. [https://www.diegesis.uni-wuppertal.de/index.php/die gesis/article/download/322/532, Zugriff: 28.01.2021]

22 Vgl. Weitbrecht, Aus der Welt, S. 11.

23 Vgl. Strohschneider, Höfische Textgeschichten, S. 178.

24 Vgl. ebd., S. 177-179, Zitat S. 177. Daher lässt sich die narrative Konstruktion von Heiligkeit auch als metonymisches Erzählen verstehen. Vgl. Harald Haferland: Metonymie und metonymische Handlungskonstruktion. Erläutert an der narrativen Konstruktion von Heiligkeit in zwei mittelalterlichen Legenden. In: Euphorion 99 (2005), S. 323-364.

25 Andreas Hammer: Erzählen vom Heiligen. Narrative Inszenierungsformen von Heiligkeit im Passional. Berlin/Boston 2015, S. 441. Wenn Hammer anmahnt, es gelte den „Blick vom Erzählen verstärkt 
Nachahmung Christi als dem grundlegenden hagiographischen Strukturelement überhaupt arbeitet er zwei weitere narrative Phänomene heraus: Heiligkeit manifestiere sich ebenso „anhand dialektisch aufeinander bezogener Basisoppositionen, die gerade keine reinen Dichotomien abbilden, sondern vielmehr Spannungsfelder, in denen sich der ambivalente Status von Heiligkeit als zusammengesetzte Kategorie in der Erzählung erweise“ ${ }^{\text {26 }}$, wobei Hammer mit dem Begriff der ,zusammengesetzten Kategorie“ die paradox anmutende Wechselbeziehung von Transzendenz und Immanenz, von Entzogenheit und Verfügbarkeit benennt. Die Basisoppositionen und Differenzsetzungen, die er beschreibt, sind die von Inklusion und Exklusion, verstanden als „Austritt aus Familie und Gesellschaft“ und „Eintritt in die Gemeinschaft der Heiligen“"27, von Stigma und Charisma sowie von Schuld und Gnade. Drittens nun komme es innerhalb dieser Spannungsfelder zu Umschlagsmomenten: „Sie markieren den Punkt, an dem die oberflächlich kausal geordnete Handlungsfolge in ein finales, providentiell vorbestimmtes Erzählziel - die Heiligkeit des Protagonisten - überführt wird.“28 Gemeint ist hier die Paradoxie, dass Heiligkeit in der Legende narrativ prozessualisiert wird, dabei eigentlich aber nur als Durchbruch der Transzendenz in die Immanenz zu verstehen ist.

Das lässt sich konkreter auf die Formen und Motive legendarischen Erzählens sowie die verschiedenen Modelle von Heiligkeit und Heiligentypen beziehen. Denn wie sich im Leben und Sterben eines Menschen Heiligung vollzieht und wie sich das Heilige in ihm vergegenwärtigt, wird in den herausragenden Stationen seiner Vita sowie deren Erzählzusammenhang dargestellt. Dabei lassen sich mit der Unterscheidung von Märtyrer- und Bekennerlegenden zwei grundlegende hagiographische Modelle ausmachen, die Edith Feistner als narrative Tiefenstrukturen beschrieben hat: Während bei den Märtyrerlegenden die Heiligwerdung in einer ,syntagmatischen Verknüpfung‘ realisiert wird, deren ,Basisnexus‘ im Geschehenszusammenhang von Verhör, Haft und Hinrichtung liegt, erscheinen in den Bekennerlegenden in einer losen ,paradigmatischen Reihung' Beispiele der Heiligung in mehr oder weniger beliebiger Zahl und Folge. ${ }^{29}$

Freilich bleibt diese Typologie in systematischer Hinsicht asymmetrisch, insofern sie nur zwischen Märtyrern und Nicht-Märtyrern differenziert und weitere Heiligkeitsmodelle unterschlägt. ${ }^{30}$ Allerdings entstammt diese basale Unterscheidung der

wieder auf die Erzählung zu richten“, bleibt seine genaue Kritik an Strohschneider und Luhmann allerdings unscharf. Am Ende geht es ihm nicht um eine grundlegenden theoretischen Neuansatz, sondern um methodische Prämissen, die helfen sollen, in der Analyse „den narrativen Umgang legendarischer Erzählungen mit Heiligkeit zu erfassen und zu beschreiben“ (S. 9).

26 Hammer, Erzählen vom Heiligen, S. 441.

27 Ebd., S. 230.

28 Ebd., S. 441.

29 Vgl. Feistner, Historische Typologie, S. 26-49.

30 Vgl. zu dieser Kritik an Feistners Typologie Eke Koch und Julia Weitbrecht: Einleitung. In: Julia Weitbrecht [u.a.]: Legendarisches Erzählen. Optionen und Modelle in Spätantike und Mittelalter. Berlin 2019 (Philologische Studien und Quellen. 273), S. 9-21, hier S. 14-15. 
für die Identitätsbildung der Kirche entscheidenden Phase der Christenverfolgungen und ist für den hagiographischen Diskurs in der Folge nicht nur retrospektiv, sondern durchaus auch prospektiv-normierend von Bedeutung. Zum anderen lassen sich erst im Rückgriff auf solche Typisierungen historische Konjunkturen und Überlagerungen verschiedener Modellierungen von Heiligkeit beschreiben. ${ }^{31}$ So hat Marina Münkler zwei biographische Modelle beschrieben, die jeweils innerhalb der beiden Legendentypen zur Geltung kommen können: Beim „lineare[n] Geburtsmodell“ ist der Heilige von seiner Geburt an frei von Sünde und eigentlich schon heilig, während im „rupturalen Konversionsmodell“ auf das Leben in der Gottesferne seine Bekehrung folgt, bevor er ein heiligmäßiges Büßerleben führt oder das Glaubensmartyrium erleidet. $^{32}$

Aus der religiösen Funktion der Legende in der Repräsentation von strukturell wie zeitlich abwesender Transzendenz und ihrem Wirksamwerden in der Immanenz lassen sich schließlich charakteristische ,hagiographische Konstanten' ableiten, die Theodor Wolpers mit Bezug auf die Legenda aurea folgendermaßen beschrieben hat: Die Legende sei geprägt durch eine ,Totalität‘ der erzählten Welt, die durchdrungen ist von der immer gegenwärtigen göttlichen Heilsgeschichte, in der der Heilige geborgen ist. ${ }^{33}$ Im Zentrum der Legende stehe allein die Figur des Heiligen, alle anderen haben nur die Funktion, gleichsam als Folie, seine Vorbildhaftigkeit zu verdeutlichen. ${ }^{34}$ Alles Geschehen erscheine aufgehoben im Willen Gottes, ,Sinn“ und ,Ziel` sind in der Transzendenz abgesichert, die Erzählung sei daher von ihrem Ende her motiviert; sämtliche äußeren Abläufe können demgegenüber zurücktreten, sodass auch die Verortung in Raum und Zeit nebensächlich zu werden scheine. ${ }^{35}$

Das religiöse Konzept der Legende in Bezug auf die Figur des Heiligen beschreibt auch Feistner folgendermaßen: „Der Heilige legt sein Leben vollständig in die Hand Gottes und dient selbst als Gefäß, in dem für andere die Präsenz Gottes in der Welt sichtbar wird.“36 Der einzige Beweggrund des Heiligen ist die Hingabe an den Willen Gottes unter Ausschluss all der Motive, die das weltliche Handeln bestimmen. ${ }^{37}$ Die Konsequenz dieser Hingabe ist schließlich das Wunder als ein Zeichen, in dem Gott

\footnotetext{
31 Insofern scheint mir die von Elke Koch und Julia Weitbrecht (ebd.) vorgetragene Kritik an Feistners Typologie etwas überzogen, wenngleich die Warnung vor Generalisierungen zweifellos wichtig und sinnvoll ist. Die von ihnen beschworene Vielgestaltigkeit legendarischen Erzählens ist nach meinem Dafürhalten zudem immer an den kirchlichen Heiligkeitsdiskurs zurückzubinden, der durchaus quer zu den narrativen Optionen und Modellen normierend und systematisierend eingreift. Der Bekennertypus entsteht zudem nicht erst nach Ende der Christenverfolgung, sondern beschreibt das Glaubenszeugnis derer, die ihren Glauben unter Todesgefahr bekennen, ohne aber am Ende dafür zu sterben. Vgl. dazu unten in Kap. 3 Martyrium: Sterben für Gott als Glaubenszeugnis, S. 87.

32 Münkler, Sündhaftigkeit als Generator von Individualität, S. 39.

33 Vgl. Wolpers, Die englische Heiligenlegende des Mittelalters, S. 22.

34 Vgl. ebd., S. 25.

35 Vgl. ebd., S. 26-27.

36 Feistner, Historische Typologie, S. 23.

37 Vgl. ebd., S. 47.
} 
die Heiligkeit seines Heiligen bestätigt. Der Heilige, von dem die Legende erzählt, ist daher auch nicht einfach ein Vorbild im Sinne eines herausragenden Helden, sondern zuallererst und ganz wesentlich ein vir Dei, der sein Leben ganz auf Gott ausrichtet und an dem und durch den dieser handelt. ${ }^{38}$

Diese Stilisierung und Typisierung in der Darstellung des Heiligen und seiner Heiligung darf aber nicht als Wendung ins Stereotype und Typologische missverstanden werden, denn die historische Verortung des Geschehens, so sehr sie im Einzelfall zurückzutreten scheint, ist eine grundlegende Bedingung für die Heiligenverehrung. Es geht ihr eben nicht nur um ein überzeitliches und rein symbolisch zu verstehendes mythisches Geschehen, sondern um Heilsgeschichte: ${ }^{39}$ um den exemplarischen, aber eben einmaligen Einbruch der Transzendenz in die Immanenz, der sich in diesem einen Heiligen vollzogen hat und sich in seiner Verehrung und Anrufung vergegenwärtigen lässt. Davon unberührt bleibt freilich die Sinnbildlichkeit des erzählten Geschehens, in der die im Sinne des christlichen Glaubens ,wahre Realität‘ aufscheint. ${ }^{40}$ Anrufbar aber ist der Heilige nur dann, ,wenn er in der Zeitlichkeit der Immanenz durch die behauptete Historizität seiner Legende fest verankert und ihm eine kohärente Identität verliehen worden ist, die es ermöglicht, ihn von anderen Heiligen zu unterscheiden“. ${ }^{41}$ Eine Anonymisierung stünde gerade seiner „Apellationsfähigkeit“ “42 entgegen und damit seiner Mittlerfunktion zwischen Immanenz und Transzendenz, die er für die Gläubigen einnimmt und um die es mir im Folgenden geht.

\subsubsection{Heiligkeit zwischen Distanz und Teilhabe}

Den Zusammenhang von der Heiligwerdung einzelner und ihrer kultischen Verehrung als Heilige beschreibt auch die jüngere Theologie mittels der funktionalen Bestimmung von Heiligkeit als spezifische Bearbeitung der Differenz von Transzendenz in die Immanenz. Heiligwerdung meint demnach

38 Vgl. Angenendt, Heilige und Reliquien, S. 69-74.

39 Das Christentum zeichnet sich ja gerade dadurch aus, dass es den Zusammenhang zwischen dem überzeitlichen Charakter von Heiligkeit als ein „Gegenwart Stiftendes und Präsenz Schaffendes“ und seiner Begründung in der Vergangenheit nicht transhistorisch und damit mythisch versteht, den Anfang also „nicht in ille tempore einer mythischen Vorzeit, sondern anno domini einer geschichtlichen“ verortet. Hammer, Erzählen vom Heiligen, S. 67.

40 Vgl. Ringler, Zur Gattung Legende, S. 260. Ringler rückt die Legende meines Erachtens allerdings insgesamt zu sehr ins Typologische. Die Person des Heiligen ist eben gerade sowohl, wie er selbst sagt, „etwas historisch Einmaliges“ (S. 258) als auch von überzeitlicher und allgemeiner Bedeutung.

41 Münkler, Sündhaftigkeit als Generator von Individualität, S. 36.

42 Strohschneider, Höfische Textgeschichten, S. 181, Anm. 121 unter Bezug auf Hans Blumenberg: Arbeit am Mythos. 5. Aufl. Frankfurt a. M. 1990, S. 22. 
in erster Linie nicht die Auszeugung eines bestimmten hochqualifizierten ethischen Verhaltens, obwohl dieses faktisch eine Existenz auf den Weg der Heiligkeit bringt, als vielmehr die Umwandlung eines profanen Lebens in ein solches, das die Transzendenz zeichenhaft transparent macht. Der heilige Mensch wird zum Medium der Erscheinung Gottes. In ihm ereignet sich Hierophanie. Damit ist wiederum nicht dieser Mensch selbst wichtig geworden, sondern nur das, was sich an und in ihm und durch ihn zeigt. Sofern er allerdings als Zeichen in die Sphäre des Heiligen anteilhabend einbezogen ist, kommt auch ihm selbst Beachtung zu. So wird der heilige Mensch zuerst Wegzeichen zu Gott und damit Leitbild, dann verdient er - nur weil er jenes ist - auch Ehre und Verehrung.43

Mit dieser theologisch-systematischen Bestimmung von Heiligkeit sind zugleich die verschiedenen Funktionen der Heiligenverehrung angesprochen, verstanden als Aspekte religiöser Kommunikation. Entsprechend ihrer Verortung zwischen Transzendenz und Immanenz ermöglichen und fordern Legenden und Heilige beim Publikum verschiedene Rezeptionshaltungen. Mit, Wegzeichen zu Gott und Leitbild“ sowie ,Ehre und Verehrung' sind dabei auch die Motive benannt, die die mediävistische Forschung unter den Begriffen von imitatio, aedificatio und admiratio als Inhalt wie Anliegen der Legende verhandelt hat.

Von der im vorangegangenen Unterkapitel dargestellten Funktionsweise legendarischen Erzählens her gedacht, besteht die eigentümliche Spannung in der Figur des Heiligen dabei darin, dass sich in ihr das Transzendente als das der menschlichen Verfügbarkeit Entzogene darstellt, sich aber gerade darin ihr enormes Integrationspotential erweist. Dieses beschränkt sich also nicht auf die allgemeine tugendhafte Vorbildlichkeit im Sinne einer ,Vergegenständlichung des Guten' wie sie André Jolles in seiner funktionstypischen Bestimmung als Wesenskern der Legende ausgemacht hat. ${ }^{44}$ Die Aufgabe des Heiligen sieht er darin, einer Gemeinschaft das erstrebenswerte Gute als Ziel der Nachahmung wahrnehmbar zu machen, auch wenn es als

43 Wolfgang Beinert: Die Heiligen in der Reflexion der Kirche. Systematisch-theologische Grundlegung. In: Die Heiligen heute ehren. Eine theologisch-pastorale Handreichung. Hrsg. von dems. Freiburg i. Br. 1983, S. 12-80, hier S. 21. Eine solche Definition nimmt dabei wohl zwangsläufig die reformatorische Kritik am Heiligenkult auf. Auch insofern darf sie daher nicht kurzschlüssig als Beschreibung mittelalterlicher religiöser Praxis verstanden werden, sondern als systematische Bestimmung des funktionalen Potentials christlicher Heiligenverehrung, das je unterschiedlich aktualisiert werden kann.

44 Vgl. Jolles, Einfache Formen, S. 35. Auch der Versuch von Hans Ulrich Gumbrecht, ausgehend von Jolles einen ,Faszinationstyp Hagiographie‘ zu beschreiben, der „durch das beständige Gerichtetsein des Menschen auf das Problem Erlangung und Erhaltung individuellen Glücks und das auf dieses Gerichtetsein zugeordnete Thema des ,gelungenen oder gescheiterten Lebens anderer Menschen konstituiert ist“, hilft wenig zur funktionalen Schärfung der Legende und des Heiligen, auch wenn er richtig erkennt: „Die Funktionsambivalenz von Imitatio und Magie und die sie ermöglichende Gattungsstruktur der Legende konstituieren [...] die im hohen Mittelalter dominierende Konkretisierung des Faszinationstyps ,Hagiographie‘.“ Faszinationstyp Hagiographie. Ein historisches Experiment zur Gattungstheorie. In: Deutsche Literatur im Mittelalter. Kontakte und Perspektiven. Hugo Kuhn zum Gedenken. Hrsg. von Christoph Cormeau. Stuttgart 1979, S. 37-84, hier S. 48 u. 61. 
höchste Entfaltung der Tugend unerreichbar bleibe: „[K]urz, er ist im Sinne der Form ein imitabile“. 45

Als Kristallisationspunkt religiöser Kommunikation reichen die Heiligkeit und das Erzählen von ihr funktional aber tiefer, denn im und durch den Heiligen der Legende soll sich ganz grundlegend das Wirken Gottes erweisen: „Hauptfunktion der Legende ist in diesem Sinn die narrative Stabilisierung von Heilsgewissheit, nach beiden Richtungen der Präsentation göttlichen Heilshandelns in der Welt einerseits, der Imitabilität der Heilsaneignung durch den Menschen anderseits“"46. Zur konsequenten imitatio des Heiligen auf seinem ebenso exemplarischen wie singulären Weg hin zu Gott sind allerdings nur wenige berufen, denn eine „glatte Umsetzung“ würde der „Ausnahmekonstellation“ des Heiligen zuwiderlaufen: „Dass mit dem Modellcharakter von Heiligkeit immer auch dessen Unmöglichkeit erhalten bleibt, macht eine Dauerirritation im christlichen Heiligkeitsentwurf aus. “47 Die Möglichkeit der Nachahmung des Heiligen muss als eine tatsächlich zu realisierende präsent gehalten werden, aber ihre allgemeine Verwirklichung würde die Grenzen von Immanenz und Transzendenz erodieren und damit den Geltungsanspruch legendarischen Erzählens und der Heiligenverehrung unterlaufen. Denn wenn sich die Immanenz problemlos in die Transzendenz - oder umgekehrt - auflösen ließe, bedürfte es keiner religiösen Kommunikation mehr.

Der Begriff der imitatio ist aber, trotz seiner Prägung bei Jolles und seiner fast ubiquitären Verwendung in der Forschung, ohnehin unscharf: Zum einen inhaltlich, weil sich in ihm die Ebenen von radikaler Nachfolge und aneignender Nachahmung überlagern und damit Ausmaß und Form der imitatio unklar bleiben. ${ }^{48}$ Zum anderen sind aber auch die Art und Weise ihrer Funktion genauer zu bestimmen. Denn wenn imitatio in den Legenden in der spezifischen imitatio Christi des jeweiligen Heiligen narrativ realisiert wird, der damit selbst wiederum zum imitabile für seine intradiegetischen wie extradiegetischen Rezipienten werden kann, dann geht es „nicht allein um ethische Orientierungsleistungen, Bekenntnisse oder Entscheidungsprozesse. Jenseits von Kognition und Reflexion wird imitatio vielmehr als eine Gnade erzählt, die einem zuteil wird“. ${ }^{49}$ Imitatio meint demnach wiederum den Einbruch der

45 Jolles, Einfache Formen, S. 36.

46 Köbele, Die Illusion der ,einfachen Form', S. 366.

47 Susanne Köbele: heilicheit durchbrechen. Grenzfälle von Heiligkeit in der mittelalterlichen Mystik. In: Sakralität zwischen Antike und Neuzeit. Hrsg. von Berndt Hamm, Klaus Herbers, Heidrun SteinKecks. Stuttgart 2007 (Beiträge zur Hagiographie. 6), S. 147-169, hier S. 167.

48 Vgl. Weitbrecht, Imitatio und Imitabilität, S. 206. In der Logik religiöser Kommunikation kann es sich letztlich nur um eine mimetische Aneignung handeln, „welche die strukturellen Distanzen zwischen Nachgeahmtem und Nachahmendem wahrt, ja akzentuiert“. Peter Strohschneider: Religiöses Charisma und institutionelle Ordnungen in der Ursulalegende. In: Institution und Charisma. Festschrift für Gert Melville zum 65. Geburtstag. Hrsg. von Franz F. Felten, Annette Kehnel, Stefan Weinfurter. Köln [u. a.] 2009, S. 571-588, hier S. 581.

49 Peter Strohschneider: Weltabschied, Christusnachfolge und die Kraft der Legende. In: GRM 60, 2 (2010), S. 143-163, hier S. 148. 
Transzendenz in die Immanenz oder - von der anderen Seite aus betrachtet - den Übertritt in eine andere Ordnung. ${ }^{50}$ Nur so sind die Inkommensurabilität des Heiligen und seine Imitabilität zusammenzudenken, deren unauflösbares Spannungsverhältnis den Geltungsanspruch der Legende ausmacht. ${ }^{51}$

Eng mit dem Gedanken der imitatio verknüpft ist der Begriff der aedificatio, wobei ,Erbauung“ in paulinischer Tradition nicht nur „die moralische oder religiöse Erneuerung des Einzelnen“ meint, sondern darüber hinaus „die Gemeinschaft der Gläubigen im Blick [hat], in die sich die Bekehrenden und Büßenden hineinstellen und damit die ,Ecclesia“ erst stiften und formieren müssen“. ${ }^{52}$ Dazu dienen Unterweisung und Ermahnung der Gläubigen, instructio und exhortatio, durch das in der Legende vermittelte Beispiel des Heiligen. ${ }^{53}$ Denn Handlung wie einzelne Motive einer Legende „meinen immer ein exemplum virtutis, von dem die Erbauung ausgeht und auf das sich die imitatio richtet“" ${ }^{54}$ Dabei werden mehrere Exempla in der Figur eines selbst exemplarischen Heiligen zentriert, dessen Leben insgesamt typologisch als imitatio Christi zu verstehen ist, die letztlich das grundlegende Strukturprinzip der Legende darstellt. ${ }^{55}$ Allerdings birgt die Kategorie der aedificatio wiederum die Gefahr, die Legende auf eine einseitige ethische Orientierungsleistung festzuschreiben, wenn sie nicht wie die imitatio als gnadenhafter Einbruch der Transzendenz in die Immanenz verstanden wird. ${ }^{56}$

Heilsvergewisserung und Heilsaneignung mittels der Legende vollziehen sich aber wesentlich auf einer anderen als der ethischen, für ihre religiöse Geltung entscheidenderen Ebene, die durchaus auch als eine magische bezeichnet werden kann, weil es bei ihr nicht mehr nur um den Einbruch der Transzendenz geht, sondern um Versuche ihrer Verfügbarmachung. Denn im Kontext einer mehr oder weniger stark liturgisch verankerten Verehrung erweist der Heilige über seinen Tod und auch den Text der Legende hinaus seine Wirksamkeit in Wundern und als Fürsprecher bei

50 Strohschneider, Religiöses Charisma, S. 582.

51 Weitbrecht, Imitatio und Imitabilität, S. 374.

52 Erhard Dorn: Der sündige Heilige in der Legende des Mittelalters. München 1967 (Medium Aevum. 10), S. 149.

53 Vgl. ebd.

54 Rolf Schulmeister: aedificatio und imitatio. Studien zur intentionalen Poetik der Legende und Kunstlegende. Hamburg 1971 (Geistes- und sozialwissenschaftliche Dissertationen. 16), S. 47. Für Schulmeister stehen die beiden Begriffe aedificatio und imitatio im Zentrum einer, intentionalen Poetik der Legende', deren Vorteil darin bestehe, das sich diese aus den Legendenprologen herausgearbeiteten ,gattungspoetischen Zielsetzungen“ auf das übertragen lassen, was er als ,Kunstlegende‘ bezeichnet (so zum Beispiel Hartmanns von Aue Der arme Heinrich). Die auf affirmativen Vollzug zielende Intention der admiratio, als kultisch-religiöse Dimension der Legende sowie der Figur des Heiligen, vernachlässigt er in seinem hermeneutischen Ansatz, dem auch die höchst fragwürdige Einengung auf die ,Kunstlegende‘ entspringt, allerdings völlig.

55 Schulmeister, aedificatio und imitatio, S. 71-72.

56 Zumal sie in der Forschung vermutlich vor allem deshalb eingeführt wurde, um dem Problem der nicht von allen Gläubigen zu realisierenden imitatio zu begegnen. 
Gott. ${ }^{57}$ Die strukturelle Grundlage der Mittlerschaft des Heiligen und seiner Anrufbarkeit ist die Unterscheidung von Transzendenz und Immanenz, denn diese erfordert und ermöglicht erst seine Rolle als intercessor und admirabile, in der er zum Transzendenzvermittler wird.

Denn im Gegensatz zur Masse der gewöhnlichen Gläubigen befindet sich der Heilige in einer besonderen Nähe zu Gott, gehört also bereits dem Bereich der Transzendenz an. Auf Grund seiner Herkunft und seiner bleibenden Verankerung in der Immanenz - auch nach seinem Tod ganz materiell beispielsweise durch Reliquien oder eben seine als Faktum erzählbare Lebensgeschichte, die seine Nähe vergegenwärtigen - bleibt er aber aus dieser heraus ,greifbar' und anrufbar. Die unüberbrückbare Distanz zum Heiligen, der ein erstrebenswertes ,Gut‘ verkörpert, das aber letztlich unverfügbar bleiben muss, kann nur in der Verehrung kompensiert werden. In der admiratio vermag er damit einer breiten und durchaus disparaten Rezeptionsgemeinschaft, unabhängig von Fragen des ethischen Vollzugs, Identität und Sinn zu stiften.

Funktional und im Hinblick auf die hier verfolgte Frage von Geltungsansprüchen wie Integrationspotentialen ausgedrückt ist Heiligkeit dabei gleichzeitig ,Distanzkategorie‘ und ,Teilhabekategorie‘, wie Susanne Köbele die spannungsreiche Vermittlung einer absoluten und relativen Perspektive auf Heiligkeit, von Heiligkeit in se und Heiligkeit ad nos, auf den Punkt bringt. ${ }^{58}$ Dabei treten zwei Aspekte dieser Spannung hervor, einmal auf der Ebene der Funktion von Heiligkeit, zum anderen auf der ihrer Konstruktion:

Der gemeinschaftsbezogene ,Imitatio‘-Appell einerseits, die Vorstellung exklusiven ,Erwähltseins“ andererseits, bereits diese beiden Implikationen von Heiligkeit können sich grundsätzlich und dauerhaft in die Quere kommen. Auch wenn Heiligkeit Erwählung, Absonderung, Ausgrenzung bedeutet, braucht sie doch - gerade als Ausnahmekonstellation außerhalb normativer Institution - immer auch Öffentlichkeit, Zeugen, Nachahmer. ${ }^{59}$

Das heißt auch: Heiligkeit beansprucht also Evidenz, ist aber immer zugleich eine Zuschreibung. ${ }^{60}$ Diese Überlegung greift Strohschneider auf, präzisiert sie aber auf die Eigenlogik religiöser Kommunikation, wenn er pointiert: „,[]]ls Distanzkategorie ist Heiligkeit zugleich eine Relationskategorie“. ${ }^{61}$ Das gilt schon rein formal, weil sich die Unverfügbarkeit des Heiligen an sich nur vom Verfügbaren aus denken lässt, aber eben auch ganz konkret in der Rezeption von Heiligkeit und Legende: Der Heilige ermöglicht Teilhabe und braucht sie, braucht zugleich aber Distanz und beruht auf ihr, weil er das ,Eigene` immer notwendigerweise übererfüllt, übersteigt - transzen-

57 Vgl. Münkler, Sündhaftigkeit als Generator von Individualität, S. 38. Ebenso Ringler, Zur Gattung Legende, S. 258.

58 Vgl. Köbele, heilicheit durchbrechen, S. 149.

59 Ebd.

60 Vgl. ebd., S. 147-148.

61 Strohschneider, Höfische Textgeschichten, S. 173. 
diert eben - und damit zum ,Fremden' wird. Andererseits erhält er gerade darin und nur so seine spezifische Relevanz für das ,Eigene‘. Auf diese Weise verkörpert der Heilige die ganze Paradoxie religiöser Kommunikation: Er erscheint als Fremder im Eigenen. $^{62}$

Vor dem Hintergrund des relationalen Charakters von Heiligkeit und mit Blick auf die eingangs entwickelte Frage nach der Verhandlung religiöser Identität im Modus legendarischen Erzählens lässt sich dieses Wechselspiel von ,eigen` und ,fremd‘ als Spannungsfeld von Inklusion und Exklusion beschreiben: Der Heilige exkludiert sich auf seinem singulären Weg der Heiligung, für den er von Gott berufen ist, aus der Masse der einfachen Gläubigen und allen gesellschaftlichen und sonstigen Bindungen der Immanenz. Denn erst die konsequente Abkehr von der Welt, ob in der innerweltlichen Askese des Bekenners oder in der Abkehr des Märtyrers von allem Heidnischen, ermöglicht überhaupt die Zuschreibung von Heiligkeit. ${ }^{63}$ Dabei inkludiert er sich - oder besser: wird er gnadenhaft inkludiert - in die communio sanctorum, die überzeitliche Gemeinschaft aller Heiligen, und lässt sich spätestens mit seinem Tod in der Transzendenz verorten. Die Differenzierung erfolgt nicht allein gegenüber dem Heidnischen, sondern „innerhalb der christlichen Sphäre“, denn der zukünftige Heilige zeichnet sich „gegenüber den anderen Gläubigen durch seine göttliche Auserwähltheit aus“, seine „exklusive Zugehörigkeit zur Sphäre des Heiligen“ und die Inklusion in die Gemeinschaft der Heiligen erweisen sich in seiner „Fähigkeit, Manifestationen des Transzendenten [...] wahrzunehmen““. ${ }^{64}$ Der Heilige ist aber nicht einfach nur aus der Masse der Gläubigen exkludiert, sondern, und das schließt an die Begriffe vom ,Transzendenzvermittler und vom ,Fremden im Eigenen“ an, auf „zweiter Stufe“ in die christliche Gesellschaft wiederum inkludiert, denn ihm „wird institutionell die Funktion des Mediators und Intercessors zugewiesen, der als Inklusionsvermittler in das himmlische Reich fungiert“. ${ }^{65}$

\subsubsection{Legenden zwischen imitatio, aedificatio und admiratio}

Im Vorangegangenen war es mir, in bewusster Absetzung von der Überbetonung der imitatio im Gefolge von André Jolles, darum gegangen darzustellen, dass es bei der Figur des Heiligen um eine vielschichtige und spannungsreiche Aushandlung von Identifikation und Entzogenheit geht und dass ihre Rezeption ein In-Beziehung-Set-

62 Vgl. Andreas Hammer, Stephanie Seidl: Die Entfremdung vom Eigenen. Narrative Wahrnehmungsmuster von Heiligkeit im mittelhochdeutschen Passional. In: Mittelalter im Labor. Die Mediävistik testet Wege zu einer transkulturellen Europawissenschaft. Hrsg. von Michael Borgolte [u. a.]. Berlin 2008 (Europa im Mittelalter. 10), S. 134-153, hier S. 136.

63 Vgl. Andreas Hammer, Stephanie Seidl: Die Ausschließlichkeit des Heiligen. Narrative Inklusionsund Exklusionsstrategien im mhd. Passional. In: PBB 130, 2 (2008), S. 272-297, hier S. 274.

64 Ebd., 2008, S. 290. Formuliert mit Bezug auf den heiligen Martin, so aber verallgemeinerbar. 65 Münkler, Sündhaftigkeit als Generator von Individualität, S. 38. 
zen über ein Wechselspiel von Zugehörigkeit und Nicht-Zugehörigkeit fordert. Die Formen von Aneignung und notwendiger Distanzwahrung, die dabei zum Tragen kommen, lassen sich als imitatio, aedificatio und admiratio bestimmen. Diese Vielschichtigkeit ist keine konstruierte, sondern erweist sich als eine im legendarischen Erzählen selbst angelegte, je unterschiedlich aktivierbare Polyfunktionalität, die in den Legenden selbst auch formuliert und reflektiert wird. Das lässt sich an den beiden dieser Arbeit maßgeblich zugrundeliegenden Legendaren veranschaulichen, die spezifischen Entstehungszusammenhängen entstammen und die damit verbundenen Intentionen und Wirkabsichten im Blick auf einen mehr oder weniger klar abgegrenzten Rezipientenkreis widerspiegeln. Zwar beinhalten sie keine „intentionale Poetik“66 des legendarischen Erzählens als solche, formulieren aber in der Einbindung der Einzellegenden in einen liturgischen Rahmen und besonders signifikant im Kapitel über Entstehung und Zweck des Allerheiligenfest ihre jeweiligen Zielsetzungen und Zweckbestimmungen. ${ }^{67}$

Die schon eingangs erwähnte beispiellose Verbreitung und Bedeutung der Legenda aurea begründet ihren Ruhm als ,Goldene Legende‘, doch sind die Annahmen der älteren Forschung, die in ihr ein Erbauungsbuch für Laien oder gar das, Volksbuch des Mittelalters sehen zu können meinte, irreführend, weil sie die eigentlichen Gebrauchszusammenhänge verfehlen. Ihre Verbreitung verdankt diese Legendensammlung zunächst einmal nicht ihrer vermeintlichen ,Beliebtheit‘, sondern dem systematischen Programm einer ,verordneten' Rezeption: Durch ihre gezielte Verwendung als Handbuch für Predigtübungen im weit verzweigten dominikanischen Schulsystem wird sie in ganz Europa verbreitet und erreicht über die sich auch den anderen Orden und dem Säkularklerus öffnenden Dominikanerschulen breite geistliche Kreise, dient dort der Ausbildung und Predigtvorbereitung und erst an letzter Stelle auch anderen Zwecken wie der klösterlichen Tischlesung. ${ }^{68}$ Erst diese Verbreitung im lateinisch-kirchlichen Bereich schafft die materielle Voraussetzung für die volkssprachige Adaption. ${ }^{69}$

Für eine solche bietet sich die Legenda aurea inhaltlich aber deshalb an, weil ihre vielfältigen Rezeptionspotentiale, die durchaus auf unterschiedlichen Ebenen liegen, sie für Klerikerkreise wie für ein Laienpublikum gleichermaßen interessant machen. ${ }^{70}$ Sie ist eben nicht nur eine Sammlung von Heiligenleben, sondern verbindet das ,narrative“ mit dem ,exegetisch-scholastischen' Moment, indem die Legenden um

66 Mit Bezug auf Schulmeister, aedificatio und imitatio, vgl. Anm. 54.

67 Vgl. Wolfgang Hieber: Legende, protestantische Bekennerhistorie, Legendenhistorie. Studien zur literarischen Gestaltung der Heiligenthematik im Zeitalter der Glaubenskämpfe. Diss. masch. Würzburg 1970, S. 79.

68 Vgl. Barbara Fleith: Studien zur Überlieferungsgeschichte der lateinischen Legenda aurea. Brüssel 1991 (Subsidia hagiographica. 72), S. 429.

69 Vgl. Feistner, Historische Typologie, S. 217.

70 Vgl. Daria Dittmeyer: Gewalt und Heil. Bildliche Inszenierungen von Passion und Martyrium im späten Mittelalter. Köln 2014 (Sensus. 5), S. 50. 
predigtartige Passagen und Auslegungsmöglichkeiten ergänzt werden; die bekannte pseudo-etymologische Deutung der Heiligennamen ist nur ein Beispiel dafür. ${ }^{71}$ Sie kann damit ebenso zur moralisch-didaktische Unterweisung genutzt werden wie zur Vermittlung theologischer und liturgischer Kenntnisse. Die Einbindung der Legenden in den Zyklus des Kirchenjahres, dessen Feste in längeren Ausführungen erläutert werden, ist dabei mehr als ein formales Ordnungsprinzip, sondern ein funktionaler Rahmen, denn

[d]amit erscheint erstmals die einzelne Heiligenlegende in die Perspektive der gesamten Heilsgeschichte eingeordnet [...] Das historisch einmalige Geschehen eines Heiligen-Lebens wird im Rahmen der kultischen Wiederkehr zur Sphäre des Dauernd-Gültigen erhoben. Der Kalender konkretisiert sich in exemplarischen Gestalten, die Lehre der communio sanctorum [...] ist in einem Lese-Buch greifbarer als im Credo dokumentiert. ${ }^{72}$

Die Legenda aurea zielt also offenbar auf die liturgische Verehrung der Heiligen, in denen sich der Einbruch und das Wirken der Transzendenz erweist, und die Erbauung der Gläubigen, die sich daraus ableitet und speist. ${ }^{73}$

Das findet sich in ihr selbst auch so formuliert, wenn zum Allerheiligenfest in gewohnt scholastisch-rubriziender Weise Wilhelms von Auxerre Summa de officio zitiert wird, der sechs Gründe für das Feiern von Heiligenfesten anführt: ${ }^{74}$ Prima est propter honorem divinae maiestatis, ${ }^{75}$ weil in den Heiligen Gott selbst geehrt wird. Secunda est propter auxilium nostrae infirmitatis, ${ }^{76}$ denn da das Heil nicht durch den Menschen selbst erlangt werden kann, bedarf er der Fürbitte. Tertia est propter augmentum nostrae securitatis, ${ }^{77}$ denn wenn die Gnade Gottes die Heiligen erhöht hat, die sterbliche Menschen ,wie wir' sind, gilt sie allen. Die Heiligen interessieren in diesem Zusammenhang vor allem als eine Art „Spiegel“, in dem „das Wirken der göttlichen Gnade auf Erden“ aufleuchten soll, ${ }^{78}$ und bezeichnenderweise folgt erst daraufhin und in sehr allgemeiner Weise ihre mögliche Vorbildfunkion: Quarte est propter exemplum nostrae imitationis. ${ }^{79}$ Das Exemplum für die imitatio der Gläubigen besteht darin, wie man Irdisches verachten und nach dem Ewigen streben soll. Fünftens und sechstens betreffen die alle und alles umfassende Gemeinschaft mit den Heiligen: Wie diese für die Gläubigen ein Fest im Himmel feiern, so sollen es umgekehrt die Gläu-

71 Feistner, Historische Typologie, S. 217-218.

72 Konrad Kunze: Art. Jacobus a (de) Voragine (Varagine). In: ${ }^{2}$ VL 4 (1983), Sp. 448-466, hier Sp. 455.

73 Vgl. Zu den Geltungsstrategien der Legenda aurea vgl. auch Prautzsch, Die Wahrheit der Legende,

S. $96-99$.

74 Hier wie im Folgenden LA 2088.

75 „Erstens zur Ehre der göttlichen Majestät.“

76 „Zweitens zur Hilfe unserer Schwäche.“

77 „Drittens zur Vermehrung unserer Sicherheit.“

78 Hieber, Legende, protestantische Bekennerhistorie, Legendenhistorie, S. 75.

79 „Viertens zum Vorbild für uns, sie nachzuahmen.“ 
bigen für sie auf Erden tun, denn in den Heiligen ehren die Gläubigen sich selbst, weil in der Liebe alles gemeinsam ist: caelestia, terrestria et aeterna. ${ }^{80}$

Die Formeln vom „erzählerischen Andachtsbild“ und einer ,andachtsbildartigen Verdichtung“, wie sie Theodor Wolpers für die Darstellungsweise der Legenda aurea geprägt hat, meinen vor allem die bildhaft-symbolische Erzählstruktur der einzelnen Legenden, die den Heiligen überhöht, doch drückt sich darin schließlich auch der hier dargestellte Vorrang der admiratio gegenüber der imitatio aus. ${ }^{81}$ Entsprechend könne man die pseudo-etymologische Namensdeutung weniger als rhetorischen Schmuck oder theologische Gelehrsamkeit verstehen, sondern als ein bewunderndes „SichEinstimmen in das heilige Wesen“ des Protagonisten „in einer zugleich mystischen wie scholastisch ordnenden Art“" ${ }^{82}$ Was die Legenda aurea mit alldem offenbar verlangt und befördern will, sind Bewunderung und Erbauung, die auf einem Abstand beruhen: „Die Bitte um Hilfe wird als wirksamster Weg empfohlen, sie ist geradezu die Lehre aus der Tatsache, daß die Kluft zwischen Heiligem und sündigem Menschen unüberbrückbar ist. “83 Nur in der admiratio des Heiligen kann die gnadenhafte Zuwendung Gottes, als Hineinragen der Transzendenz in die Immanenz, herbeigerufen werden, nur in der aedificatio ist eine Aneignung der solchermaßen vergegenwärtigten Heiligkeit möglich, während die imitatio kein konkretes Vorbild meint, sondern ein allgemeines Beispiel für christliches Streben.

Das Ende des 13. Jahrhunderts entstandene Passional entwirft den Zusammenhang von imitatio, aedificatio und admiratio auf eigene Weise, was sich aus seinen Entstehungszusammenhängen und dem Zielpublikum erklären lässt. Nach oder neben dem Märterbuch (wahrscheinlich in der zweiten Hälfte des 13. Jahrhunderts) und dem Väterbuch (letztes Drittel des 13. Jahrhunderts), das sehr wahrscheinlich von demselben Verfasser stammt wie das Passional, ist es das erste deutsche Verslegendar, bleibt von den dreien aber in jedem Fall das wirkungsreichste. ${ }^{84}$ Mit fast 110.000 Versen ist es zudem das umfangreichste, allerdings wurden die drei Bücher, aus denen es besteht, vermutlich immer getrennt überliefert: Buch I umfasst Marienlegenden und das Leben Jesu, Buch II bietet die Apostellegenden, während Buch III mit über 66.000 Versen der mit Abstand umfangreichste Teil und das eigentliche Legendar ist. Seine 75 Heiligenleben sind eine systematische Verarbeitung der Legenda aurea, die als Hauptquelle dient, wobei sich für einzelne Legenden weitere Vorlagen nachweisen lassen. Das Passional insgesamt findet eine weite Verbreitung, bis die Verslegendare

80 „Himmlisches, Irdisches und Ewiges.“

81 Vgl. Wolpers, Die englische Heiligenlegende des Mittelalters, S. 30 - 31 u. 197-202.

82 Ebd., S. 203.

83 Hieber, Legende, protestantische Bekennerhistorie, Legendenhistorie, S. 76.

84 Eine genaue Datierung und damit Chronologie der drei Werke ist bislang nicht möglich, vgl. dazu Konrad Kunze: Art. Buch der Märtyrer (Märterbuch). In: ${ }^{2}$ VL 1 (1978), Sp. 1093-1095; Sabina Foidl: Buch der Märtyrer (Märterbuch). In: DLL MA 1 (2011), Sp. 815-817; Volker Zapf: Väterbuch. In: DLL MA 1 (2011), Sp. 907-911; Hans-Georg Richert: Art. Passional. In: 2VL 7 (1989), Sp. 331-340; Volker Zapf: Passional. In: DLL MA 1 (2011), Sp. 902-907. 
ab Mitte des 14. Jahrhunderts durch Prosaauflösungen langsam verdrängt werden; als Quelle behält es allerdings noch länger seine Bedeutung. ${ }^{85}$ Sein Autor ist unbekannt, aus Sprache und Überlieferung hat man aber darauf geschlossen, dass er in engen Beziehungen zum Deutschen Orden stand, wenn er ihm nicht selbst angehörte, und im Deutschordensland dichtete. Aus der straffen Organisation des Ordens lassen sich jedenfalls auch Verbreitung und Wirkung des Legendars erklären, das seine Funktion in der in den Ordensstatuten festgeschriebene Tischlesung und Predigt für die lateinunkundigen Ordensbrüder gefunden haben dürfte. ${ }^{86}$

Die genaue Abhängigkeit des Passionals von der Legenda aurea ist dabei bislang ebenso wenig erforscht wie der tatsächliche Einfluss anderer Quellen, doch stellt es zweifellos eine eigenständige Verarbeitung dar, allein schon durch die Übertragung in die Volkssprache und die sprachlichen Erfordernisse gereimter Versdichtung nach dem Muster der höfischen Literatur. Dazu kommt die erläuternde Vermittlung des Wiedererzählten in Erzählerkommentaren und am auffälligsten in der Rahmung der Einzellegenden mit jeweils einem Prolog und Epilog, die keine Entsprechung in der Legenda aurea hat. Die stilistische Transformation gegenüber der lateinischen Hauptquelle zielt zudem auf eine predigtnahe Gestaltung durch „Apostrophen, rhetorische Fragen, lateinische Bibel- und Väterzitate mit anschließender Übersetzung, adhortative Einschübe, Gebete am Schluß von Abschnitten“. ${ }^{87}$ Inhaltlich wird darin der moralpädagogische Anspruch erkennbar, ein Laienpublikum „,zu bessern und zu bekehren“ und die Stoffe der Vorlage im Sinne der Spiritualität des Deutschen Ordens umzusetzen, was sich unter anderem in der Betonung der Marienverehrung niederschlägt. $^{88}$

Entsprechend greift der Autor des Passionals die Zielsetzungen der Legenda aurea im Allerheiligenkapitel wohl auf, verarbeitet sie aber auf eigene Weise. Gegenüber der theologischen Gelehrsamkeit und scholastischen Durchgliederung des lateinischen Legendars rückt hier die Vorbildhaftigkeit der Heiligen stärker in den Mittelpunkt. Die Gemeinschaft der Heiligen und die Möglichkeit, zu ihnen zu gelangen, werden gleich am Anfang ausdrücklich benannt:

Aller heiligen tac

fal ieglich menfche durch beiac

85 Vgl. Zapf, Art. Passional, Sp. 903.

86 Vgl. ebd. Zu einer kritischeren Abwägung der Zuschreibungen des Passionals an den Deutschen Orden und die angenommenen Kontexte seiner dortigen Nutzung vgl. die Einleitung in: Passional. Buch I: Marienleben. Hrsg. von Annegret Haase, Martin Schubert, Jürgen Wolf. Berlin 2013 (Deutsche Texte des Mittelalters. 91, 1), S. XXIX-XLV.

87 Vgl. Richert, Art. Passional, Sp. 338. Einen ausführlicheren stilistischen Vergleich des Passionals mit der Legenda aurea bietet die in ihrem Duktus und den darin durchscheinenden ästhetischen Werturteilen freilich altertümliche, inhaltlich aber - was die herausgearbeiteten Bearbeitungstendenzen betrifft - ganz treffende Studie Ernst Tiedemann: Passional und Legenda aurea. Berlin 1909 (Palaestra. Untersuchungen und Texte aus der deutschen und englischen Philologie. 87).

88 Vgl. Zapf, Art. Passional, Sp. 903. 


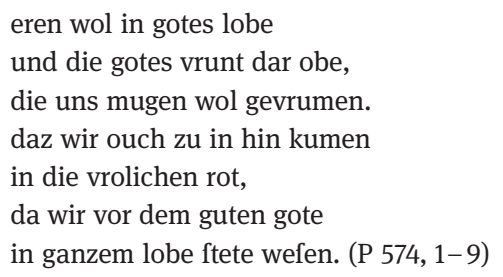

Bezeichnend ist hier vor allem die Semantik der Gottesbeziehung: Die Heiligen gelten ob ihrer besonderen Nähe zu Gott als seine ,Freunde، und - so jedenfalls die begriffliche Reichweite des mittelhochdeutschen vriunt - ,Verwandten'. Dass hier eine erst einmal rein menschliche und alltägliche Beziehungsform zur Beschreibung der Heiligkeit dient, verwischt zwar nicht den Unterschied von Immanenz und Transzendenz, ändert aber die Perspektive auf ihre Zuordnung: Durch die Heiligen erweist sich nicht wie in einem ,Spiegel' die Gnade Gottes, als unverfügbarer Einbruch einer radikal unterschiedenen Transzendenz, sondern die Heiligkeit erscheint aus der Immanenz heraus erreichbar, jeder Gläubige kann Teil der vrolichen rot werden und die Distanzkategorie wird zu Teilhabekategorie. ${ }^{89}$

Allerdings ist das wiederum nicht einfach als imitatio im Sinne der Nachahmung eines erstrebenswerten und im Heiligen vergegenständlichten Guten zu verstehen, sondern als enges Ineinander von Anrufung, Vermittlung und Vorbildhaftigkeit. Denn gleich darauf heißt es im Text, die Christenheit hoffet helflichen rat / von gottes vrunden werden vro (P 574, 14-15). Der Hilfe der Heiligen, die bereits ins Himmelsreich gekommen sind, soll also das eigene Heil garantieren, ohne dass deutlich werden würde, auf welche Weise sich die Heiligung des Gläubigen genau vollziehen soll, außer eben durch Fürbitte, die den Gläubigen aus Sünde und Falschheit zu befreien vermag (P 577, 40 - 45). Die Vorbildfunktion bleibt im Ungefähren:

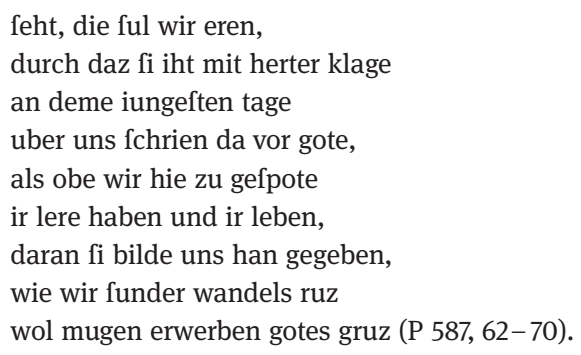

89 Vgl. in diesem Zusammenhang die Überlegungen zum „durch Verfügbarkeit und Vermitteltheit gekennzeichnete[n] Umgang mit dem Heiligen“ in der mittelalterlichen Frömmigkeit, der die „paradoxen Unverfügbarkeitspostulate“ der Theologie - wie sie Strohschneider mit seiner ,Differenzlogik fokussiert hat - kontrastiert und ergänzt, bei Elke Koch: Zwischenstufen. Überlegungen zur Transzendenzproblematik in geistlichen Spielen. In: Paragrana. Internationale Zeitschrift für Historische Anthropologie 21, 2 (2012), S. 77-92, hier S. 77-80, Zitate S. 80. 
Das erinnert an die Funktion der Heiligen, wie sie in der Legenda aurea beschrieben wird: Ihre Lehre und ihr Leben geben ein Beispiel für die Abkehr vom Irdischen und die Hinwendung zu Gott. Dieser Bewegung des Gläubigen entspricht hier aber eine besondere Zuwendung Gottes, sein gruz, der durch menschliches Tun erreicht werden kann. Gegenüber der Legenda aurea mit ihrer liturgischen und scholastischen Zielsetzung ergibt sich damit kein kategorialer Unterschied, es zeigt sich aber eine andere Akzentuierung, die der Intention des Passionals zur Unterweisung eines Laienpublikums entspricht. Am Ende steht auch hier die Verbundenheit der Gläubigen auf Erden mit der himmlischen Gemeinde: Der Anruf der Heiligen führt zur communio sanctorum und ist zugleich ihr beredtster Ausdruck. Die umfassende Gemeinschaft der Heiligen, die in Ewigkeit Gott lobpreist, ist das ersehnte und angestrebte, dabei doch immer zugleich der menschlichen Verfügbarkeit entzogene und nur gnadenhaft gewährte Ziel. Daher erbittet sie der Erzähler im Gebet:

got herre, daz la nicht verdrumen

dikeinen ungluckes val,

wir enkumen in den fal

des himelrichs reinekeit,

und loben dich in der ewikeit. (P 582, 30-34)

Alle am gläubigen Mitvollzug der Erzählungen von den Heiligen Beteiligten und von ihnen Angesprochenen, Erzähler wie Adressaten der Legenden, bilden auf diese Weise eine Zeit und Raum übersteigende Rezeptionsgemeinschaft, die in der Transzendenz ihren identifikatorischen Maximalpunkt findet, $\mathrm{zu}$ dem sie in spannungsreiche Beziehung gesetzt ist.

\subsection{Heidentum und die Aushandlung des religiösen Gegensatzes}

Im Vorangegangenen war es mir darum gegangen, Heiligkeit als relationale Größe und damit als ein Wechselspiel von Zugehörigkeit und Nichtzugehörigkeit zu beschreiben. Ein solches ist auch für die Konstruktion des Heidentums und die Aushandlung des religiösen Gegensatzes konstitutiv, die nicht gezwungenermaßen auf Formen polemischer Distanzierung und pejorativer Kontrastierung von ,eigen' und ,fremd“ hinauslaufen. Das will ich zunächst am Begriff des Heidentums selbst zeigen, der als Gegenbegriff weit weniger statisch und negativ ist, als es zunächst scheint, weil die Grenze zwischen Christen und Heiden unter eschatologischer Perspektive immer unsicher bleibt. In einem zweiten Schritt werde ich dann das Heidentum als spezifische Ausformung des Problems von Fremdheit darstellen, die nicht kurzschlüssig als Abwertung und Ausschluss des Anderen zu verstehen ist, sondern als Bearbeitung von Selbst- und Fremdbild und der Grenzen von Zugehörigkeit. Davon ausgehend nehme ich in einem dritten Schritt die missionarische Überschreitung des religiösen Gegensatzes zu den Heiden in den Blick, die diesen auf besondere Weise dynamisiert, 
wenn in ihrem Zeichen Heiden zu Christen werden sollen - und dabei selbst zu Heiligen werden können.

\subsubsection{Heidentum als dynamischer Gegenbegriff}

Heidentum, so definieren es die theologischen Nachschlagewerke, „ist wie das eng damit verknüpfte ,Götzendienst‘ ein Beziehungsbegriff, der sich nur ,in Beziehung auf' oder sogar noch häufiger durch ,im Gegensatz zu' einem anderen als Bezugspunkt gewählten Begriff fassen läßt“90. Die mit der Einführung der Kategorie des Heidentums gedanklich vollzogene Unterscheidung ist daher niemals neutral oder einfach nur faktisch beschreibend, sondern sie entwirft einen Innenraum des Eigenen, den es gegen einen Außenraum des Fremden abgrenzt und dabei diese beiden Bereiche axiologisch aufeinander bezieht. So verstanden ist das Heidentum der Gegenbegriff zum Christentum. Doch sind die gedanklichen Operationen in der Konstruktion des Heidentums sowie des religiösen Gegensatzes zu ihm vielschichtiger. Das zeigt sich in der Binnendifferenzierung des Begriffs des Heidentums im Zuge der systematischen Unterscheidung verschiedener Formen des Unglaubens, wie sie in der theologischen Reflexion seit dem frühen Christentum bis ins Mittelalter entfaltet wird.

Am Anfang steht dabei die Unterscheidung von Christen, Juden und Heiden, wobei in letzterer Kategorie all diejenigen subsumiert werden, die außerhalb der jüdisch-christlichen Tradition stehen, egal welche genaue Religionszugehörigkeit sie haben. ${ }^{91}$ Unterhalb der Ebene des Heidentums findet hier also zunächst keine weitere Differenzierung statt, denn diese Dreigliederung ist keine im neuzeitlichen Sinn rationale, sondern wesentlich eine funktionale. Es geht ihr um das Heidentum, lateinisch gentes, die Völker, als Kollektivzuschreibung im Gegensatz zu den Christen, nicht um den konkreten persönlichen Einzelfall. ${ }^{92}$ Wiederum aufgrund funktionaler Erfordernisse findet sich dann in der hochmittelalterlichen Kanonistik und Scholastik eine Unterscheidung innerhalb der Kategorie der Ungläubigen hinsichtlich der Ursache ihres Unglaubens. Thomas von Aquin widmet sich in seiner Summa theologica der Frage, utrum sint plures infidelitatis species, also ob es mehre Arten des Unglau-

90 Jean-Claude Fredouille: Art. Heiden. In: RAC 13 (1986), Sp. 1113-1149, hier Sp. 1115. Zum Begriff vgl. ebenso Hans-Werner Gensichen: Art. Heidentum I. Biblisch/Kirchen-missionsgeschichtlich. In: TRE 14 (1985), S. $590-601$.

91 Vgl. Elmar Seebold, Knut Schäferdiek: Art. Heide. In: RGA 14 (1999), S. 142-144, hier S. $142-143$. Diese formelhafte Unterteilung, mitunter ergänzt um die Ketzer als vierte Kategorie, schlägt sich auch jenseits des klerikal-gelehrten Diskurses in der volkssprachigen Literatur nieder, vgl. Timothy R. Jackson: christen, ketzer, heiden, jüden. Questions of identity in the middle ages. In: Encounters with Islam in German literature and culture. Hrsg. von James R. Hodkinson, Jeff Morrison. Rochester, New York 2009 (Studies in German literature, linguistics, and culture), S. 19-35.

92 Vgl. ebd., S. 143. Damit verweist sie auf die grundlegende Funktion der Konstruktion kollektiver Identitäten für eine kulturelle Selbstverortung. 
bens gebe. ${ }^{93}$ Die Sünde des Unglaubens, peccatum infidelitas, bestehe in der Ablehnung des Glaubens, renitendo fidei, und dies könne in zweifacher Weise der Fall sein:

Quia aut renititur fidei nondum susceptae: e talos infidelitas est paganorum sive gentilium. Aut renititur fidei Christianae susceptae: vel in figura, et sic infidelitas Judaeorum; vel in ipsa manifestatione veritatis, et sic infidelitas haereticorum. Unde in generali possunt assignari tres praedictae species infidelitatis. (Summa theologica II-II, 10, 5)

Denn entweder widerstrebt man dem Glauben, den man noch nicht angenommen hat, und derart ist der Unglaube der Heiden. Oder man widerstrebt dem bereits angenommenen christlichen Glauben; und zwar entweder in seinem Vorbild, und derart ist der Unglaube der Juden; oder in der offenen Darlegung der Wahrheit, und derart ist der Unglaube der Häretiker. Also kann man allgemein die drei eben genannten Arten des Unglaubens aufzeigen.

Aus dieser Unterscheidung der Ungläubigen entsprechend ihrer Fähigkeit und Bereitschaft zum Glauben ergibt sich bei Thomas eine Abstufung ihrer Sündhaftigkeit und von daher schließlich auch ein unterschiedliches Maß der Duldung. Zwar gelte hinsichtlich der Irrtümer des Unglaubens: gravior est infidelitas gentilium quam Judaeorum, et Judaeorum quam haereticorum, doch sei das Verhältnis der Ungläubigen zum Glauben entscheidend, denn aliquis gravis contra fidem peccat qui fidei renititur susceptae quam qui renititur fidei nondum susceptae (Summa theologica II-II, 10, 6). ${ }^{94}$

Daher erscheint Thomas der Unglaube der Häretiker, die den Glauben des Evangeliums verfälschen und auf diese Weise ablehnen, eine größere Sünde als der Unglaube der Juden, die diesen nie angenommen haben. Letztere hätten aber sein Vorbild im Alten Testament angenommen, das sie falsch deuten, daher sei ihr Unglaube schwerer als der der Heiden, qui nullo modo fidem Evangelii suceperunt, die also auf keinerlei Weise den Glauben angenommen habe (Summa theologica II-II, 10, 6). Weil aber letztlich beide, Heiden wie Juden, den Glauben nie angenommen haben, dürfe man sie nun aber nicht dazu zwingen, denn die Freiheit der Entscheidung sei ein konstitutives Element der Annahme des Glaubens, wie Thomas mit Rückgriff auf Augustinus und Bestimmungen des Kirchenrechts argumentiert (Summa theologica II-II, 10, 8). ${ }^{95}$

93 Summa theologica II-II, 10, 5. Hier wie im Folgenden zitiert nach: Die deutsche Thomas-Ausgabe. Vollständige, ungekürzte deutsch-lateinische Ausgabe der Summa Theologica, Bd. 15: Glaube als Tugend. Graz 1950.

94 „[D]er Unglaube der Heiden [ist] schwerwiegender als der der Juden, und derjenige der Juden schwerwiegender als der der Häretiker“ und es „sündigt einer schwerer gegen den Glauben, der sich gegen den bereits angenommenen Glauben auflehnt, als der dem Glauben widerstrebt, den er noch gar nicht angenommen hat".

95 Vgl. zum hier Dargestellten Alexander Patschovsky: Toleranz im Mittelalter. Idee und Wirklichkeit. In: Toleranz im Mittelalter. Hrsg. von dems. und Harald Zimmermann. Sigmaringen 1998 (Vorträge und Forschungen. 45), S. 391-402, hier S. 395, ebenso Hans-Jürgen Becker: Die Stellung des kanonischen Rechts zu den Andersgläubigen: Heiden, Juden und Ketzer. In: Wechselseitige Wahrnehmung der Religionen im Spätmittelalter und in der Frühen Neuzeit, Bd. 1. Hrsg. von Ludger Grenzmann [u. a.]. 
Solche feinen Nuancen im Blick auf die Ferne vom rechten Glauben erscheinen freilich schnell sekundär, wenn es um konkrete historische Auseinandersetzungen geht, die andere Funktionalisierungen verlangen und daher alle Andersgläubigen zum Feindbild machen. ${ }^{96}$ Denn auch theologisch bleibt der eigentliche Dualismus bestehen, weil die Binnendifferenzierung der Andersgläubigen nichts an der binären Codierung auf der Ebene von Wahrheit und Glaube ändert; letztlich haben sie alle den falschen Glauben und gelten daher nicht als Andersgläubige, sondern als infideles, als Ungläubige. Daher wird der Islam im christlichen Mittelalter kaum als eigene Religion wahrgenommen beziehungsweise anerkannt und als solche in ihren spezifischen Glaubensinhalten beschrieben. ${ }^{97}$ Er stellt sich den christlichen Autoren funktional als Form des Unglaubens dar und muss sich daher in deren Kategorien von paganer Vielund Abgötterei oder häretischer, gar auch teuflischer Entstellung des Christentums fügen.

In der Unterscheidung verschiedener Formen des Unglaubens deutet sich allerdings schon an, dass die Unterscheidung von Christen und Heiden keineswegs eine statische und auf eine simple Opposition hin angelegte ist. Denn unter heilsgeschichtlich-eschatologischer Perspektive vermag sich der religiöse Gegensatz zum Heidentum zu verschieben oder gar aufzulösen. Diese dem Begriffspaar ChristenHeiden inhärente Dynamik beschreibt Reinhart Koselleck in seinen Überlegungen „Zur historisch-politischen Semantik asymmetrischer Gegenbegriffe“. ${ }^{98}$ Unter asymmetrischen Gegenbegriffen versteht Koselleck „nur einseitig verwendbare, auf ungleiche Weise konträre Zuordnungen“, die der Definition durch eine Gruppe entspringen, die „einen exklusiven Anspruch auf Allgemeinheit [erhebt], indem sie einen sprachlichen Universalbegriff nur auf sich selbst bezieht und jede Vergleichbarkeit ablehnt“. ${ }^{99}$ Ihnen ist daher ein Wertungsgefälle eingeschrieben, das gegenseitige Anerkennung ausschließt und Negatives und Positives eindeutig zuordnet: „Aus dem

Berlin 2009 (Abhandlungen der Akademie der Wissenschaften zu Göttingen. Neue Folge. 4), S. 101123.

96 Vgl. zum Beispiel Alexander Patschovsky: Feindbilder der Kirche. Juden und Ketzer im Vergleich (11.-13. Jahrhundert). In: Juden und Christen zur Zeit der Kreuzzüge. Hrsg. von Alfred Haverkamp. Sigmaringen 1999 (Vorträge und Forschungen. 47), S. 327-357.

97 Vgl. Hans-Werner Goetz: Die christlich-abendländische Wahrnehmung anderer Religionen im frühen und hohen Mittelalter. Methodische und vergleichende Aspekte. Berlin 2013 (WolfgangStammler-Gastprofessur für Germanische Philologie Vorträge. 23), S. 11-46, hier S. 39-45.

98 Reinhart Koselleck: Zur historisch-politischen Semantik asymmetrischer Gegenbegriffe. In: Positionen der Negativität. Hrsg. von Harald Weinrich. München 1975 (Poetik und Hermeneutik. 6), S. 65104. Auch wenn diese Dynamik in der Rezeption übersehen oder unterschlagen worden ist, so zum Beispiel bei Koschorke, Wahrheit und Erfindung, S. 96-99, den Kosellecks Gegenbegriffe - und damit auch der Dual Christ-Heide - nur als „hegemoniale Wir/Sie-Konstellationen“ (S. 96) interessieren, deren Grenzen er nur insofern thematisiert, als jede Klassifikation immer unscharf bleibt. Diese verengende Wahrnehmung dürfte wesentlich damit zusammenhängen, dass Koselleck neben dem Begriffspaar Christ-Heide mit Hellene-Barbar und vor allem Mensch-Unmensch zwei weitere beschreibt, die viel stärker auf Negation und im letzteren Fall gar auf Annihilation hin angelegt sind. 99 Koselleck, Zur historisch-politischen Semantik asymmetrischer Gegenbegriffe, S. 65 u. S. 66. 
Begriff seiner selbst folgt eine Fremdbestimmung, die für den Fremdbestimmten sprachlich einer Privation, faktisch einem Raub gleichkommen kann."100

In Bezug auf die Selbstkonstituierung von Gemeinschaften bieten sich solche Dualismen an, um einen Innenraum des Eigenen zu bilden und gegenüber dem Außen abzugrenzen, denn sie ermöglichen es einer Gruppe sich als Handlungseinheit wahrzunehmen und als solche aufzutreten. ${ }^{101}$ Damit ist aber nicht gemeint, dass das Fremde gegenüber dem Eigenen zwangsläufig abgewertet würde, sondern eine spezifische Zuspitzung von Fremdzuschreibung benannt. Die jeweilige Semantik der Gegenbegriffe, wie die von Christen und Heiden, kann sich einerseits historisch-politisch wandeln, andererseits in ihrer strukturellen Antithetik „die Vielfalt tatsächlicher Beziehungen und Abschichtungen zwischen verschiedenen Gruppen“102 überformen.

Die Unterscheidung von Christen und Heiden ist ein spezifischer Fall solcher binärer Begriffe, zumal solcher von universalem Anspruch, die die gesamte Menschheit umfassen sollen. ${ }^{103}$ Ihre Besonderheit besteht dabei darin, dass das Christentum die herkömmlichen Bezeichnungen und Antithesen gerade aufhebt, wenn der Apostel Paulus schreibt: ubi non est gentilis et Iudæus, circumcisio et praeputium, barbarus et Scytha, servus et liber, sed omnia et in omnibus Christus (Kol 3, 11). ${ }^{104}$ In diesen exemplarischen Zweierreihen wird die gesamte bisherige Menschheit umfasst, um sie schließlich unter eine völlig neue Ordnung zu stellen:

Alle Positionen und Negationen der Menschen, der Völker, Stände und Religionen werden insgesamt überholt von den in Christo Erlösten. Die paulinische Negation ist radikaler, als bisher sagbar schien. Die sprachliche Antithese von Christen und allen Menschen ist nicht mehr asymmetrisch, die Leugnung der Asymmetrie wird gleichsam mitgeliefert, um die Heilsgewißheit zu erhärten. ${ }^{105}$

Die neue Antithese besteht jetzt also im wahren Glauben, der Christen und Heiden nicht in erster Linie in einen territorialen, sondern in einen zeitlichen Gegensatz stellt: „Alle vorfindlichen Völker, die Hellenen, ethnai, gentes, die durch die christliche Ansprache zu ,Heiden', gentiles, pagani werden, gehören als solche der Vergangenheit an. Durch Christi Tod gehört die Zukunft den Christen. Sie bringt die neue Welt. “106 Doch wandelt sich dieser Gegensatz angesichts der fortschreitenden Institutionalisierung der Kirche: Einerseits wird er territorialisiert, indem der Begriff der Chris-

100 Ebd., S. 66.

101 Vgl. ebd.

102 Ebd., S. 68.Vgl. auch Marina Münkler: Erfahrung des Fremden. Die Beschreibung Ostasiens in den Augenzeugenberichten des 13. und 14. Jahrhunderts. Berlin 2000, S. 206.

103 Vgl. ebd., S. 66.

104 „Da ist nicht mehr Grieche oder Jude, Beschnittener oder Unbeschnittener, Nichtgrieche, Skythe, Sklave, Freier, sondern alles und in allen Christus.“ Vgl. ebenso Gal 3, 28.

105 Ebd., S. 81.

106 Ebd., S. 82. 
tenheit auf die sichtbare Kirche zurückbezogen wird, andererseits wird er auf das Verhältnis des Christentums zur Welt hin spiritualisiert, und diese Ambivalenz zeigt sich auch im Begriff christianitas selbst, der sowohl die Gemeinschaft der Gläubigen als auch die Glaubenslehre bezeichnen kann. ${ }^{107}$

Das Christsein hebt letztlich doch nicht alle Unterschiede auf und das paulinische Paradox muss sich mit den konkreten soziokulturellen Gegebenheiten und Funktionalisierungen wandeln, kann letztlich nur in dieser Wandlungsfähigkeit überleben und weiterhin Gültigkeit beanspruchen. Augustinus vereint schließlich die spirituellen, territorialen und eschatologischen Dimensionen des Gegensatzes von Christ und Welt in seiner Zwei-Reiche-Lehre, die den Kampf des Christentums gegen das Heidentum nicht im territorialen Sinne beschreibt, sondern als eschatologische Auseinandersetzung zwischen der civitas terrena und der civitas Dei. Augustinus teilt die Menschheit in zwei Gruppen:

unum eorum, qui secundum hominem, alterum eorum, qui secundum deum uiuunt; quas etiam mystice appellamus ciuitates duas, hoc est duas societates hominum, quarum est una quae praedestinata est in aeternum regnare cum deo, altera aeternum supplicium subire cum diabolo. sed iste finis est earum (De civitate dei XV, 1). ${ }^{108}$

[D]ie eine, die nach dem Menschen, die andre, die nach Gott lebt. Wir sprechen auch in mystischem Sinne von zwei Staaten, das heißt zwei menschlichen Genossenschaften, deren eine vorherbestimmt ist, in Ewigkeit mit Gott zu herrschen, während die andre mit dem Teufel die ewige Strafe auf sich zu nehmen hat. Das bezieht sich allerdings erst auf ihr Ende.

Damit schafft er ein formales Deutungsmuster, das vordergründig immer eine dualistische Deutung ermöglicht, ohne die temporale Spannung auf die eigentliche Scheidung im letzten Gericht hin zu verabschieden. ${ }^{109}$ Alle Menschen, ob Christen oder Heiden, stehen im Kampf zwischen dem Bösen und dem Guten, indem es keine letzte Gewissheit gibt: Auch der Heide ist eingebunden in die göttliche Ordnung, weil er ein potentieller Christ ist, während sich andererseits der Christ seines Heils bis zum Ende nie vollständig sicher sein kann. ${ }^{110}$

Die Zuordnung der Gegenbegriffe ist also nie letztgültig, weil immer noch die Entscheidung für oder gegen den wahren Glauben möglich ist, sie bleibt prozessual und dynamisch: „Temporal gesprochen, war der Heide Noch-nicht-Christ, der Häretiker Nicht-mehr-Christ: als solche hatten sie verschieden Qualitäten."111 Entsprechend ist auch der Umgang mit ihnen unterschiedlich: Während die mittelalterliche Theologie an der Forderung festhält, dass die Annahme des wahren Glaubens letztlich immer eine Sache der freiwilligen Entscheidung sein müsse, kann sie gleichzeitig

107 Vgl. ebd., S. 82-83.

108 Zitiert nach: Aurelius Augustinus: Der Gottesstaat - De civitate dei, Bd. 2. In deutscher Sprache von Carl Johann Perl. Paderborn [u. a.] 1979 (Aurelius Augustinus’ Werke), S. 3 u. 4.

109 Vgl. ebd., S. 87.

110 Vgl. Münkler, Erfahrung des Fremden, S. 207-208.

111 Koselleck, Semantik asymmetrischer Gegenbegriffe, S. 88. 
diskutieren, wie viel und welche Form von Gewalt legitim sei, die Heiden zur Konversion zu drängen. Die Rückkehr vom Christentum zum Heidentum, der ,Abfall‘ vom einmal gewonnen Heil, erscheint allerdings weit weniger akzeptabel als das Verharren im Heidentum, das doch immer noch die Möglichkeit der Bekehrung offenlässt. Von daher sind Zwang und Gewaltmaßnahmen gegen Apostaten, Ketzer und Häretiker leichter zu legitimieren und können sogar angeraten scheinen angesichts der Gefahr, sie könnten das Heil der Gläubigen gefährden.

\subsubsection{Heidentum als Erfahrung des religiös Fremden}

In der Dynamisierung der Gegenbegriffe von ,Christen` und ,Heiden“ in der heilsgeschichtlichen Spannung auf eine erst am Ende der Tage zu erwartende Eindeutigkeit der Unterscheidung, wie ich sie eben beschrieben habe, wird bereits deutlich, dass die Konstruktion des Heidentums nicht im Ausschluss des schlichtweg ,Anderen“ besteht, sondern in der Verwiesenheit eines religiösen Fremdbildes auf das eigene Selbstbild. Fremdheit und Andersheit weisen in ihrer jeweiligen binären Codierung von ,eigen` und ,fremd' sowie ,gleich` und ,anders‘ zwar wohl eine strukturelle Nähe auf, sind darin aber nicht identisch: Während die Grenze zum Anderen klar definiert scheint, kann sie zwischen ,eigen' und ,fremd' nie genau bestimmt werden, denn das Fremde bewegt sich außerhalb des Eigenen, seine Andersheit kann vermutet, aber eben nicht mit Sicherheit gewusst werden. ${ }^{112}$ Die Grenze zum Fremden muss daher thematisiert und bearbeitet werden, sie muss - um den eingangs skizzierten narratologisch-kulturtheoretischen Ansatz weiterzuführen - ,erzählt‘ werden:

Im Vergleich zum Wissen über den Anderen zeichnet sich Wissen über das Fremde dadurch aus, das in ihm die Unvertrautheit thematisch wird, und es seine besondere Relevanz daher erst durch die Beschreibung gewinnt. Das Fehlen von Wissen muß, spätestens dort, wo es durch die Konfrontation mit dem Fremden unausweichlich erfahrbar geworden ist, durch die Deskription des Fremden ,wegerzählt‘ werden. Beschreiben und erzählen bilden somit eine spezifische Form der Konstitution wie auch der Aneignung des Fremden. ${ }^{113}$

112 Vgl. Münkler, Erfahrung des Fremden, S. 148. Vgl. grundlegend zur Fremdheit als sozialer Konstruktion und zur Forschungsdiskussion Herfried Münkler, Herfried, Bernd Ladwig: Dimensionen der Fremdheit. In: Die Herausforderung durch das Fremde. Hrsg. von Herfried Münkler unter Mitarbeit von Karin Meßlinger und Bernd Ladwig. Berlin 1998 (BBAW. Schriftenreihen. Forschungsberichte der interdisziplinären Arbeitsgruppen. 5), S. 11-44. Speziell für die germanistische Mediävistik vgl. außerdem Marina Münkler: Alterität und Interkulturalität. Ältere deutsche Literatur. In: Germanistik als Kulturwissenschaft. Eine Einführung in neue Theoriekonzepte. Hrsg. von Claudia Benthien, Hans Rudolf Velten. Reinbek bei Hamburg 2002, S. 323-344.

113 Münkler, Erfahrung des Fremden, S. 148. 
Die die Fremdheit konstituierende Leitdifferenz besteht also zwischen ,vertraut ${ }^{\text {‘ }}$ und ,unvertraut' oder anders: ,zugehörig‘ und ,nicht zugehörig‘ $\cdot{ }^{114}$ Gemeint ist mithin kein absoluter, kategorialer Ausschluss, sondern gerade die Bearbeitung eines Gegensatzes oder genauer: einer ,Geschiedenheit', als eines Bezugs, der einen Entzug einschließt. ${ }^{115}$

Andersheit und Fremdheit sind denn auch philosophisch strikt zu trennen: Das ,Andere“ ist wie das ,Selbe“ ontologisch bestimmt und „allen Seienden gemeinsam“, setzt daher die Unterscheidung durch einen Dritten voraus, während das ,Fremde“ eben das ,Eigene‘ voraussetzt, das von ihm nicht unterscheiden wird, sondern sich unterscheidet, weil es sich von ihm abhebt. ${ }^{116}$ Fremdheit bedarf also immer einer relationalen oder kontextuellen Bestimmung - also in Bezug worauf etwas als ,fremd gelten kann - und eine absolute oder totale Fremdheit bleibt ebenso leer wie die Rede vom ,ganz Anderen' ${ }^{117}$ Daher lässt sich Fremdheit auch als Alterität bezeichnen, denn dieser Begriff meint ja eben, dass das Eigene vom Fremden her bestimmt wird und Identität sich in der Abgrenzung vom Anderen herausbildet, womit aber gerade nicht der Andere im ontologischen Sinne (aliud) gemeint sein kann, sondern der andere von beiden (alter), also in Bezug auf das Eigene. ${ }^{118}$

In diesem Sinne lässt sich der ,Heide‘ als Sonderfall des ,Fremden‘ und die gedankliche oder konkrete Auseinandersetzung mit dem ,Heidentum‘ als spezifische

114 Vgl. Marina Münkler, Werner Röcke: Der ordo-Gedanke und die Hermeneutik der Fremde im Mittelalter. Die Auseinandersetzung mit den monströsen Völkern des Erdrandes. In: Die Herausforderung durch das Fremde. Hrsg. von Herfried Münkler unter Mitarbeit von Karin Meßlinger und Bernd Ladwig. Berlin 1998 (BBAW. Schriftenreihen. Forschungsberichte der interdisziplinären Arbeitsgruppen. 5), S. 701-766, hier S. 711. Zur Unterscheidung ,vertraut‘ versus ,unvertraut‘ vgl. besonders auch Kai-Uwe Hellmann: Fremdheit als soziale Konstruktion. Eine Studie zur Systemtheorie des Fremden. In: Die Herausforderung durch das Fremde. Hrsg. von Herfried Münkler unter Mitarbeit von Karin Meßlinger und Bernd Ladwig. Berlin 1998 (BBAW. Schriftenreihen. Forschungsberichte der interdisziplinären Arbeitsgruppen. 5), S. 401-459, hier S. 410.

115 Vgl. Bernhard Waldenfels: Fremdheit und Alterität im Hinblick auf historisches Interpretieren. In: Alterität als Leitkonzept für historisches Interpretieren. Hrsg. von Anja Becker, Jan Mohr. Berlin 2012 (Deutsche Literatur. Studien und Quellen, Bd, 8), S. 61-71, hier S. 61.

116 Vgl. ebd.

117 Vgl. ebd., S. 62.

118 In diesem Sinne verwende auch ich im Weiteren den Begriff des Anderen, wenn nicht ohnehin an seiner Statt vom Fremden die Rede ist. Fremdheit und Alterität werden ansonsten in der Forschung zumeist austauschbar verwendet, ohne dass die Begrifflichkeiten genauer bestimmt und der Unterschied von Fremdheit und Andersheit problematisiert würden. So erklärt eines der neueren Handbücher, der Begriff der Alterität bezeichne die Tatsache, dass sich „Identität [...] zunächst in Abgrenzung vom Anderen“ konstituiere, um dann unvermittelt zum Begriff Fremdheit überzugehen. Vgl. Michael Hofman, Iulia-Karin Patrut: Einführung in die interkulturelle Literatur. Darmstadt 2015, S. 12. Auch aus dieser Unschärfe erklärt sich wohl die irreführende Neubildung und letztlich eher unklare Verwendung des Begriffs ,Alienität‘ (zu alienus - fremd), der dann gegenüber der Alterität für ,Andersheit" die ,Fremdheit" bezeichnen soll. Bernhard Waldenfels, Fremdheit und Alterität, S. 62, betont dagegen, dass Alterität eine andere Bezeichnung für die „Fremdheit des oder der Anderen“ sei, und sieht Alienität als „preziöse Wortbildung, die nichts Neues erbringt“. 
Form der Erfahrung von Fremdheit begreifen. ${ }^{119}$ Die Heiden sind nicht einfach ,die Anderen', sondern fordern zur Relationierung heraus, bei der die Frage der Zugehörigkeit im Hinblick auf das ,Eigene، immer wieder neu bearbeitet werden muss. Als ,absolut Anderes‘ wäre das Gegenüber auch kaum darstellbar und, angesichts der engen Verbindung zwischen epistemologischen Möglichkeiten und sprachlichem Ausdruck, auch gar nicht wahrnehmbar. Auch die Zuschreibung von Andersheit rekurriert letztlich immer schon auf Vorstellungen vom Eigenen, mit dem sie das Anderssein in Relation setzt. Davon zeugen die ,vereinnahmenden' Strategien, ausgerechnet das religiös ,Andere“ als das irrige Eigene $\mathrm{zu}$ erfassen, wie die lange und gerade im Mittelalter lebendige Tradition, den Islam als christliche Häresie zu beschreiben. ${ }^{120}$

Daran wird deutlich, welche Bedeutung das Selbstbild für die Art der Wahrnehmung des Fremden hat, unter welchen ,Vorzeichen' also das Fremde wahrgenommen und in welche Wissensordnungen es dabei integriert wird. Das Fremdbild bestimmt seinerseits wieder die Wahrnehmung des Eigenen und befördert ein Selbstbild. Soziologisch wird Fremdheit denn auch gerade als „das Ergebnis eines Zuschreibungsprozesses in der Beziehung zwischen verschiedenen Personen oder Gruppen“ beschrieben, sie „kann in einer faktischen Differenz gründen, ihre Bedeutung erhält sie jedoch erst als ,Rückseite، von Selbstidentifikation: Was nicht als Teil des Selbstbildes akzeptiert beziehungsweise wahrgenommen wird, ist fremd“" ${ }^{121}$ Fremdheit bezeichnet in diesem Sinne weder die Eigenschaft von Dingen und Personen noch ein objektives Verhältnis, sondern eine Beziehung auf Grund einer Unterscheidung, ist also zugleich eine Zuschreibung und eine Identitätsbestimmung. Diese Differentsetzung erfolgt sehr häufig unbewusst und vor allem durchaus kontingent:

Gegeben ist stets eine Fülle von Gemeinsamkeiten und Verschiedenheiten. Fremdheit im emphatischen Sinne entspringt daraus, daß einige dieser Verschiedenheiten als Basis für die Selbstidentifikation eines Systems genützt werden, so daß die Gemeinsamkeiten, die es mit den Fremden teilt, auf sozial verbindliche Weise unerheblich werden, obwohl diese für viele Beteiligte viel gravierender sein mögen als die, die zur Definition des „Wir“ ausgewählt wurden. ${ }^{122}$

Demnach machen nicht faktische Unterschiede jemanden zum Fremden, sondern es ist „die institutionalisierte Fremdheit [...], die zur Wahrnehmung und Dramatisierung von Unterschieden führt“. ${ }^{123}$ Das Fremde ist erst vor dem Hintergrund des Eigenen

119 Vgl. Schotte 2009, S. 17.

120 Vgl. Reinhard Leuze: Wahrnehmung des Anderen. Der Islam in der Sicht christlicher Theologie. In: Der Orient im Okzident. Sichtweisen und Beeinflussungen. 44. Jahrestagung der Gesellschaft für Geistesgeschichte im Herbst 2002 in Potsdam. Hrsg. von Irene A. Diekmann, Thomas Gerber, Julius H. Schoeps. Potsdam 2003 (Neue Beiträge zur Geistesgeschichte. 3), S. 63-75, hier S. 63-64.

121 Andreas Feldtkeller: Art. Fremde IV. Sozialgeschichtlich, soziologisch, sozialethisch. In: ${ }^{4}$ RGG 3 (2000), Sp. 342-343., hier Sp. 342.

122 Hahn, Die soziale Konstruktion des Fremden, S. 141.

123 Ebd. 
wahrnehmbar und umgekehrt, beides sind also Zuschreibungsgrößen, die sich nur im Wechselspiel ergeben und gegenseitig konstituieren helfen: „Wenn man sagt, was man ist, muß man dies in Abgrenzung von dem tun, was man nicht ist. Die paradoxe Funktion von ,Fremden' besteht eben darin, daß sie Selbstidentifikationen gestatten. “124

Das gilt für individuelle und wie kollektive Selbstbilder und entsprechend stellt sich die Konstituierung einer Gesellschaft über die Konstruktion von Fremdheit systemtheoretisch als ,Differenz von Identität und Differenz“ dar, „da sich die Identität eines System immer nur in Differenz zur Umwelt bestimmen läßt“ und ,jede Kommunikation mit dem Zugleich von Selbst- und Fremdreferenz operiert, also ständig den Verweis auf das Fremde mitführt, was auch immer thematisiert wird““. ${ }^{125}$ Damit ist die Konstruktion von Fremdheit eine „Beobachterleistung, die den Blick vom Phänomen des Fremden zurück auf den Beobachter des Fremden wirft“ “. ${ }^{126}$ Beide Größen, das Eigene wie das Fremde, definieren sich gegenseitig und stehen immer in einer engen Verwiesenheit aufeinander im Dienste einer Identitätskonstruktion, die sich folglich in einer Art Kreisbewegung vollzieht:

Aus der identitätsstiftenden Unterscheidung von innen und außen, eigen und fremd ergibt sich als weiteres wesentliches Merkmal der Fremdzuschreibung die Normalität des Eigenen gegenüber dem Fremden, die in der Regel als Normativität gedeutet wird. Da die solcherart bekräftigte Normalität aber immer nur innerhalb der Gruppe gilt und damit für alle erfahrbar begrenzt ist, wird sie durch Fremde permanent in Frage gestellt. Das veranlaßt wiederum die Gruppe, sich nach außen schärfer abzugrenzen und die eigene Identität nach innen deutlicher zu artikulieren. ${ }^{127}$

Bei der Unterscheidung von Eigen und Fremd handelt es sich also wiederum um die Konstruktion einer Grenze, die narrativ bearbeitet werden muss und damit Identitätsstiftung ermöglicht.

Diese Bearbeitung ist aber eben keinesfalls nur auf die Option der Exklusion beschränkt, im Sinne einer hegemonialen Wir/Sie-Konstellation, wie sie Albrecht Koschorke anhand von Kosellecks asymmetrischen Gegenbegriffen beschreibt. Er betont vor allem, dass solche kulturellen Selbstbeschreibungen nicht neutral sind, sondern „aktiv ebenjene Ungleichheiten ins Werk [setzen], die sie als vorfindlich auszugeben versuchen“, als besondere und gerade narrativ vermittelte Art der „Intervention in die soziale Welt“, die Reziprozität ausschließt. ${ }^{128}$ Koschorke sieht dabei wohl den Doppelcharakter der mit den Gegenbegriffen einhergehenden narrativen Operation, nach außen gegenüber den ausgeschlossenen Anderen ,negativ a abzugrenzen und darin gleichzeitig nach innen ,positiv` Homogenität zu schaffen, Einheit

124 Ebd., S. 142.

125 Vgl. Hellmann, Fremdheit als soziale Konstruktion, S. 447.

126 Ebd., S. 448.

127 Münkler, Röcke, Der ordo-Gedanke und die Hermeneutik der Fremde im Mittelalter, S. 710.

128 Koschorke, Wahrheit und Erfindung, S. 97. 
also über eine Polarisierung herzustellen, wobei er ganz richtig feststellt, dass sowohl Exklusion als auch Inklusion ,potentiell gewalttätige Operation[en]“ sind, insofern sie Differenzen auf beiden Seiten der Unterscheidung unterdrücken. ${ }^{129}$

Es scheint mir aber fraglich, ob gerade im Fall der Kontrastierung von Christen und Heiden, die Koschorke als Beispiel von Koselleck selbstverständlich übernimmt, die wechselseitige Bedingtheit des Selbst- und Fremdbildes tatsächlich ein blinder Fleck bleiben, also verleugnet und „dem Anderen die Anerkennung als Gegenüber in einer symbolischen Wechselbeziehung verweigert werden“ muss. ${ }^{130}$ Den christlichen Diskurs über das Heidentum und den religiösen Gegensatz $\mathrm{zu}$ ihm sehe ich demgegenüber gerade als Reflexion der Bedingtheit der eigenen kulturell-religiösen Identität, denn die Möglichkeit sich vom Heidentum zum Christentum zu bekehren und die Gefahr von diesem wieder zum Heidentum ,abzufallen` bilden sein Grundthema. Die temporäre Spannung und Binnendifferenzierung des Heidenbegriffs im Hinblick auch auf die eigene Nähe und Ferne zum Heil zeugen davon, dass diese religiöse Selbstbeschreibung nicht eindimensional, sondern als spannungsreiche und multioptionale Übersetzungsleistung zu verstehen ist.

Wenn das Heidentum eine relationale Kategorie ist, dann bleibt der Dualismus der Unterscheidung wie des Gegensatzes unhintergehbar, das heißt Christen und Heiden sind nicht ohne einander zu denken, und dieses Verhältnis ist als eine besondere Form der Wechselwirkung und in diesem Sinn ,positive“ Beziehung zu verstehen, denn der Fremde ist letztlich „ein Element der Gruppe selbst“ ${ }^{131}$ Im Erkenntnishorizont dieser Arbeit bedeutet das auch: Was Christen über Heiden sagen, sagt mehr über die Christen aus als über die Heiden. ${ }^{132}$ Die Begegnung mit den Heiden oder unspezifischer: die gedankliche Auseinandersetzung mit dem Heidentum als faktische Größe fordert zur Bewältigung über eine Relationierung heraus, die gerade auch auf narrative Weise erfolgt.

Diese Narrativierung des religiös Fremden bleibt allerdings ambivalent, denn zum einen bringt das Beschreiben oder Erzählen überhaupt erst Fremdheit hervor, weil es Differenzen ins Werk setzt und solchermaßen im Akt des Beschreibens und Erzählens

129 Vgl. ebd., S. 98.

130 Ebd., S. 97. Wohlgemerkt ist der Andere, dem hier die Anerkennung verweigert wird, wiederum und immer noch einer von zweien. Er bleibt also selbst dann, wenn die wechselseitige Bedingtheit verleugnet wird, als Fremder auf das Eigene bezogen.

131 Georg Simmel: Exkurs über den Fremden. In: Ders.: Soziologie. Untersuchungen über die Formen der Vergesellschaftung. 4. Aufl. Berlin 1958, S. 509-512, hier S. 509.

132 Vgl. Ines Hensler: Ritter und Sarrazin. Zur Beziehung von Fremd und Eigen in der hochmittelalterlichen Tradition der Chansons de geste. Köln/Weimar/Berlin 2006 (Beihefte zum Archiv für Kulturgeschichte. 62), S. 2-9. Vgl. in diesem Zusammenhang auch die Überlegungen von Jan Assmann, wonach Kulturen als „Systeme kollektiver Identität“ in Bezug auf andere Kulturen nicht nur Fremdheit erzeugen, sondern ,auch Techniken der Übersetzung“ ausbilden, es also gerade auch bei der Konstruktion des Heidentums nicht um etwas absolut Anderes geht, sondern um das Andere ,im Sinne einer Schablone als Gegensatz unserer selbst“. Jan Assmann: Heiden. Der religiöse Unterschied. In: Merkur 49, 9/10 (1995), S. 957-962, hier S. 957. 
immer Distanz zum Beschriebenen respektive Erzählten erzeugt wird, andererseits wird das Fremde durch Narrativierung ins Eigene hineingeholt. ${ }^{133}$ Die mit der Beschreibung des Fremden einhergehenden Übersetzungsleistungen weisen ihrerseits darauf hin, dass Fremdheit weniger durch Andersartigkeit bestimmt ist, als durch eine kulturell erst einmal neutrale Distanz, ${ }^{134}$ also die Nichtzugehörigkeit des Gegenübers und die Nichtvertrautheit mit ihm. Ebendiese Erfahrung von Distanz wird bewältigt, indem das noch nicht Bekannte in Relation zu den eigenen Ordnungen des Wissens gesetzt wird. ${ }^{135}$ Grenzen werden auf diese Weise zu Kontaktflächen, an denen das Wissen über das Fremde mit dem über das Eigene abgeglichen werden muss.

Auf welche Weise dies geschieht, lässt sich mit den „Deutungsmuster[n] im Umgang mit Fremdheit“ beschreiben, die Ortfried Schäffter unter dem Titel „Modi des Fremderleben“ herausgearbeitet hat. ${ }^{136}$ Zwar bezieht er sich bei seinen Überlegungen auf neuzeitliche Phänomene und in einem postkolonialen Ansatz auf „europäischen Formen, in denen die Fremdheit der Welt entdeckt und erfahren werden kann“, und beschreibt diese zunächst als „,äumlich expansives Ausgreifen, geistige Vereinnahmung und Subsumption in das eigene Weltbild durch Unterordnung der anderen Erfahrungswelten und Traditionen unter die Perspektivität unserer eigenen Geschichtsschreibung“. ${ }^{137}$ Doch begreift er Fremdheit als einen Beziehungsmodus, „eine die eigene Identität herausfordernde Erfahrung “138, die sich durch Nähe noch intensiviert, und verschiedene Formen der Übersetzung oder Vermittlung erfordert und ermöglicht, die sich durchaus auf mittelalterliche Formen der Wahrnehmung und Deutung des Fremden übertragen lassen.

Den ersten Modus bilden „Ordnungen transzendenter Ganzheit: Das Fremde als Resonanzboden von Eigenheit“, bei denen sich die Unterscheidung von ,eigen “ und ,fremd“ „gegen die Grundlage einer noch ungeteilten Basis“ richtet und sich das Fremde als die „abgetrennte Ursprünglichkeit“ darstellt. ${ }^{139}$ Die Spannung beruht dabei auf einer basalen Gemeinsamkeit, nicht auf einem prinzipiellem Bruch, und das Eigene entsteht durch das Heraustreten aus der ursprünglichen, undifferenzierten Ganzheit, die dadurch zur Kontrastfläche der eigenen Identitätsbildung wird, die sich

133 So mit Bezug auf Jurij Lotmans kultursemiotische Bestimmung der Grenze Christina Henß: Das Erzählen vom fremden Heiligen in Reiseberichten des Mittelalters. Masterarbeit masch. Konstanz 2010, S. 8.

134 Vgl. Jürgen Osterhammel: Distanzerfahrung. Darstellungsweisen des Fremden im 18. Jahrhundert. In: Der europäische Betrachter außereuropäischer Kulturen. Zur Problematik der Wirklichkeitswahrnehmung. Hrsg. von Hans-Joachim König, Wolfgang Reinhard, Reinhard Wendt. Berlin 1989 (ZHF. Beiheft. 7), S. 9-42, hier S. 10.

135 Vgl. ebd., S. 33.

136 Ortfried Schäffter: Modi des Fremderlebens. Deutungsmuster im Umgang mit Fremdheit. In: Das Fremde. Erfahrungsmöglichkeiten zwischen Faszination und Bedrohung. Hrsg. von dems. Opladen 1991, S. 11-42, hier S. 12.

137 Ebd.

138 Ebd.

139 Ebd., S. 16. 
in einem Spannungsverhältnis von Abhängigkeit und Emanzipation herausbildet. ${ }^{140}$ Fremdheit wird in diesem Ordnungsschema als „Schwellenerfahrung“ erlebt, nicht als schroffer Gegensatz, ${ }^{141}$ der gemeinsame Ursprung kann also entdeckt und wiedergewonnen werden. ${ }^{142}$ Die Vorstellung einer solchen Ordnung transzendenter Ganzheit liegt dem mittelalterlichen Diskurs über die Gottesgeschöpflichkeit der Heiden zugrunde.

Der zweite Modus sind „Ordnungen perfekter Vollkommenheit: Fremdheit als Gegenbild“, bei denen das Fremde als „Negation der Eigenheit, und zwar im Sinne von gegenseitiger Unvereinbarkeit“143 erscheint. Das impliziert eine „feste und klar definierte Grenzlinie“, wobei der Kontrast nur in der Selbstreferenz wahrgenommen wird, insofern der Fremde „als Gegenbild gerade die Identität des Eigenen verstärken kann““ ${ }^{144}$ Dieses Deutungsmuster ist in der Forschung, auch der mediävistischen, oft als für das Mittelalter grundlegend behauptet worden, wobei auch begrifflich das Fremde mit dem Anderen enggeführt wurde, das von mittelalterlichen Beobachtern nur abwertend wahrgenommen worden sei, ${ }^{145}$ zumal im Hinblick auf das Heidentum. Eine solche Abwertung ist allerdings immer als eine besondere, konflikthafte $\mathrm{Zu}$ spitzung des Fremderlebens zu sehen, eben als spezifischer und funktionaler Modus und nur eine Option unter vielen. Auch kann die duale Gegensätzlichkeit sich so weit steigern und schließlich kippen, dass das Feindbild zum Idealbild wird. ${ }^{146}$ Von daher erklärt sich der Mythos vom ,edlen Wilden` ebenso wie der vom kultivierten Sarazenen, wie er im Saladin-Kult nicht erst seit der Aufklärung, sondern auch schon in der Kreuzzugsliteratur greifbar wird. Im Kontext von Heiligkeit und Mission wäre zudem zu überlegen, ob nicht beispielsweise der Wunsch, Sultan al-Kamil habe sich auf die Predigt des heiligen Franziskus hin heimlich bekehrt, nicht nur der Utopie vom Erfolg einer friedlichen Verbreitung des christlichen Glaubens entspringt, sondern auch einer gewissen Faszination für den ,edlen Heiden'.

Den dritten Modus stellen „Ordnungskonzepte dynamischer Selbstveränderung: Fremdheit als Ergänzung “ dar, unter denen Fremdheit als Reservoir von Möglichkeiten der Bereicherung und Selbstveränderung erscheint. Das Fremde hat hier die „Funktion eines externen Spielraums, der entwicklungsfördernde Impulse und auch strukturelle Lernanlässe erschließen hilft“ ${ }^{147}$ Dadurch entsteht eine Ambivalenz zwischen expansiver Assimilation und internen Verarbeitungsmöglichkeiten, die dort

140 Vgl. ebd.

141 Vgl. ebd., S. 17.

142 Vgl. ebd., S. 18.

143 Ebd., S. 19.

144 Ebd.

145 Vgl. Harry Kühnel: Das Fremde und das Eigene. Mittelalter. In: Europäische Mentalitätsgeschichte. Hauptthemen in Einzeldarstellungen. Hrsg. von Peter Dinzelbacher. 2., durchgesehene und ergänzte Aufl., Stuttgart 2008, S. 477-492. Dagegen richten sich schon Münkler, Röcke, Der ordoGedanke und die Hermeneutik der Fremde im Mittelalter, S. 701.

146 Vgl. Schäffter, Modi des Fremderlebens, S. 20.

147 Ebd., S. 22. 
unproblematisch ist, „wo Entdeckung von Fremdheit als Wiedergewinnung abgespaltener Erfahrungsmöglichkeiten und als Entfaltung latenter Potenzen der Eigenheit gedeutet werden kann“. ${ }^{148}$ Ein solches Verhältnis wäre auch für die mit Franziskus und seiner Bewegung verbundene weltmissionarische Rückbesinnung und Neuausrichtung anzunehmen, bei der die Mission unter den Heiden als positive Herausforderung und Chance zur Verwirklichung der vollen Christusnachfolge erscheint. Wenn allerdings „Akkomodation an fremde Strukturen als Selbstentfremdung erlebt“"149 und somit als Gefahr wahrgenommen wird, schlägt Expansion schnell in den zweiten Erfahrungsmodus schroffer Abgrenzung um.

Ein Beispiel für die Parallelität beider Optionen sind zeitgenössische Berichte über die unterschiedliche Wahrnehmung der Andersgläubigen in den Kreuzfahrerstaaten: Während die im Orient lebenden Kreuzfahrer in einen wechselseitigen und kulturell durchaus förderlichen modus vivendi getreten waren, rief dieser bei frisch aus der Heimat Eingetroffenen mitunter Empörung und heftige Reaktion hervor, so zumindest erzählt es der muslimische Kreuzzugschronist Usama ibn Munqidh (10951188). Dieser stand in diplomatischen Beziehungen mit den Templern, die ihm bei seinen Besuchen in Jerusalem stets bereitwillig eine Kapelle geräumt hätten, damit er dort seine Gebete verrichten konnte. Einmal habe ihn ein erst vor kurzem in Jerusalem angekommener Franke mit Gewalt davon abhalten wollen, die anderen Kreuzfahrer hätten dies aber verhindert und um Entschuldigung gebeten, denn der Neuankömmling habe noch nie einen Menschen gen Mekka beten sehen. Dieses Erlebnis gilt ihm als Beleg dafür, dass „[a]lle Franken, die erst seit kurzem ihr Land verlassen haben, [...] roher in ihrem Wesen [sind] als jene, die sich schon an unser Land gewöhnt haben und mit den Muslimen Umgang pflegen“. ${ }^{150}$

Der vierte Modus schließlich sind „Konzeptionen komplementärer Ordnungen: Fremdheit als Komplementarität“. Ordnungsstrukturen sind hier polyvalent und leben „von einem permanenten ,Oszillieren“ zwischen Positionen der Eigenheit und Fremdheit, die sich im wechselseitigen Kontakt gegenseitig hervorrufen““ ${ }^{151}$ Im Wissen um die Unverfügbarkeit der Kategorien von ,eigen' und ,fremd' relativieren sich beide, ist die Anerkennung von Differenzen und des Fremden als Fremden möglich. ${ }^{152}$ Dieser

148 Ebd., S. 24.

149 Ebd.

150 Vgl. Usâma ibn Munqidh: Ein Leben im Kampf gegen Kreuzritterheere. Aus dem Arabischen übertragen und bearbeitet von Gernot Rotter. Lenningen 2004 (Bibliothek arabischer Klassiker), S. 158-159, Zitat S. 158. Vgl. dazu Ernst-Dieter Hehl: Die Kreuzzüge. Feindbild - Erfahrung - Reflexion. In: Kein Krieg ist heilig. Die Kreuzzüge. Katalog-Handbuch zur Ausstellung im Dom- und Diözesanmuseum, Mainz, 2.4.-30.7.2004. Hrsg. von Hans-Jürgen Kotzur. Mainz 2004, S. 237-247, hier S. 243-244. Diese Episode verdeutlicht zugleich, dass kollektive Identitätsbildungsprozesse über strikte Abgrenzung weit mehr mit der Homogenisierung nach innen und der kulturellen Selbstbeschreibung des Zentrums zu tun haben, als mit der Realität an den Peripherien, an denen Vermittlung tägliche Notwendigkeit ist.

151 Schäffter, Modi der Fremderlebens, S. 25.

152 Vgl. ebd., S. 28. 
Modus entspricht dem modernen, emphatischen Toleranzverständnis und dem Anspruch interkultureller Verständigung, eine Übertragung auf den Kontext mittelalterlichen Fremderlebens in Begegnung mit den Heiden bliebe daher ein irreführender Anachronismus, denn der universale Anspruch des Christentums scheint für diesen Kontext zumindest hinsichtlich religiöser Gesichtspunkte unhintergehbar. ${ }^{153}$ Denn wie sich an verschiedenen Beispielen zeigen lässt, gilt das mittelalterliche Interesse nicht den anderen Religionen ,an sich', sondern dem eigenen Selbstverständnis, dem die anderen eingeordnet werden. ${ }^{154}$ Das Wissen über die anderen Religionen, deren Wahrnehmung und Beschreibung, ist solchermaßen immer funktional. Daraus erklären sich negative Stereotypisierungen und satirische Verzerrungen in der Polemik ebenso wie die theologische Versuche, eine gemeinsame Verständigungsbasis auf der Ebene der Vernunft herzustellen. Außerdem erhellt sich von hier aus die zunächst erstaunliche Beobachtung, dass bessere Kenntnis der anderen Religionen nicht zu mehr Verständnis oder gar Akzeptanz führen muss - mitunter gar genau das Gegenteil erzeugt, wenn nämlich im Prozess des Erkennens deutlich wird, dass eine gemeinsame Basis ausgeschlossen und die Hoffnung aus eine Bekehrung des Gegenübers vergeblich ist. ${ }^{155}$

153 Das Verständnis christlicher Mission als eine Hermeneutik des Fremden ist zeitlich wie ideengeschichtlich ein sehr modernes Konzept und das Ergebnis einer missionstheologischen Neubesinnung in der zweiten Hälfte des 20. Jahrhunderts, die Mission als Dialog entwirft. Vgl. Henning Wrogemann: Mission und Religion in der systematischen Theologie. Das Missionsverständnis deutschsprachiger protestantischer Dogmatiker im 20. Jahrhundert. Göttingen 1997 (Forschungen zur systematischen und ökumenischen Theologie. 79).

154 Vgl. noch einmal Goetz, Die christlich-abendländische Wahrnehmung anderer Religionen im frühen und hohen Mittelalter, S. 11-46, und in diesem Zusammenhang auch die anderen Arbeiten im Rahmen des Advanced Grant des European Research Council „Die Wahrnehmung anderer Religionen im frühen und hohen Mittelalter“ 2009-2012, die in vielen Einzelstudien eine beeindruckende Informationsfülle zusammentragen, dabei aber leider auf einer „,vorstellungsgeschichtlich“ beschreibenden Ebene bleiben und den funktionalen Status der Deutungsmuster über den jeweiligen Kontext heraus kaum systematisch verknüpfen und theoretisch-strukturell durchdringen. Damit bleibt letztlich auch der konzeptionell angekündigte Bezug der Fremdwahrnehmung auf das Eigene uneingelöst: Hans-Werner Goetz: Die Wahrnehmung anderer Religionen und christlich-abendländisches Selbstverständnis im frühen und hohen Mittelalter (5.-12. Jahrhundert). Zwei Bände. Berlin 2013; Anna Aurast, Hans-Werner Goetz (Hrsg.): Die Wahrnehmung anderer Religionen im früheren Mittelalter. Terminologische Probleme und methodische Ansätze. Berlin [u. a.] 2012 (Hamburger geisteswissenschaftliche Studien zu Religion und Gesellschaft. 1); Norman Bede, Bele Freudenberg (Hrsg.): Von Sarazenen und Juden, Heiden und Häretikern. Die christlich-abendländischen Vorstellungen von Andersgläubigen im Früh- und Hochmittelalter in vergleichender Perspektive. Bochum 2013.

155 Dieses Phänomen zeigt sich häufiger im Fall der spezifischen Auseinandersetzung des Christentums mit dem Judentum, vgl. dazu auch unten in Kap. 5.2.2 Adversus Judaeos - Die Aushandlung des religiösen Gegensatzes zum Judentum, S. 376. Noch Luthers polemische Auslassungen nach anfänglicher Duldsamkeit gegenüber den Juden entspringen, zumindest zu einem Teil, seiner Frustration über ihre, Verstocktheit‘. 


\subsubsection{Die Dynamik der Mission}

Die Konstruktion des Heidentums als Sonderfall von Fremdheit meint also immer ein Verhältnis von Inklusion und Exklusion, das in unterschiedlichen Formen bearbeitet wird. ${ }^{156}$ Der Gegensatz zwischen Christen und Heiden erscheint dann nicht als ein absolut und endgültig gegebener, sondern als ein dynamischer, dessen Trennlinie bis zur letzten Scheidung am jüngsten Tag nie genau gewusst werden kann und daher immer wieder neu bestimmt und erzählt werden muss. Gerade in der Mission erfährt der religiöse Gegensatz eine grundlegende Dynamisierung und Reflexion, wenn Heiden Christen nicht einfach gegenüberstehen, sondern selbst Christen werden sollen. ${ }^{157}$ Mission erweist sich dabei als ständig wiederholte Bestätigung einer Grenze, die es eigentlich zu überwinden gilt, und eben an dieser Grenze haben Selbst- und Fremdbeschreibungen polemischer, apologetischer oder wie auch immer vermittelnder Art ihren Ort. Das lässt sich wie beim Heidenbegriff zunächst auf eher theologischer Ebene beschreiben, schließlich aber auch systemtheoretisch verstehen.

Zunächst einmal stellt sich Mission religionswissenschaftlich als ein Spezifikum besonders des frühen Christentums, denn dessen Universalismus unterscheidet es von den anderen Religionen der Antike. Weil es nicht an den üblichen Grenzen der Kulte und Lebensbereiche stehenbleibt, sondern die exklusive Autorität seiner Heiligkeitserfahrung behauptet, die gleichzeitig einen radikalen Lebenswandel seiner Anhänger verlangt und eine totale Lebensdeutung bietet, kann es erfolgreich expandieren. ${ }^{158}$ Die missionarische Verbreitung des eigenen Glaubens erscheint dabei als Grundzug christlicher Lebensweise überhaupt, zumal sie als Auftrag Christi an seine Jünger fest im Evangelium (Mt 28, 19-20 und Parallelstellen) verankert ist.

Allerdings ist der dort formulierte ,Missionsbefehl' selten wirklich als Aufgabe aller Christen, sondern schon früh als spezielle Beauftragung des engsten Jüngerkreises oder besonders befähigter und eigens beauftragter Einzelner verstanden worden. Die Apostellegenden betonen die universale Sendung der Kirche gerade darin, dass sie die Weltmission als bereits abgeschlossen verstehen: Die Missionsfelder unter den Völkern werden zwischen den Aposteln aufgeteilt, der Missionsbefehl scheint damit abgegolten. ${ }^{159}$ Zudem wird der missionarische Anspruch des Christentums nicht in dem Sinne konkretisiert, dass tatsächlich alle Menschen Christen werden müssten, sondern dass die christliche Botschaft unter allen Völkern zu hören und diesen damit prinzipiell die Möglichkeit zur Bekehrung gegeben ist.

156 Vgl. Hellmann, Fremdheit als soziale Konstruktion, S. 409.

157 Zur Differenzierung des Heidenbegriffs im Kontext der Mission vgl. Münkler, Erfahrung des Fremden, besonders S. 66-83 u. 206-221.

158 Vgl. Lauster, die Verzauberung der Welt, S. 76. Lauster spricht in diesem Zusammenhang und mit Blick auf die pluralistische Religionspraxis der Antike, der Mission und Bekehrung ferngelegen habe, von einer „Kulturrevolution“.

159 Vgl. Michael Sievernich: Die christliche Mission. Geschichte und Gegenwart. Darmstadt 2009, S. 107. 
Dennoch bleibt die im Missionsbefehl formulierte Verwiesenheit des christlichen Glaubens auf die Ungläubigen dem Christentum theologisch eingeschrieben und bestimmt den Charakter seines universalen Anspruchs. Denn „[r]eligionsethnologisch verlangt das ,Hingehen zu allen Völkern' die Durchbrechung des Ethnozentrismus, demzufolge allein die Angehörigen des eigenen Volkes wirklich Menschen sind, die Anderen dagegen von Natur aus Minderwertige oder gar Feinde““ ${ }^{160}$ Der Universalismus des Christentums erhebt nicht ein erwähltes Volk und seinen Gott über die anderen, sondern stellt alle Völker unter dem für alle Menschen geltenden Anspruch eines Universalgottes gleichberechtigt nebeneinander. ${ }^{161}$ Die missionarische Hinwendung zu den Heiden erfordert und befördert also ein Durchbrechen der gewohnten Grenzen und Ordnungen, wie es auch die Verhandlung von Transzendenz und Immanenz hinsichtlich des Phänomens ,Heiligkeit‘ bestimmt.

Das Problemfeld der Mission erscheint daher in besonderem Maße geeignet für die Narrativierung von Heiligkeit, wie ich sie hier verstehe als Herausforderung des Eigenen, denn Mission stellt nicht nur den zu missionierenden Unglauben in Frage, sondern steht gleichzeitig vor der Aufgabe, die eigene Wahrheit in der Vermittlung an die Andersgläubigen zu bewahren und zur Geltung kommen zu lassen. Da eine missionierende Religion die vorfindlichen Glaubensvorstellung selten einfach verdrängen und auslöschen kann, muss sie sich in eine „kritische, aber zugleich auf Kooperation angewiesene Beziehung zu ihr setzen“. ${ }^{162}$ Mission lässt sich dabei beschreiben als Weitergabe von Religion jenseits der Grenzen der Abstammungsgemeinschaft, deren religiöse Sozialisationsleistung auf die ,natürlichen' Bedingungen des menschlichen Lebens wie den familiären Lebenszyklus oder den Vegetationszykus begrenzt sei. ${ }^{163}$ Was Mission weitergebe, sei hingegen

eine Form von religiöser Lehre, die kritisch auf all diese Vorgegebenheiten menschlichen Lebens bezogen ist, die herausruft aus der Familienbindung in eine Vorstellung von der Gleichheit aller Menschen, aus der Heimatverbundenheit zur Offenheit gegenüber der Welt, aus der Abhängigkeit von materiellen Gütern in die Suche nach einem Schatz, der unvergänglich ist.

Daher ist der Anspruch einer missionarischen Religion wie der des Christentums nicht nur auf einen Religionswechsel im Sinne des Austauschs eines Kultes gegen den eigenen beschränkt, sondern er transzendiert innerweltliche, kulturelle Grenzen, mit Folgen nicht nur für die zu missionierende Religion, sondern auch für sich selbst. Dabei lässt sich feststellen, dass „[i]n verschiedenen geschichtlichen Zusammenhängen missionarischer Religionen [...] das Idealbild eines ehelosen, heimatlosen und besitzlosen Menschen ausgebildet worden [ist], der in seiner Lebensführung ganz auf

160 Angenendt, Toleranz und Gewalt, S. 373.

161 Ebd.

162 Andreas Feldtkeller: Sieben Thesen zur Missionsgeschichte. Berlin 2000 (Berliner Beiträge zur Missionsgeschichte. 1), S. 10.

163 Vgl. ebd., S. 9. 
das Jenseits ausgerichtet ist“"164, womit ein wesentliches Muster christlicher Heiligkeit benannt ist, die freilich wenigen vorbehalten ist:

Da dieses Ideal aber nur von wenigen Menschen gelebt werden kann und einer Symbiose bedarf mit Menschen, die stärker der Welt verbunden sind, ist die Geschichte der missionarischen Religionen eine Geschichte immer neuer Verbindungen mit der Form von Religiosität, wie sie innerhalb der Abstammungsgemeinschaften weitergegeben wird. Bei jeder kulturellen Grenzüberschreitung durch eine missionarische Religion ist diese Aufgabe neu zu leisten. ${ }^{165}$

Insofern erfordert Mission neben der Verhandlung der Grenzen der Zugehörigkeit zum eigenen Glauben immer auch die der Grenze zwischen Transzendenz und Immanenz, sie bearbeitet also nicht nur das Problemfeld des Heidentums, sondern auch das der Heiligkeit.

Nicht nur die Konstruktion des Heidentums, sondern auch Mission lässt sich dabei systemtheoretisch beschreiben. Denn wie jedes soziale System durch die Grenzen der Zugehörigkeit bestimmt wird, so braucht auch Religion „Kriterien der Inklusion und der Exklusion, die die Bedingungen der Mitgliedschaft festlegen“, so der Ausgangspunkt bei Bernd Hausberger. ${ }^{166}$ Religionen können dabei kollektive Identitäten entlang ethnischer Grenzen definieren, die jeden Andersgläubigen als Angehörigen einer anderen Gruppe zum Fremden oder gar Feind machen: „Solche Religionen werden rein über Abstammungsgemeinschaften tradiert und erzeugen keine Motivation zur Bekehrung Andersgläubiger." ${ }^{\text {"167 }}$ Mission ist daher nur im Horizont eines universalen Anspruchs denkbar, der aber systemtheoretisch betrachtet ein nicht unerhebliches Problem darstellt:

Das religiöse System braucht einerseits zur Sicherung seiner Stabilität Grenzen und einen definierten Exklusionsbereich und kann andererseits, um seine universelle Gültigkeit zu beweisen, die Grenzen selbst nicht anerkennen, weil auch alle Ausgeschlossenen im Prinzip eingeschlossen sein müssten. Missionare definieren die Außenstehenden als Heiden oder Ungläubige und bemühen sich gleichzeitig um ihre Inklusion. ${ }^{168}$

Die damit verbundene Destabilisierung des Systems wird auf bezeichnende Weise „neutralisiert“169, wie Hausberger es nennt. Das Spannungsverhältnis von der Notwendigkeit zur Exklusion der Andersgläubigen und der Anspruch auf ihre Inklusion

164 Ebd., S. 9-10.

165 Ebd., S. 10.

166 Bernd Hausberger: Mission. Kontinuitäten und Grenzen eines universalen Anspruchs. In: Im Zeichen des Kreuzes. Mission, Macht und Kulturtransfer seit dem Mittelalter. Hrsg. von dems. Wien 2004 (Expansion, Interaktion, Akkulturation. Historische Skizzen zur Europäisierung Europas und der Welt. 7), S. 9-25, hier S. 10, mit ausdrücklichem Verweis auf Luhmann, die Religion der Gesellschaft, S. 241.

167 Hausberger, Mission, S. 10.

168 Ebd.

169 Ebd. 
wird zur autopoietischen Basisoperation einer auf Mission hin angelegten Religion, denn: „Missionare ziehen deshalb die Grenzen nach jedem Erfolg wieder neu, mit anderen Worten: Sie erzeugen die Dynamik einer anhaltenden missionarischen Expansion. " ${ }^{170}$ Dabei handelt es sich nicht um eine Lösung des Stabilitätsproblems im eigentlichen Sinn, sondern um seine zeitliche Verschiebung, denn nach der erhofften Bekehrung der gesamten Menschheit kann nur noch das Ende der Zeiten kommen. ${ }^{171}$ Allerdings bestätigt diese Verschiebung wiederum die eschatologische Spannung wie den universalen Anspruch des Christentums, wie ich sie oben dargestellt habe.

Interessant ist dabei eine weitere Beobachtung Hausbergers, der feststellt, die Situation könne auch durch „die Setzung eines außerweltlichen Exklusionsbereichs stabilisiert werden, etwa in der Gestalt des Teufels, der auch bei Inkludierung aller Exkludierten nicht verloren geht und im Inneren des Systems ständig neue Fronten eröffnet“. ${ }^{172}$ Auf diese Weise lässt sich die auffällige Parallelität von Heidenmission und Ketzerbekämpfung gerade im 13. Jahrhundert erklären, denn beide Phänomene verhandeln ja auf je eigene Weise die Grenzen der Zugehörigkeit zum Christentum: während erstere auf die Inklusion der ,Ungläubigen' zielt, eröffnet letztere neue Fronten im System selbst, indem sie abweichende Glaubensvorstellungen innerhalb der Kirche auszumachen und diese zu exkludieren bestrebt ist.

Für noch bemerkenswerter halte ich den Gedanken eines systemstabilisierenden ,außerweltlichen Exklusionsbereichs' aber im Hinblick auf den Zusammenhang von Mission und Heiligkeit. Denn gerade die Heiligen markieren, wie oben gezeigt, eine solche Sphäre des Ausgeschlossenen und erhalten damit die für die Autopoiesis einer missionarischen Religion konstitutive Spannung von Inklusion und Exklusion: Selbst wenn alle Andersgläubigen erfolgreich ins Christentum inkludiert wären, wäre das letzte Ziel noch nicht erreicht, denn grundsätzlich sollen alle Gläubigen heilig sein oder werden. Da aber tatsächlich noch nicht alle in die Gemeinschaft der Heiligen inkludiert sind, stellt diese Setzung ein Exklusionsmuster dar, das die eschatologische Spannung auf die letzte Scheidung im jüngsten Gericht und die Gottesnähe aller dann als wahrhaft Gläubige Erkannten hin aufrechterhält.

Auch für die Figur des Heiden als Adressat von Mission, zumal in der Begegnung mit dem christlichen Heiligen im Modus legendarischen Erzählens, bleibt die Spannung von Exklusion und Inklusion konstitutiv. Denn wie ich im Vorangegangen gezeigt habe, ist Mission theoretisch-strukturell und vor allem auch in ihrer praktischen Gestaltung nicht als Überspringen eines Gegensatzes zu verstehen, in dem der Heide unter Auslöschung seiner vorherigen Identität ins Eigene, einverwandelt‘ würde. Mission stellt daher grundlegend eine Form der Aushandlung von Identität dar, bei der das religiöse Eigene behauptet werden muss, um es in einen anderen religiösen und kulturellen Kontext vermitteln und überhaupt in der ,Welt‘ verwirklichen zu können: 
Da es nach christlichem Grundverständnis keine prinzipielle Abwertung von Welt und Menschheit geben kann, das sie aus der „guten“ Schöpfung Gottes (Gen 1, 31) hervorgehen, aber auch keine totale Anpassung ans jeweils Gegebene, da mit der Differenz auch die Identität verschwände, bedürfen missionarische Konzeptionen beider Momente von Anpassung und Abgrenzung $[\ldots]^{173}$

Deshalb stellt sich in historischen Missionssituationen, das zeigt gerade auch die franziskanische Neubegründung der Heidenmission, ${ }^{174}$ je neu die Frage nach der angemessen Methode, nach dem strategisch erfolgversprechenden wie religiös legitimen Maß der Akkulturation und Adaption in beide Richtungen der Aushandlung: des Missionars und der missionierenden Religion an die zu missionierende Umgebung wie der zu Missionierenden an die neue Religion und ihr kulturelles Herkunftssystem.

Historische Diskurse und Theorien, die Mission reflektieren und handhabbar machen wollen, dienen dabei natürlich „der Selbstdarstellung und der Rechtfertigung“ der Missionare und sind Versuche, „notwendige Informationen zusammenzustellen, um die Effizienz ihrer Strategien und Methoden zu erhöhen“. ${ }^{175}$ Gleichzeitig und vor allem aber zeigt sich in ihnen, wie die Aushandlung des religiösen Gegensatzes unter bestimmten kulturellen und theologischen Bedingungen überhaupt denkbar ist und wie die Spannung von Exklusion und Inklusion konkret bearbeitet werden kann, die die eigene religiöse Identität bestimmt. Das gilt aber ebenso für die Heiden: Der einzelne Bekehrte interessiert gerade als erfolgreich angesprochener Adressat von Mission, als einer, der vom Heiden zum Christen geworden ist, damit in seiner neu gewonnenen Identität den Sieg des Christentums über das Heidentum bezeugt oder neutraler: die Möglichkeit verkörpert, dass und auf welche Weise der Gegensatz zu überwinden ist, der Fremde ins Eigene inkludiert werden kann. ${ }^{176}$

Mit dem Begriffspaar ,Heiden und Heilige“ sind also zwei Konstruktionen der religiös-kulturellen Selbstbeschreibung benannt, die zwar auf unterschiedlichen konzeptionellen und bedeutungsstiftenden Ebenen anzusiedeln sind und deshalb ihrerseits keine zueinander konträren Gegenbegriffe bilden können. Dennoch markieren sie die beiden möglichen entgegengesetzten Pole einer religiösen Identitätsbildung, indem sie die Integrations- und Distinktionsfiguren in der Selbstbeschreibung einer Glaubensgemeinschaft darstellen. Während der Heilige als religiöser Virtuose gerade dadurch, dass er sich als Exklusionsfigur von der christlichen Masse abhebt, einen integrativ-identifikatorischen Maximalpunkt markiert, wirken die Heiden zunächst als Negativfolie. Die religiöse Identitätskonstruktion über eine strikt

173 Sievernich, Die christliche Mission, S. 110. Mission ist zwangsläufig Assimilation, darf aber nicht zur Dissimilation führen. Vgl. Hans von Soden: Die christliche Mission in Altertum und Gegenwart. In: Kirchengeschichte als Missionsgeschichte, Bd. 1: Die Alte Kirche. Hrsg. von Heinzgünter Frohnes, Uwe W. Knorr. München 1974, S. 18-31, hier S. 26.

174 Vgl. dazu unten in Kap. 3.3.1 Martyrium und Mission im frühen Franziskanertum.

175 Hausberger, Mission, S. 11.

176 Vgl. für diese Spannung und Verschränkung von alter und neuer Identität des Konvertiten unten in Kap. 5.1.1 Konversion als Grundmuster christlicher Identitätsbildung. 
binäre Logik von Selbst- und Feindbild bleibt aber eine Verkürzung, die nur unter bestimmten kulturellen Bedingungen wie der kriegerischen Konfrontation Geltung beanspruchen kann. ${ }^{177}$ Zwar steht der Heilige als einzelner und berufener Vertreter des christlichen Glaubens einer meist zahlenmäßig wie qualitativ nicht näher bestimmbaren Menge von Andersgläubigen gegenüber und wird die Asymmetrie noch gesteigert, weil er eben kein ,gewöhnlicher' Christ ist, sondern ein Heiliger. Dabei zielt sein Zeugnis aber darauf, gerade sein heidnisches Gegenüber für den christlichen Glauben zu gewinnen, er ist also Integrationsfigur gerade auch für die Heiden, die als Bekehrte ihrerseits zu Kündern und Zeugen des neuen Glaubens und letztlich zu Heiligen werden können.

\subsection{Aushandlungen des religiösen Gegensatzes im 13. Jahrhundert}

Im Vorangegangenen ging es mir darum, Heiligkeit und Heidentum als die beiden Pole einer religiösen Identitätsbildung darzustellen, die sich insofern entsprechen, als sich an beiden Enden Aushandlungsprozesse in einem Wechselspiel von Zugehörigkeit und Nicht-Zugehörigkeit beschreiben lassen. Sie ermöglichen damit eine dynamische Bestimmung kollektiver Identität im Reflexivwerden religiöser Zugehörigkeit und entsprechender Selbstbilder. In einem dritten Schritt will ich diesen allgemeinen kulturwissenschaftlichen Ansatz auf den konkreten historischen Kontext und die Diskurse des 13. Jahrhunderts beziehen. Dazu werde ich zunächst grundlegend nach

177 So hat Edith Feistner anhand der Statuten des Deutschen Ordens gezeigt, dass die „antagonistische Konfiguration“, bei der Selbstbild und Feindbild „gleichsam den Positivabzug und den Negativabzug ein und desselben Bildes“ darstellen, das Produkt einer kollektiven Komplexitätsreduktion ist, die kriegerische Konfliktsituationen kennzeichne. In der existentiellen Bedrängnis zwischen Leben und Tod lasse sie sich ,als kognitiver und affektiver Automatismus verstehen, der zu Gunsten einer auf den Kampf fokussierten Konzentrationsleistung die Beteiligten von Differenzierungsaufgaben entlastet“. Abseits der akuten Kampfsituation aber sei diese Leistung als Erfahrungsmuster reflexiv hintergehbar und könne dabei in propagandistischer Absicht auch bewusst aktiviert werden. Vgl. Edith Feistner, Michael Neecke, Gisela Vollmann-Profe: Krieg im Visier. Bibelepik und Chronistik im Deutschen Orden als Modell korporativer Identitätsbildung. Tübingen 2007 (Hermaea. Germanistische Forschungen. Neue Folge. 114), S. 29, Zitate ebd. Vgl. dazu auch schon Edith Feistner: Selbstbild, Feindbild, Metabild. Spiegelungen von Identität in präskriptiven und narrativen Deutschordenstexten des Mittelalters. In: Forschungen zur deutschen Literatur des Spätmittelalters. Festschrift für Johannes Janota. Hrsg. von Horst Brunner, Werner Williams-Krapp. Tübingen 2003, S. 141-158. Wie in der Kreuzzugswerbung, für die Kreuzfahrer selbst und schließlich die Chronisten der Kreuzzüge „die Anhänger des Islam weniger in ihrer Rolle als religiös und damit kulturell Fremde, sondern in ihrer Funktion als Feinde der Christen" von Interesse waren und wie diese Feinbildkonstruktion einerseits funktional auf das Selbstbild bezogen ist, sich andererseits angesichts der Fremderfahrung infolge der persönlichen Konfrontation mit der muslimischen Alterität verändert, zeigt Martin Völkl: Muslime Märtyrer - Militia Christi. Identität, Feindbild und Fremderfahrung während der ersten Kreuzzüge. Stuttgart 2011 (Wege zur Geschichtswissenschaft), Zitat S. 214. 
den möglichen Formen des Kulturkontakts in dieser Zeit fragen und daran anknüpfend die beiden für diese Zeit prägenden Formen der ,realen' Aushandlung des religiösen Gegensatzes, Kreuzzug und Mission, auf ihren religiösen Gehalt wie auf ihren spezifischen Zusammenhang hin untersuchen.

Wenn dabei der Islam und die militärischen wie missionarischen Bestrebungen im Orient im Mittelpunkt stehen, soll damit nicht unterschlagen werden, dass die lateinische Christenheit andersgläubigen Fremden nicht nur dort begegnet. Die Kreuzzüge im weiteren Sinn umfassen eben auch die „Unternehmungen gegen Ketzer, gegen die Muslime auf der Iberischen Halbinsel oder gegen die Heiden an der Ostsee“178 und natürlich wird auch hier die Frage nach den Formen des Kulturkontakts wichtig. Den Kreuzzügen ins Heilige Land und den an sie anknüpfenden Missionsbestrebungen kommt aber insofern eine herausragende Bedeutung $\mathrm{zu}$, als sich im ,Orient‘ als Kontaktzone und realer wie imaginärer Erfahrungsraum die Muster für die Wahrnehmung, Darstellung und Aushandlung des religiösen Gegensatzes zum Heidentum herausbilden. Die Kreuzzugsidee entsteht nicht zufällig im Zusammenhang mit den kriegerischen Unternehmungen im Heiligen Land, hier hatte sie für die Zeitgenossen ihren angestammten Platz und hier entfaltete sie ihre eigentliche mobilisierende Kraft. ${ }^{179}$ Als „neue Form militärischer Unternehmungen“ bildete sie den Maßstab und „trug wesentlich dazu bei, der europäischen Expansion des Mittelalters Kohärenz zu verleihen“. ${ }^{180}$

Die methodische Konzentration auf den Orient und die Kulturkontakte mit den Muslimen entspricht außerdem der spezifischen Bedeutung, die dem Islam für die Identitätskonstruktion des mittelalterlichen Christentums insgesamt zukommt. Denn „aufgrund seiner militärischen und bis zum Hochmittelalter auch kulturellen Überlegenheit und auch, weil er Jahrhunderte nach dem Christentum entstand und Mohammed den expliziten Anspruch erhob, als letzter monotheistischer Prophet die Offenbarung abzuschließen“181, tritt er in direkte Konkurrenz zum Anspruch des Christentums. Gerade die Begegnung mit den Muslimen zwingt daher die lateinische Christenheit dazu, sich der Grenzen und Bedingungen religiös-kultureller Zugehörigkeiten und ihrer eigenen Identität zu versichern.

\subsubsection{Formen religiösen Kulturkontakts}

In meinen theoretischen Überlegungen zum Heidentum ging es mir darum herauszuarbeiten, dass die Beziehung des mittelalterlichen Christentums zu den ,Heiden“

178 Jaspert, Die Kreuzzüge, S. IX.

179 Vgl. ebd.

180 Ebd., S. 12.

181 Markus Riedenauer: Das mittelalterliche Christentum in Auseinandersetzung mit dem Islam. In: Mittelalterliches Denken. Gestalten, Ideen und Debatten im Kontext. Hrsg. von Christian Schäfer, Martin Thurner. Darmstadt 2007, S. 105-126, hier S. 106. 
keine eindimensionale, sondern vielmehr von einer grundsätzlichen Vielfalt an Optionen bestimmt ist. Die für die Kulturkontakte des 13. Jahrhundert denkbaren Formen stelle ich daher in bewusster Absetzung von einer Forschung dar, die an dieser Stelle kaum kulturwissenschaftlich-methodisch analysiert, sondern einerseits allzu oft mit der anachronistischen und moralisierenden Frage nach ,Toleranz' die spannungsvolle Vielschichtigkeit interkultureller Konstellationen verfehlt und daher dann anderseits oftmals einseitig die kriegerischen Konfrontationen fokussiert hat.

Angesichts dieses Defizits scheint es mir berechtigt, mit Urs Bitterlis „Grundformen des Kulturkontakts“"182 auf eine Systematik und Terminologie zurückzugreifen, die für einen anderen historischen Kontext, die europäische Expansion der frühen Neuzeit, entwickelt wurden. ${ }^{183}$ Bitterli nennt als erstes die „Kulturberührung“ und versteht darunter das kurzzeitige, erstmalige oder punktuelle Zusammentreffen unterschiedlicher Kulturen. ${ }^{184}$ Wenn es nicht bei einer solchen vorübergehenden Kulturberührung bleibt, entwickele sich daraus die „Kulturbeziehung“ als „ein Modus vivendi friedfertigen gegenseitigen Austauschs [...], der zu neuen Abhängigkeiten und beidseitigen Anpassungen führte“185. Oder aber es komme, und das scheint der häufigere Fall, zum „Kulturzusammenstoß“, worunter Bitterli verschiedene Formen feindseliger Konflikte militärischer oder machtpolitischer Natur subsumiert, die sich gegen die kulturelle und gegebenenfalls auch die physische Existenz des Gegenübers richten, sei es als einseitiger Hegemonieanspruch einer stärkeren gegenüber einer schwächeren Kultur oder wechselseitig zwischen gleichstarken Kulturen. ${ }^{186}$

Marina Münkler weist darauf hin, dass Bitterli keine unterschiedlichen Grade von Kulturzusammenstoß benennt, die zu unterscheiden für die mittelalterlichen Kontakte aber durchaus sinnvoll sei, und schlägt eine Unterscheidung von peripheren und zentralen Kulturzusammenstößen vor, sowohl was territoriale als auch kulturelle Hegemonieansprüche betrifft. ${ }^{187}$ Dafür sieht Bitterli seine drei Grundformen in gegenseitiger Durchdringung und mit fließenden Übergängen, wobei keine zwangsläufigen Zielrichtungen anzunehmen sind, wonach die eine Form zwingend aus der anderen hervorgehen oder in eine andere Stufe zurückfallen müsste: Kulturberührungen können zu Kulturbeziehungen führen, müssen es aber nicht, letztere können sich wieder zur Kulturberührung zurück entwickeln, Kulturzusammenstöße sind nie unvermeidbar und bilden auch nicht das Ende eines Kulturkontakts. ${ }^{188}$

182 Urs Bitterli: Alte Welt - neue Welt. Formen des europäisch-überseeischen Kulturkontakts vom 15. bis zum 18. Jahrhundert. München 1986, Kap. 1: Grundformen des Kulturkontakts, S. 17-54.

183 Damit folge ich Marina Münkler, die freilich anmerkt, dass sich die drei von Bitterli beschriebenen Formen im Mittelalter ,in geringerer Extensität und Intensität als in der Neuzeit“ finden. Münkler, Erfahrung des Fremden, S. 15.

184 Vgl. Bitterli, Alte Welt - neue Welt, S. 17.

185 Ebd., S. 27.

186 Ebd.

187 Vgl. Münkler, Erfahrung des Fremden, S. 15, Anm. 4.

188 Vgl. Bitterli, Alte Welt - neue Welt 1986, S. 17. 
Von allen diesen Optionen ist für das 13. Jahrhundert grundsätzlich auszugehen, gerade auch für die interreligiösen Kulturkontakte. Denn die Erfahrung religiöser Pluralität ist für das Mittelalter sehr wohl Realität, ebenso wie der gestaltende Umgang mit ihr. ${ }^{189}$ Wenn das aus moderner Sicht oft nicht wahrgenommen worden ist, liegt das weniger an der Unkenntnis historischer Fakten als an einer anachronistischen Interpretation, die ein nachaufklärerisch-säkulares, kritisches Verständnis von Religion zum Maßstab macht und die interreligiösen Kulturkontakte, seien es Beziehungen oder Zusammenstöße, daran misst. Dieses Problem verdichtet sich im Begriff der Toleranz, der heute weitgehend von seinem Zumutungscharakter gelöst worden ist, während er im eigentlichen und ursprünglichen Sinne aber gerade die Herausforderung meint, dass Andersheit „das Eigene in seinem wesentlichen Kern betrifft, die eigene Identität belastet ${ }^{“ 190}$, seine Selbstverständlichkeit und seinen Anspruch also in Frage stellt. Das Andere oder Fremde erscheint dann nicht als ,Bereicherung`, wird nicht in seiner eigenen religiös-kulturellen Identität ,respektiert‘, sondern geduldig ertragen, erduldet und geduldet. Genau eine solche Duldung meint der Begriff tolerantia und bezeichnet damit letztlich

ein Herrschaftskonzept: Eine andere Religion beziehungsweise eine andere confessio wird nicht als solche anerkannt, sondern nur nicht konsequent mit herrschaftlicher Gewalt an der Religionsausübung gehindert - bei deutlichen Einschränkungen für die religiöse Freiheit. ${ }^{191}$

189 Dafür lassen sich mittlerweile einige religionswissenschaftliche Beiträge anführen, zum Beispiel die von Christoph Auffarth: Mittelalterliche Modelle der Eingrenzung und Ausgrenzung religiöser Verschiedenheit. In: Europäische Religionsgeschichte. Ein mehrfacher Pluralismus, Bd. 1. Hrsg. von Hans G. Kippenberg, Jörg Rüpke und Kocku von Stuckrad. Göttingen 2009, S. 193-218; Pluralität, Einheitszwang und Pluralismus. Religionen im latein-europäischen Mittelalter. In: Modelle des religiösen Pluralismus. Historische, religionssoziologische und religionspolitische Perspektiven. Hrsg. von Karl Gabriel, Christian Spieß, Katja Winkler. Paderborn 2012 (Katholizismus zwischen Religionsfreiheit und Gewalt. 5), S. 51-79 und Dorothea Weltecke: Jenseits des „Christlichen Abendlandes“. Grenzgänge in der Geschichte der Religionen des Mittelalters. Konstanz 2010 (Konstanzer Universitätsreden. 238); Einführende Bemerkungen. In: Religiöse Vielfalt und der Umgang mit Minderheiten. Vergangene und gegenwärtige Erfahrungen. Hrsg. von ders., Ulrich Gotter, Ulrich Rüdiger. Konstanz/ München 2015, S. 9-24. Für die altgermanistische Forschung vgl. Ulrich Müller: Toleranz zwischen Christen und Muslimen im Mittelalter? Zur Archäologie der Beziehungen zwischen dem christlichlateinischen Okzident und dem islamischen Orient. In: Kulturthema Toleranz. Zur Grundlegung einer interdisziplinären und interkulturellen Toleranzforschung. Hrsg. von Alois Wierlacher. München 1996, S. 307-353. Durchaus noch repräsentativ für die Versuche der älteren Forschung, neuzeitliche Toleranzvorstellungen im Mittelalter zu finden: Barbara Sabel: Toleranzdenken in mittelhochdeutscher Literatur. Würzburg 2003 (Imagines medii aevi. 14), Kap. II „Toleranzdenken in der Bibel und in theoretischen Texten des Mittelalters“ und Kap. III „Konstanten der Behandlung Andersgläubiger im Mittelalter“.

190 Georg Wieland: Das Eigene und das Andere. Theoretische Elemente zum Begriff der Toleranz im hohen und späten Mittelalter. In: Toleranz im Mittelalter. Hrsg. von Alexander Patschovsky, Harald Zimmermann. Sigmaringen 1998 (Vorträge und Forschungen. 45), S. 11-25, hier S. 11.

191 Auffarth, Pluralität, Einheitszwang und Pluralismus, hier S. 60. 
Ein solches Aushalten oder Hinnehmen anderer Religionen in der eigenen Gesellschaft ist im theologischen Denken des Mittelalters fest verankert und eine gelebte,

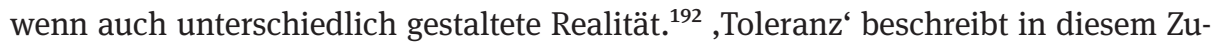
sammenhang keine Werthaltung und kein klares Modell interkultureller beziehungsweise interreligiöser Kulturbeziehungen, sondern eine je nach Kontext unterschiedliche Aushandlung, welcher Spielraum dem unwahren oder gar bösen Anderen zugestanden werden kann, ohne dass damit das Eigene bedroht oder verhandelbar wird. ${ }^{193}$

Entsprechend stellt sich das Problem religiöser Toleranz gegenüber Andersgläubigen im Mittelalter komplexer dar, als ein anachronistisches Verständnis wahrnehmen lässt. Denn mit der semantischen Verschiebung weg von einer ablehnenden Duldung hat der Toleranzbegriff gerade in Bezug auf religiöse Verschiedenheit eine stark normative Aufladung erfahren, im Sinne einer Bejahung aller anderen Religionen unter Ablehnung absoluter religiöser Wahrheiten. Ein solches Postulat steht dem Anspruch des mittelalterlichen Christentums natürlich entgegen und stellt daher keine angemessene Kategorie kulturwissenschaftlicher Analyse dar, auch weil es keine Differenzierungen und Abstufung im Hinblick auf historisch tatsächlich denkbare und verwirklichte Formen religiöser Kulturkontakte zwischen gewaltsamen Konflikten und friedlichem Zusammenleben erlaubt. Wenn jedoch der Toleranzbegriff diese politisch-pragmatische Dimension nicht berücksichtigt, ist er schließlich wenig geeignet, die Formen mittelalterlicher Kulturkontakte zu beschreiben. ${ }^{194}$

In welcher Weise in den unterschiedlichen Kontexten des 13. Jahrhunderts der religiöse Pluralismus tatsächlich bearbeitet wird, hängt neben den strukturellen Bedingungen, die ich in den vorangegangenen Überlegungen zum Heidentum dargelegt habe, maßgeblich von der zeitgenössischen Wahrnehmung ab, die von verschiedenen konkreten Faktoren bestimmt wird, beispielsweise

von der tatsächlichen Interaktion mit Andersgläubigen, welche wiederum von militärischen, wirtschaftlichen und kulturellen Begegnungen gefördert und gefordert wird, von der Selbstsicherheit oder aber Verunsicherung im eigenen Glauben (z.B. durch binnenchristliche Vielfalt oder Uneinigkeit), bis hin zur Wahrnehmung der anderen Religion als Bedrohung. ${ }^{195}$

192 Und kann im 11. und 12. Jahrhundert sogar Bezug auf Häretiker gedacht werden, denn auch für diese gilt der eschatologische Vorbehalt, dass erst Gott Glaube von Unglaube scheiden und endgültig urteilen wird. Am Ende bestimmend bleibt aber die augustinische Legitimation von Gewalt gegen Schismatiker und Häretiker, wenn die Kirche durch diese ernsthaft gefährdet ist. Vgl. Heinrich Holze: Religiöse Toleranz im Mittelalter? Überlegungen zum Umgang mit der ,diversitas‘ im 11. und 12. Jahrhundert. In: Berliner Theologische Zeitschrift 15 (1998), S. 41-55, hier S. 44-46.

193 Vgl. Patschovsky, Toleranz im Mittelalter, S. 393.

$194 \mathrm{Vgl}$. Dorothea Weltecke: Müssen monotheistische Religionen intolerant sein? Drei Ringe, Drei Betrüger und der Diskurs der religiösen Vielfalt im Mittelalter. In: Die Gewalt des einen Gottes. Die Monotheismus-Debatte zwischen Jan Assmann, Micha Brumlik, Rolf Schieder, Peter Sloterdijk und anderen. Hrsg. von Rolf Schieder. Berlin 2014, S. 301-323, hier S. 306-307.

195 Riedenauer, Das mittelalterliche Christentum in Auseinandersetzung mit dem Islam, S. 107. 
Diese unterschiedlichen Wahrnehmungen, die sich dabei diachron abwechseln oder aber synchron nebeneinanderstehen können, schlagen sich in unterschiedlichen Formen von Kulturkontakten nieder, die funktionalen Erfordernissen entsprechen und sich ihrerseits wieder überlagern, ineinanderfließen oder gegeneinander wirken können. Welche Wahrnehmungen jeweils aktualisiert und welche Formen des Kulturkontakts jeweils realisiert oder zumindest imaginiert werden, hängt dabei auch sehr stark vom jeweiligen ,Ort' in der kulturellen Semiosphäre ab.

Der Prozess der Homogenisierung der lateinischen Christenheit erscheint so an der Peripherie eher als einer der Polarisierung, der Errichtung enormer kultureller Grenzen angesichts einer oft konfliktreichen „Mischung von Sprachen, Kulturen und manchmal auch Religionen“. ${ }^{196}$ Die Kreuzzüge als Kulturzusammenstöße nehmen ihren Ausgang immer wieder von den geografischen wie spirituell-kulturellen Zentren der westlichen Kirche, ${ }^{197}$ während die alltägliche Interaktion mit den Andersgläubigen an der Peripherie in den Kreuzfahrerstaaten gerade den Aufbau von Kulturbeziehungen erfordert und befördert, weil sich eine permanente Konfrontation gar nicht durchhalten lässt. In einer von Pragmatismus geprägten Situation des interkulturellen Mit- oder wenigstens Nebeneinanders steht die Bewältigung sprachlicher und kultureller Gegensätze gegenüber den religiösen meist im Vordergrund. ${ }^{198}$

Die spezifische Zuordnung von interner Homogenisierung und peripherer Polarisierung zeigt erneut die Logik kultureller Identitätsbildungsprozesse im Wechselspiel von Identifikation und Abgrenzung, das durch die Wahrnehmung und Bearbeitung der religiösen Pluralität maßgeblich bestimmt wird. ${ }^{199}$ Dabei gibt es

verschiedene Möglichkeiten, auf die Herausforderungen durch erfolgreiche Fremdreligionen zu reagieren: auf militärischer Ebene oder durch Mission, also praktisch mit Gewalt und praktisch mit der Kraft des Wortes, sowie theoretisch durch rationale Argumentation. Diese wiederum kann ad intra gerichtet sein oder tatsächlich die Andersgläubigen als Zielgruppe haben. ${ }^{200}$

Eine entscheidende Rolle bei der rationalen Auseinandersetzung des mittelalterlichen Christentums mit dem Islam spielt die Entdeckung des Gesamtwerks des Aristoteles

196 Bartlett, Die Geburt Europas, S. 374-375.

$197 \mathrm{Zu}$ denken ist dabei nicht nur an Rom als Sitz des Papsttums, sondern auch daran, dass der Erste Kreuzzug im kulturellen Zentrum des damaligen Frankreich begann und auch später immer wieder französische, burgundische, deutsche und englische Adlige die Träger der Kreuzzüge in den Orient waren, nicht etwa die herrschende Schicht ohnehin umkämpfter Randgebiete der lateinischen Christenheit.

198 Vgl. Elisabeth Erdmann: Die Kreuzzüge. In: Arbeitsbuch Religion und Geschichte. Das Christentum im interkulturellen Gedächtnis, Bd. 1. Hrsg. von Harry Noormann. Stuttgart 2009, S. 225-252, hier S. 249.

$199 \mathrm{Zu}$ überlegen wäre, ob nicht auch umgekehrt die verschiedenen Akkulturationsprozesse in den Kreuzfahrerstaaten als periphere Homogenisierung zu beschreiben wären, die als interne Pluralisierung im kulturellen Zentrum als Gefahr erscheinen muss.

200 Ebd., S. 106. 
im 13. Jahrhundert, der die christliche Theologie und Philosophie neu zur Auseinandersetzung mit der zumindest theoretischen „Möglichkeit nichtchristlicher Wahrheiten“201 und damit auch anderer Religionen zwingt. Und auch wenn man die Wahrheitsfrage als eine rein theoretische und angesichts des christlichen Universalismus von vornherein entschiedene versteht, kann man die Bearbeitung des religiösen Gegensatzes nicht ohne Weiteres auf kriegerische Gewalt oder aktive missionarische Bestrebungen verengen, sondern muss die „friedlichen und persuasiven Methoden und Theorien, die das Mittelalter entfaltet“202, berücksichtigen.

In der Auseinandersetzung mit dem Islam findet sich daher die ganze Bandbreite von Ignoranz, Polemik, Apologetik bis hin zur Vision der argumentativen Bekehrung oder gar gemeinsamen, dialogischen und rationalen Erkenntnis mit den Muslimen. Wenn man die geistig-philosophische Auseinandersetzung des Christentums mit dem 13. Jahrhundert überhaupt als Form der Kulturkontakts bestimmen will - denn tatsächlich fehlt ihr ja zumeist der Charakter eines echten Kontakts von Vertretern beider Religionen -, dann wird man hier ein Changieren zwischen Kulturbeziehungen und Kulturzusammenstoß ausmachen können: Neben polemische Abwehr tritt vermittelnde rationale Argumentation, wobei im Einzelnen zu entscheiden wäre, ob diese Formen nicht eher didaktisch-bestärkend ins Eigene zielen oder tatsächlich missionarisch-überzeugend an die Andersgläubigen gerichtet sind, also interne oder externe kulturelle Prozesse beschreiben.

Aber auch die konkreten Formen, in denen das Christentum des 13. Jahrhunderts die religiöse Pluralität beziehungsweise den Gegensatz zu den Andersgläubigen praktisch gestaltet, gehen nicht einfach in der Klassifikation von Kulturzusammenstoß und Kulturbeziehung auf: Mission ist im Hinblick auf ihr interkulturelles Potential immer ein prekäres Unterfangen, das an der Grenze von Kulturbeziehung und Kulturzusammenstoß zu verorten ist. Einerseits braucht es eine Ebene der kulturellen, auch religiösen Verständigung, wenn ernsthaft die Bekehrung der Un- beziehungsweise Andersgläubigen in den eigenen Glauben forciert werden soll. Andererseits bewegt sich Mission damit meist schon im Bereich des Kulturzusammenstoßes, denn es geht ihr letztlich um eine religiöse Hegemonie, wie friedlich und rein persuasiv diese auch immer durchgesetzt werden soll. Nicht selten schlägt daher eine anfängliche Offenheit gegenüber Missionaren in feindselige Ablehnung um, die zum Abbruch eines etablierten Kulturkontakts führt, oder endet zumindest in der Zurückweisung des religiösen Anspruchs, wie die erfolglose Predigt des heiligen Franziskus vor dem Sultan zeigt. Mission als spezifische Form des Kulturkontakts zeigt damit auf ihre Weise, wie dicht die von Bitterli beschriebenen Formen beieinander liegen, wie sie „koexistieren und vom einen zum anderen abrupt oder allmählich übergehen“203 können.

201 Leppin: Geschichte des mittelalterlichen Christentums, S. 372.

202 Sievernich, Die christliche Mission, S. 106.

203 So in konkretem Bezug auf Bitterlis Klassifikation Jürgen Osterhammel: Kulturelle Grenzen in der Expansion Europas. In: Saeculum. Jahrbuch für Universalgeschichte 46 (1995), S. 101-138, hier S. 116. 
Ebenso wenig lassen sich die Kreuzzüge auf die Form des Kulturzusammenstoßes beschränken, denn sie sind nicht nur durch einen kriegerischen Antagonismus bestimmt, sondern führen zu Kulturbeziehungen. Nicht erst in den sich etablierenden Kreuzfahrerstaaten, sondern schon während der Kreuzzüge selbst sind die Kreuzfahrer politisch und militärisch darauf angewiesen, mit den Muslimen belastbare Vereinbarungen einzugehen, zum Beispiel um Waffenstillstände auszuhandeln und Versorgungsprobleme zu lösen. ${ }^{204}$ Ein längerfristiger modus vivendi wird dann jeweils dort erforderlich, wo lateinische Christen und Muslime dauerhaft unter einer Herrschaft leben, wobei kulturelle und sprachliche Verständigung oftmals ein entscheidenderes Problem darstellen als der religiöse Pluralismus und Fremdheit auf produktive Weise bearbeitet wird. Diese komplexe kulturelle Leistung lässt sich dabei wiederum nicht mit dem Begriff der Toleranz fassen, ${ }^{205}$ zumal er die Ebenen dieser Kulturbeziehungen vermischt oder zumindest methodisch ungeklärt lässt, wie sich die religiöse Ebene zu den anderen Feldern kultureller Kontakte verhält.

Denn auch für das mittelalterliche Christentum ist durchaus anzunehmen und gerade auch im Kontext der Kreuzzüge vielfältig zu belegen, dass aus einer „Ablehnung der anderen Religion [nicht] notwendig eine Ablehnung des anderen Menschen“ resultiert und auch „exklusivistische Positionen in der Praxis sehr wohl Respekt vor dem anderen Menschen beinhalten“ können. ${ }^{206}$ Gleichzeitig dürfen solche Optionen des Umgangs mit religiöser Pluralität nicht kurzschlüssig als Teleologie einer fortschreitenden Verständigung und ,Humanisierung' verstanden werden. Mit dem Aufbau von Kulturbeziehungen geht nicht immer ein Abbau von Stereotypen einher, denn gerade hier können sie ihr identitätsstiftendes Potential entfalten. Daraus erklärt sich die nur vermeintliche Paradoxie,

204 Vgl. dazu die konkreten Beispiele bei Hehl, Die Kreuzzüge, S. 240 - 243.

205 Für die ältere Forschung vgl. Rainer Christoph Schwinges: Kreuzzugsideologie und Toleranz. Studien zu Wilhelm von Tyrus. Stuttgart 1977 (Monographien zur Geschichte des Mittelalters. 15), der in seinem Vorwort unter der Überschrift „Ersetzung von Ideologie durch Toleranz auf Grund von Bildungsprozessen“ die Humanität des im Heiligen Land geborenen und dort wirkenden Erzbischofs und Kreuzzugschronisten (um 1130-1186) herauszustellen bemüht ist. Methodisch und sachlich weiterführender ist Bernard F. Hamilton: Knowing the Enemy. Western Understanding of Islam at the Time of the Crusades. In: Ders.: Crusaders, Cathars and the holy places. Ashgate 1999 (Variorum Collected Studies Series. 656), S. 373-387.

206 Weltecke, Müssen monotheistische Religionen intolerant sein?, S. 320. Dass die Wahrnehmung des religiösen Gegensatzes zu den Muslimen nicht zwangsläufig deren Achtung als militärische Gegner ausschließt, lässt sich gerade auch anhand der Kreuzzugschronistik belegen; sie sind eben „,[g]ute Ritter [und] böse Heiden“ zugleich, vgl. Niels Brandt: Gute Ritter, böse Heiden. Das Türkenbild auf den Kreuzzügen (1095-1291). Köln/Weimar/Wien 2016. Das Bild der muslimischen ,Heiden“ in der höfischen Literatur des 13. Jahrhunderts ist entsprechend vielschichtig und reicht von polemischer Verzerrung bis hin zur Faszination für den exotischen ,Orient‘ und der kulturellen Vermittlung über religiöse Grenzen hinweg. 
dass Fremdstereotype, wie sie beispielsweise bei der Konstruktion des Heidnischen wirksam werden, durch Reduktion der Komplexität des Neuen Orientierung stiften wollen und eine kommunikative Funktion haben, [...] trotz zunehmenden Kulturkontaktes weiterleben können. ${ }^{207}$

Das gilt umso mehr und besonders „[f]ür literarische Texte als Medien gesellschaftlicher Sinngebungsprozesse, die sich von allgemeinen kulturellen Vorgaben gegebenenfalls relativ weit entfernen können“. ${ }^{208}$ Das zeigt sich gerade im legendarischen Erzählen des 13. Jahrhunderts, das in der Aushandlung des religiösen Gegensatzes zum Heidentum auf die tradierten Formen zurückgreift und diese fortschreibt.

\subsubsection{Das Verhältnis von Kreuzzug und Mission}

Kreuzzug und Mission bilden für das 13. Jahrhundert die beiden bestimmenden und damit für die Frage nach der Aushandlung des religiösen Gegensatzes zum Heidentum im legendarischen Erzählen relevanten Formen des tatsächlichen religiösen Kulturkontakts zwischen Christen und Heiden. Die moderne Sicht auf sie ist mit einigen Missverständnissen und anachronistischen Bewertungen behaftet - und vor allem umstritten. Gerade die Beurteilung der Kreuzzüge divergiert extrem, vom Zerrbild ungebremster Gewalt im Zeichen religiösen Eifers und fanatischen Eroberungswillens bis hin zur positiven Würdigung des kulturellen Austausches in den Kreuzfahrerstaaten. ${ }^{209}$

Im Rahmen dieser Arbeit interessieren dabei vor allem zwei Fragen: erstens die einer näheren Bestimmung des spezifisch religiösen Charakters der Kreuzzüge als Kriege gegen die Heiden sowie davon ausgehend zweitens das Verhältnis von Kreuzzug und Mission als verschiedene und doch miteinander korrelierende Formen der religiösen Auseinandersetzung mit den Heiden. Denn die Kreuzzüge stellen sich zwar als vielfältig motivierte und vielschichtige Expansionsbewegung dar, doch interessieren sie hier gerade in ihrem religiösen Kern und dieser liegt nicht im Streben nach der gewaltsamen Bekehrung oder kriegerischen Vernichtung der Heiden. Als politisch-militärisches Unterfangen scheitern die Kreuzzüge und stehen in einem komplexen, teilweise spannungsreichen Verhältnis zur Mission, die im 13. Jahrhundert durch die Mendikanten neu begründet wird. Hier bleibt näher zu bestimmen, welche grundlegenden Formen der Aushandlung des religiösen Gegensatzes diese beiden konkreten Formen des Kulturkontakts umfassen und inwiefern sie dabei die in den beiden vorangegangenen Kapiteln beschriebenen Diskurse von Heiligkeit und Heidentum berühren.

Zweifellos stehen die Kreuzzüge dabei in einem größeren gesellschaftlichen, wirtschaftlichen und politischen Zusammenhang. Doch neigt die Forschung heute

207 Goerlitz, Haubrichs, Einleitung, S. 7.

208 Ebd.

209 Vgl. Angenendt, Toleranz und Gewalt, S. 419-420. 
mehrheitlich dazu, die materielle Begründung nicht überzubewerten gegenüber einem Verbund vielfältiger religiöser Faktoren und Beweggründe, die den Kern der Kreuzzugsidee ausmachen: die Idee des gerechten und gar gottgewollten Krieges, die Verchristlichung des Rittertums, die im Reformpapsttum des 11. Jahrhunderts gewachsene päpstliche Autorität, die gemeinschaftlichen religiösen Aufbrüche im Zeichen der imitatio Christi, das Buß- und Ablasswesen, schließlich die Bedeutung des Heiligen Landes und besonders Jerusalems für die religiöse Identität des mittelalterlichen Christentums. ${ }^{210}$

Freilich wird man die Motivation der einzelnen Kreuzfahrer wiederum nicht allein auf die religiösen Motive und insbesondere die fromme Sorge um das eigene Seelenheil beschränken können, sondern „von einem ganzen Konglomerat an Beweggründen“, darunter höchst weltliche wie das Streben nach Macht und Besitz, ausgehen müssen, deren Einzelmotive situativ neu gewichtet wurden und verschiedene Handlungsoptionen boten. ${ }^{211}$ Doch rührt diese Frage nicht an die Kreuzzugsidee als genuin religiöses Phänomen, die Jonathan Riley-Smith, führend für die englische Kreuzzugsforschung der letzten Jahrzehnte, folgendermaßen definiert:

Ein Kreuzzug war ein heiliger Krieg, der zur Wiedererlangung christlicher Besitzrechte oder zum Schutze der Kirche oder der Christen gegen diejenigen ausgetragen wurde, die als äußere oder innere Feinde der Christenheit angesehen wurden. Er galt als Angelegenheit der Christenheit insgesamt, und daher wurde ein Kreuzzugsheer als international angesehen, selbst wenn seine Teilnehmer tatsächlich nur aus einem Landstrich kamen. Man glaubte, daß der Krieg, den ein solches Heer austrug, unmittelbar von Christus selbst durch den Papst als sein Sprachrohr gebilligt worden sei. ${ }^{212}$

Die öffentliche Ansprache Papst Urban II. im Jahr 1095 in Clermont, die als symbolträchtiger Ausgangspunkt der Kreuzzüge gilt, zielt inhaltlich auf die militärische Unterstützung der christlichen Kirchen im Osten und den bewaffneten Schutz der Pilger ins Heilige Land. Ob Urban dabei schon Jerusalem als konkretes geographisches Ziel des Kreuzzugs nennt, lässt sich aus der vielgestaltigen chronikalischen Überlie-

210 Zum Überblick dieser verschiedenen Motivationskomplexe und zur Rolle Jerusalems im kulturellen Leben der lateinischen Christenheit vgl. Nikolas Jaspert: „Wo seine Füße einst standen“ (Ubi steterunt pedes eius) - Jerusalemsehnsucht und andere Motivationen mittelalterlicher Kreuzfahrer. In: Kein Krieg ist heilig. Die Kreuzzüge. Katalog-Handbuch zur Ausstellung im Dom- und Diözesanmuseum, Mainz, 2.4.-30.7.2004. Hrsg. von Hans-Jürgen Kotzur. Mainz 2004, S. 173-185, hier S. 173-176. Zur Entstehung des Kreuzzugsgedankens und den Motivationen vgl. auch Jonathan Riley-Smith: Der Aufruf von Clermont und seine Folgen. In: ebd., S. 51-64.

211 So das Fazit von Martin Völkl, der ausführlich die Diversität der Kreuzfahrer hinsichtlich ihrer Handlungsmotive diskutiert, vgl. Völkl, Muslime - Märtyrer - Militia Christi, S. 111-146, Zitat S. 146. Fromme und materielle Motive müssen sich für den einzelnen Kreuzzugsteilnehmer freilich nicht ausschließen, wenn es sich um einen ,gottgewollten‘ Krieg handelt. Die Diversität der Motive besteht nicht nur innerhalb der Kreuzfahrerheere, sondern im Phänomen der Kreuzzüge selbst, die als religiöse Bewegungen von höchst weltlichen Faktoren bestimmt sind.

212 Riley-Smith, Art. Kreuzzüge, S. 1. 
ferung seiner Rede nicht sicher erschließen, doch wird die Heilige Stadt rasch zu einem zentralen Motiv und bleibt spätestens mit der Eroberung Jerusalems 1099 als Erfolg des Ersten Kreuzzugs fest mit der Kreuzzugsidee verbunden. ${ }^{213}$

Der religiöse Charakter dieser und der folgenden militärischen Unternehmung findet seinen zeichenhaften Ausdruck in den Kreuzen, die sich die Ritter an ihre Kleidung nähen. Entscheidend für den spezifischen religiösen Charakter der Kreuzzüge als ,heilige Kriege‘ ist dabei die Übernahme von Begriffen und Vorstellungen aus dem Wallfahrtswesen: Zumindest einige der Teilnehmer legen entsprechende Gelübde ab und genießen dieselben Privilegien wie Pilger, außerdem werden ihnen entsprechende Ablässe zugesagt. ${ }^{214}$ Zwischen Kreuzzug und Pilgerfahrt bestehen neben den rechtlichen auch terminologische Ähnlichkeiten: Der Begriff des Kreuzzugs selbst (cruciata) kommt erst später auf, im 13. Jahrhundert finden sich in diesem Zusammenhang Begriffe wie peregrini, expeditio oder peregrinatio. ${ }^{215}$ Der eigentliche Kern der Kreuzzugsidee ist also nicht der Kampf gegen die Muslime oder andere Andersgläubige, sondern die Idee einer „bewaffnete[n] Wallfahrt“216, die ihren Teilnehmern einen persönlichen religiösen Nutzen verspricht. Denn die Kreuzzüge erscheinen als Möglichkeit zur Buße, die bei Urban ursprünglich wohl nur den Ablass der irdischen Bußstrafen umfasst und auch diesen nur unter der Bedingung, dass man sich sola devotione auf den Weg nach Jerusalem mache, was noch einer sehr klaren und eng gefassten Bußtheologie folgt.

Doch schon bald setzt sich im allgemeinen Verständnis die Auffassung durch, der Papst habe nicht nur den vollständigen Erlass irdischer, sondern auch den der Sündenstrafen im Jenseits und sogar die Tilgung aller Sünden (remissio peccatorum) zugesagt, also denjenigen, die während der Kreuzzuges sterben, den unmittelbaren

213 Vgl. Jaspert, Jerusalemsehnsucht und andere Motivationen mittelalterlicher Kreuzfahrer, besonders S. 176-182. Der genaue Wortlaut der Rede, die, so zumindest die Inszenierungen der chronikalischen Überlieferung, eine mitreißende Wirkung gehabt und zur spontanen Kreuznahme vieler anwesender Ritter geführt haben soll, ist nicht tradiert, Darstellungen ihres Inhalts finden sich in verschiedenen zeitgenössischen Chroniken. Jerusalem als Ziel wird vor allem in der Historia Iherosolimitana Roberts von Reims, die bis in die Frühe Neuzeit zu den populärsten Darstellungen des Ersten Kreuzzugs gehörte, benannt $(1,1)$, allerdings auch nur unspezifisch im Kontext der Bedrohung der Christen im Orient durch die Muslime: Ab Hierosolymorum finibus et urbe Constantinopolitana relatio gravis emersit, et sæpissime jam ad aures nostras pervenit quod videlicet gens regni Persarum, gens maledicta, extranea gens porsus a Deo aliena [...] terras illorum Christianorum invaserit ferro, rapina, incendio depopulaverit. Zitiert nach: Patrologiae cursus completus. Series latina; Bd. 155. Hrsg. von Jacques-Paul Migne. Paris 1844, Sp. 669-758, hier Sp. 671. „Von den Grenzen Jerusalems und der Stadt Konstantinopel ist eine schreckliche Geschichte $\mathrm{zu}$ und gedrungen und uns sehr häufig zu Ohren gebracht worden, nämlich dass ein Volk aus dem Königreich der Perser, ein verfluchtes Volk, ein Volk, das Gott völlig entfremdet ist [...] in die Länder dieser Christen eingedrungen und sie durch Schwert, Plünderung und Feuer entvölkert hat.“ (Übersetzung F. P.)

214 Vgl. Riley-Smith, Art. Kreuzzüge, S. 1.

215 Vgl. Jaspert, Die Kreuzzüge, S. 21.

216 Hans Eberhard Mayer: Geschichte der Kreuzzüge. 10., überarbeitete und erweiterte Aufl. Stuttgart 2005, S. 25. 
Einzug ins Paradies versprochen. ${ }^{217}$ Obwohl diese Vorstellung der kirchlichen Bußordnung offenkundig widerspricht, wird sie in den folgenden Kreuzzugspredigten durch Dritte verbreitet und popularisiert. Auf fruchtbaren Boden fällt sie wohl auch deshalb, weil es sich letztlich um keinen neuen Gedanken handelt: Der Gedanke, dass diejenigen, die in der Verteidigung der Kirche gegen Heiden fallen, mit himmlischem Lohn rechnen dürfen, findet sich schon im frühen Mittelalter und auch davor, ${ }^{218}$ er wird im Kontext der Kreuzzugsidee nur neu aufgegriffen und mit der zeitgenössischen Frömmigkeitspraxis verbunden. Heilbringend ist aber auch dabei gerade nicht der Heidenkampf als solcher, schon gar nicht das Töten der Heiden, sondern der Wallfahrtscharakter der Kreuzzüge, den die Kreuzzugspredigten denn auch immer wieder betonen. ${ }^{219}$

Dementsprechend sind die Kreuzzüge nicht nur als kriegerische Expansionsbewegung nach außen $\mathrm{zu}$ verstehen, sondern gerade auch als eine Bewegung nach innen, die im Zeichen laikaler Frömmigkeit auf die Vergewisserung des persönlichen wie kollektiven Heils zielt, also weniger das religiöse Fremde bekämpft als das Eigene finden und verteidigen will. ${ }^{220}$ Das gilt selbst und gerade im Hinblick auf die ,Befreiung' und ,Rückeroberung“ Jerusalems, die als Wiedergewinnung der verlorenen heiligen Stätten der Christenheit verstanden wird. Für die religiöse Weltdeutung der mittelalterliche Bedeutungstopografie sind diese Stätten von zentraler Bedeutung, weil sich an ihnen das Heilsgeschehen in Christus vollzogen hat; es sind die Orte, ubi steterunt pedes eius, wie es mit Ps 131(132), 7 heißt. ${ }^{221}$ Aus dieser Sicht erscheinen die Kreuzzüge auch nicht als illegitime Angriffskriege, sondern haben - zumindest in ihrer eigenen Rechtfertigung - zunächst einmal defensiven Charakter. Sie richten sich nicht gegen die Heiden selbst, sondern nur insofern diese Besitz und Rechte der Christenheit bedrohen oder sich bereits widerrechtlich angeeignet haben. ${ }^{222}$ Die Kreuzzugspredigten entwerfen daher kein konsistentes Feindbild, auch wegen ihrer Konzentration auf den geistlichen Gewinn der als Wallfahrt verstandenen kriegeri-

217 Vgl. Jaspert, Die Kreuzzüge, S. 29-30.

218 Vgl. Carl Erdmann: Die Entstehung des Kreuzzugsgedankens. Unveränderter Nachdruck des 1935 als sechster Band der Forschungen zur Kirchen- und Geistesgeschichte erschienenen Werkes. Stuttgart 1955, S. 22-24.

219 Vgl. die umfangreiche Darstellung bei Valmar Cramer: Kreuzpredigt und Kreuzzugsgedanke von Bernhard von Clairvaux bis Humbert von Romans. In: Das Heilige Land in Vergangenheit und Gegenwart, Bd. 1. Köln 1939 (Palästina-Hefte des Deutschen Vereins vom Heiligen Lande. 17/20), S. 43 204.

220 ,[T] he First Crusade, and to some extent all the expeditions up to 1291, were essential Euro-centric ventures. That is to say, they were characterized far less by their opposition to Islam as a religion than by their expression of trends whose roots lay deep within Catholic society." Norman Housley: The crusades and Islam. In: Medieval encounters 13, 2 (2007), S. 189-208, hier S. 195.

221 Vgl. dazu besonders Jaspert, Jerusalemsehnsucht und andere Motivationen mittelalterlicher Kreuzfahrer.

222 Vgl. Jonathan Riley-Smith: Wozu heilige Kriege? Anlässe und Motive der Kreuzzüge. Berlin 2005, S. 29. 
schen Aufbrüche. ${ }^{223}$ Wenn die Kreuzzüge darüber hinaus als Kriege gegen die Heiden dargestellt werden, dann als Verteidigung des Heiligen Landes und der gesamten Christenheit gegen die einfallenden Sarazenen, die dann allerdings als Kampf gegen das Böse in eine heilsgeschichtlichen Rahmen eingeordnet werden kann. ${ }^{224}$

Doch ist damit noch nicht die Frage beantwortet, inwiefern die Kreuzzüge eine aus christlich-mittelalterlicher Sicht legitime oder gar gebotene Form der Aushandlung des religiösen Gegensatzes zu den Heiden darstellen, als Glaubenskriege im Sinne des ,Tötens für Gott‘, wie Assmann es beschreibt. Ob sie mit Blick auf ihre spezifische Verbindung von kriegerischem Gewalthandeln mit religiöser Motivation und Legitimation als ,heilig' gelten zu haben und mit ,Heiligen Kriegen“ in anderen Religionen zu vergleichen sind, ist in der Forschung durchaus umstritten. Das liegt einerseits daran, dass es an einer verbindlichen Definition dieses Begriffs fehlt, andererseits am prekären Zusammenhang von Krieg und Heiligkeit für das Christentum. ${ }^{225}$ Das zeigt sich auch in der Kreuzzugsidee selbst, wenn sie zuvorderst auf der Wallfahrt beruht, „deren sündentilgend-verdienstliche Wirkung schon seit Jahrhunderten selbstverständlich war“ und nun neu akzentuiert wird, ohne dass das Problem, „ob nämlich militärische Gewalt zugunsten geistlicher Unternehmungen überhaupt erlaubt sei“, eindeutig und abschließend geklärt worden wäre. ${ }^{226}$

Zwar lässt sich herausarbeiten, dass die zeitgenössische Bezeichnung bellum sacrum für die Kreuzzüge nicht einen geheiligten Krieg im Sinne von sanctum oder beatum bellum meint, sondern - so die entscheidende begriffliche Differenz - einen seine Teilnehmer heiligenden Krieg, und dass man sich auch im Mittelalter bewusst gewesen sei, „,[d]aß Krieg an sich, selbst wenn er um des Glaubens willen geführt wird, nie ,heilig‘ ist“. ${ }^{227}$ Oder pointiert gewendet: „Nicht der Krieg an sich wurde als heilig

223 Vgl. Hehl, Die Kreuzzüge, S. 239.

224 So zum Beispiel im um 1266 verfassten De praedicatione s. crucis contra Saracenos des Dominikaners Humbert von Romans, wobei es sich aber eben nicht um eine aktuelle Kreuzzugspredigt handelt, sondern um einen umfangreicheren und elaborierteren Traktat, der den Kreuzzug unter universellen Gesichtspunkten behandelt. Vgl. Cramer, Kreuzpredigt und Kreuzzugsgedanke, S. 184.

225 Die Engführung der Kreuzzüge auf „eine der Formen sakraler Gewalt des Christentums“, die die „Lizenz zum Töten“ einschließe, aus kirchlicher Sicht sogar „unbedingt geboten“ erscheinen lasse, so Martin Treml: Kreuzzug und heiliger Krieg - sakrale Gewalt im Christentum. In: Märtyrer-Porträts. Von Opfertod, Blutzeugen und heiligen Kriegern. Hrsg. von Sigrid Weigel. München 2007, S. 89-94, hier S. 89, ist bestenfalls einseitig, wenn nicht gar - im Blick auf die aktuellen Implikationen der Thematik gefährlich unterkomplex.

226 Angenendt, Toleranz und Gewalt, S. 421.

227 Rudolf Hiestand: „Gott will es!“ Will Gott es wirklich? Die Kreuzzugsidee in der Kritik ihrer Zeit. Stuttgart 1998 (Beiträge zur Friedensethik. 29), S. 5. Zur zeitgenössischen Begrifflichkeit anders ErnstDieter Hehl, der feststellt, dass auch die Bezeichnung bellum sacrum nur ein Forschungsbegriff sei und der Begriff des ,heiligen“ Krieges im Mittelalter selbst keine Rolle gespielt habe; er finde sich nur in den modernen lateinischen Kopfregesten in der Patrologia Latina. Vgl. Ernst-Dieter Hehl: Heiliger Krieg eine Schimäre? Überlegungen zur Kanonistik und Politik des 12. und 13. Jahrhunderts. In: Krieg und Christentum. Religiöse Gewalttheorien in der Kriegserfahrung des Westens. Hrsg. von Andreas Holzem. Paderborn 2009 (Krieg in der Geschichte. 50), S. 323-340, hier S. 324. 
angesehen, sondern er wirkte heilbringend auf den Menschen“. ${ }^{228}$ Doch bleibt dabei das Problem, das kriegerisches Gewalthandeln in Bezug auf Heiligkeit oder zumindest legitimes christliches Handeln auch im mittelalterlichen Kontext darstellte, eigentümlich unaufgelöst. Denn als heilbringend erscheint nun die Teilnahme an einem Unternehmen, das als solches kein heiliges ist. Insofern bleiben die Kreuzzugspredigten der Mendikanten ein Spagat, wenn sie in päpstlichem Auftrag zum Kampf aufrufen und „die kanonistischen Bedenken durch Berufung auf die alttestamentlichen Makkabäer“229 ausräumen. Darin zeigt sich aber zugleich, dass im Zusammenhang mit den Kreuzzügen eben nicht an die althergebrachten und ungebrochen gültigen Heiligkeitsmodelle angeknüpft werden kann, worauf ich im Verlauf meiner Arbeit zurückkommen werde. ${ }^{230}$

Mit der Frage nach der Heiligkeit der Kreuzzüge ist aber noch nicht die nach deren Charakter als Glaubenskriege berührt, denn ein solcher muss nicht zwangsläufig als heilig verstanden werden, sondern besteht zunächst einmal in einer spezifischen Verbindung von Religion und Krieg. Allerdings lässt sich die Problematik, was ein ,religiöser' oder eben gar ,heiliger Krieg ' ist, wiederum nicht allein an der religiösen Motivation seiner Teilnehmer festmachen, auch nicht an seiner offiziellen kirchlichen Sanktionierung und Legitimierung. Denn diese beiden Momente, die fraglos auch die Kreuzzüge bestimmen, gelten letztlich genauso hinsichtlich der für das Mittelalter maßgeblichen theologischen Bestimmung der Kriterien für einen ,gerechten' Krieg, der selbst aber ein säkularer bleibt. ${ }^{231}$ Überdies weisen die Kreuzzüge zunächst einmal eher nach innen, als Teil einer religiösen Selbstvergewisserung, denn nach außen in der Bekämpfung der Andersgläubigen.

Letztere aber wäre das entscheidende Kriterium für die Bestimmung eines Glaubenskrieges im engeren Sinne, wie Arnold Angenendt sie im Blick auf das Problem von Religion und Krieg im mittelalterlichen Christentum vorschlägt: „Eindeutig religiös wird ein Krieg erst, wenn die Waffen direkt für Gott erhoben werden, etwa gegen Menschen, die einer fremden Religion angehören oder von der rechten Religion abgefallen sind.“232 Der andersgläubige Gegner soll dabei entweder getötet oder zur Konversion gezwungen, in jedem Fall der hegemoniale Anspruch des eigenen Glaubens durchgesetzt werden. Ebendiese Engführung auf Vernichtung oder Mission der Heiden aber bleibt für die Kreuzzüge fraglich; zum einen, weil wie gesagt ihr religiöser Kern in eine andere Richtung weist, zum anderen, weil dort, wo diese beiden Optionen eines Glaubenskrieges im Laufe der verschiedenen Kreuzzüge relevant werden, sie durchaus unterschiedlich realisiert und theologisch höchst differenziert verhandelt werden. Denn die Kreuzzugsidee wird eben nicht in den Kategorien eines ,heiligen Krieges gedacht, wie auch immer diese zu bestimmen wären, sondern entsprechend

228 Jaspert, Die Kreuzzüge, S. 14.

229 Angenendt, Toleranz und Gewalt, S. 428.

230 Vgl. unten in Kap. 4.2 militia Christi - Zwischen Dulden und Streiten für Gott.

231 Vgl. Angenendt, Toleranz und Gewalt, S. 375.

232 Vgl. ebd. 
der augustinische Lehre vom ,gerechten Krieg‘, die für das Mittelalter maßgeblich bleibt und sogar neu betont wird.

Die Kriterien, die sich bei Augustinus an verschiedenen Stellen finden und noch nicht systematisch formuliert sind, werden in der Scholastik zusammengefasst und ergänzt: Zur causa iusta, dem gerechten Kriegsgrund, der intentio recta, womit der Wille zum Frieden gemeint ist, und der legitima auctoritas, der Kriegserklärung durch eine legitime Obrigkeit, kommt der debitus modus, also die Verhältnismäßigkeit der Kriegsführung. ${ }^{233}$ In diesen Kriterien zeigt sich der Doppelcharakter der Lehre vom gerechten Krieg, die eigentlich begrenzend gedacht ist und der Wahrung oder Wiederherstellung von Frieden und Recht dienen soll. So richten sich die Überlegungen bei Augustinus gegen Glaubensfeinde im Inneren, wobei der Krieg gegen sie gar als Akt der Nächstenliebe erscheint. ${ }^{234}$ Damit erweist sich aber auch, wie interpretationsbedürftig die einzelnen Kriterien, gerade hinsichtlich des ,gerechten` Kriegsgrunds, bleiben und wie sehr sie offen bleiben für ganz verschiedene Legitimationszwecke. $^{235}$

In der zweiten Hälfte des 13. Jahrhunderts, etwa zeitgleich mit dem Entstehen der Legenda aurea greift Thomas von Aquin die Lehre vom gerechten Krieg in seiner Summa theologica auf und verbindet sie mit dem bereits zitierten Diskurs über das Heidentum und die Arten des Unglaubens entsprechend der Erkenntnisfähigkeit. ${ }^{236} \mathrm{Er}$ betont, dass Kriege gegen die Heiden nicht deshalb geführt werden dürften, weil diese keine Christen sind, sondern allein zum Schutz der Christenheit:

Respondeo dicendum quod infidelium quidam sunt qui nunquam susceperunt fidem, sicut gentiles et Iudaei. Et tales nullo modo sunt ad fidem compellendi, ut ipsi credant, quia credere voluntatis est. Sunt tamen compellendi a fidelibus, si facultas adsit, ut fidem non impediant vel blasphemiis, vel malis persuasionibus, vel etiam apertis persecutionibus. Et propter hoc fideles Christi frequenter contra infideles bellum movent, non quidem ut eos ad credendum cogant (quia si etiam eos vicissent et captivos haberent, in eorum libertate relinquerent an credere vellent), sed propter hoc ut eos compellant ne fidem Christi impediant. (Summa theologica II-II, 10, 8)

Von den Ungläubigen haben einige niemals den Glauben angenommen, wie die Heiden und die Juden. Solche sind denn auf keine Weise zum Glauben zu nötigen, damit sie aus sich glauben; denn Glauben ist Sache des Willens. Doch müssen sie von den Gläubigen, wenn die Möglichkeit besteht, genötigt werden, dem Glauben nichts in den Weg zu legen, sei es durch Lästerungen oder durch bösartiges Zureden oder gar durch offene Verfolgungen. Und aus diesem Grunde führen die Christgläubigen häufig Krieg gegen die Ungläubigen, nicht um sie zum Glauben zu zwingen, denn wenn sie sie auch besiegten und gefangen hielten, würden sie es doch ihrer Freiheit überlassen, ob sie glauben wollen; sondern nur deshalb, um sie zu nötigen, den Glauben an Christus nicht zu hindern.

233 Vgl. Hans-Richard Reuter: Art. Krieg VI. Christentum. In: ${ }^{4}$ GGG (2001), Sp. 1770-1772, hier Sp. 1770.

234 Vgl. Jaspert, Die Kreuzzüge, S. 13.

235 Vgl. Reuter, Art. Krieg, Sp. 1770.

236 Vgl. oben in Kap. 2.2.1 Heidentum als dynamischer Gegenbegriff, S. 44-45. 
Trotz der unumstößlich und eindeutig scheinenden Maxime des credere voluntatis est bietet diese Argumentation einen Spielraum, Zwang in der Mission, zumindest in gewissem Maße, zu legitimieren. Vorbild dabei ist wiederum Augustinus, der mit Bezug auf das Gleichnis vom großen Abendmahl und die Formulierung compelle intrare in Lk 14, 23 den Einsatz von Gewaltmitteln gerechtfertigt hatte, um die Häretiker zur Rückkehr in den Schoß der Kirche zu bewegen. ${ }^{237}$ Die Grenze von der Nötigung zu offenem Zwang ist dabei freilich fragil, zumal dann, wenn das positive Ziel, nämlich die Einheit der Kirche in Christus, Gewalt zu rechtfertigen scheint. Der Gedanke des „Nötige sie hereinzukommen“ findet sich jedenfalls, im Kontrast zu seinem ursprünglichen Kontext bei Augustinus, im Laufe der Kirchengeschichte immer wieder auch in Bezug auf die Heiden.

Die Überlegungen bei Augustinus wie bei Thomas von Aquin, die breiten Niederschlag in der Scholastik und Kanonistik fanden, bieten also „Ansätze sowohl für eine tolerante Haltung wie auch für die Rechtfertigung von Glaubenskriegen“. ${ }^{238}$ Von daher erhellt sich auch die Doppeldeutigkeit des mittelalterlichen Toleranzkonzeptes, das nach zwei Seiten ausschlagen kann: „zur Begründung [...] für das Abschlachten des Andersgläubigen“ oder „um die Bewahrung von dessen Existenz zu rechtfertigen“. ${ }^{239}$ Im Kontext der Kreuzzüge wird daher, so widersprüchlich es aus moderner Sicht auch scheinen mag, die Idee des gerechten Krieges zur Verteidigung ebenso wiederbelebt wie das Verbot des Heidenkrieges. ${ }^{240}$ Inwieweit ein Glaubenskrieg zur Bekämpfung des Heidentums und zur Durchsetzung des christlichen Glaubens erlaubt erscheint, ist dabei oft nur eine Frage der Akzentuierung.

So kann zum Beispiel die Sündhaftigkeit der Heiden als gerechter Kriegsgrund gelten, wie im Mitte des 13. Jahrhunderts verfassten Dekretalenkommentar Innozenz IV., der zwar feststellt, dass die Heiden nicht wegen ihres Unglaubens (infidelitas) ihrer Freiheit und ihres Besitzes beraubt werden dürften, gleichzeitig aber betont, dass der Papst als vicarius Iesu Christi Gewalt über Gläubige wie Ungläubige habe und daher einen Heiden bestrafen dürfe, wenn er gegen das Naturgesetz verstoße oder Götzenbilder (idola) verehre: Papa super omnes habet iurisdictionem et potestatem de iure, licet non de facto, unde per hanc potestatem, quam habet Papa, credo quod si gentilis, qui non habet legem, nisi naturae, si contra legem naturae facit, potest, licite

237 Diesen Bibelvers zitiert Thomas kurz vor der oben zitierten Antwort auf die Frage: Utrum inifideles compellendi sint ad fidem, und legt ihn anschließend mit Augustinus aus. Summa theologica II-II, 10, 8. Vgl. dazu Hans Maier: Compelle intrare. Rechtfertigungsgründe für die Anwendung von Gewalt zum Schutz und zur Ausbreitung des Glaubens in der Theologie des abendländischen Christentums. In: Heilige Kriege. Religiöse Begründungen militärischer Gewaltanwendung. Judentum, Christentum und Islam im Vergleich. Hrsg. von Klaus Schreiner, Elisabeth Müller-Luckner. München 2008 (Schriften des Historischen Kollegs. Kolloquien. 78), S. 55-70, hier besonders S. 58-59.

238 Becker, Die Stellung des kanonischen Rechts zu den Andersgläubigen, S. 103.

239 Patschovsky, Tolerant im Mittelalter, S. 396.

240 Vgl. Angenendt, Toleranz und Gewalt, S. 404. 
puniri per Papam. ${ }^{241}$ Wohl sei es dabei nicht erlaubt, die Ungläubigen zur Annahme des Glaubens zu zwingen, weil auch ihnen der freie Wille zuzugestehen sei, doch dürfe der Papst ihnen befehlen, quod admittant praedicatores Evangelii in terris suae iurisdictiones. ${ }^{242}$ Sollten sie sich weigern, müssten sie für diese Sünde bestraft werden. ${ }^{243}$

Auch wenn auf die Freiwilligkeit der Bekehrung in allen vergleichbaren Überlegungen größter Wert gelegt wird, ist damit also nicht die Nötigung, selbst durch Waffengewalt, ausgeschlossen. Darin zeigt sich die Ambivalenz des mittelalterlichen theologischen Denkens in Bezug auf die Legitimation von Gewalt überhaupt: Einerseits hatte Gewaltanwendung für die gerechte Sache darin ihren festen Platz, während anderseits „die Gegenposition, die die Verpflichtung zum Gewaltverzicht betonte, immer präsent blieb und vielfach wortmächtigen Ausdruck fand““.244 Die Anwendung von Gewalt gegen Andersgläubige wird dabei vor allem hinsichtlich der Möglichkeit von Bekehrung problematisiert, also im Hinblick darauf, inwiefern sie geeignet ist, den heidnischen Unglauben $\mathrm{zu}$ bekämpfen und dem christlichen Glauben zur Durchsetzung zu verhelfen. Keinesfalls aber wird Gewalt in diesem Zusammenhang sakralisiert, als sei das Töten der Heiden, die physische Vernichtung der Ungläubigen, als ein ,Töten für Gott‘ göttlich legitimiert und ein Weg zur Heiligung des Gläubigen.

Die im Kontext der Kreuzzüge ausgeübte Gewalt gegen Andersgläubige entspricht dabei durchaus dem Maß, das auch in anderen Kriegen dieser Zeit geübt wurde. Denn der Antrieb für die Kreuzzüge ist nicht der Hass gegen Andersgläubige, sondern dieser und die darauf zurückzuführende Brutalität der Kreuzfahrer beispielsweise bei der Eroberung Jerusalems 1099 sind eher ein Nebeneffekt der glühenden Verehrung für die heiligen Stätten. ${ }^{245}$ Wenn in der Kreuzzugspropaganda und Chronistik die Vernichtung der Heiden dennoch als zentrales Motiv erscheint, dann folgen diese in der Reduktion des religiösen Gegensatzes auf eine binäre Logik von Selbst- und Feindbild und der Dämonisierung des Gegners religionsgeschichtlich älteren Vorstellungen von der Reinigung entweihter Stätten durch das Blut der Ungläubigen, wie sie für das

241 Innozenz IV: In libro III Decretalium, titulus 34 De voto et voti redemptione, Caput 8 Quod super. Zitiert nach: Commentaria Innocentii Quarti Pont. Maximi super libros quinque decretalium. Francofurti ad Moenum 1570, f. 430r. „Der Papst hat die Gerichtsbarkeit und Macht über alle, laut Gesetz, nicht in der Praxis, und durch diese Macht glaube ich, dass ein Heide, der kein Gesetz hat außer das der Natur, wenn er gegen das Gesetz der Natur handelt, vom Papst bestraft werden kann.“ (Übersetzung F. P.)

242 Ebd., f. 430v. „[D]ass sie Predigern des Evangeliums Zugang in die Länder unter ihrer Herrschaft gewähren.“ (Übersetzung F. P.)

243 Vgl. dazu Sievernich, Die christliche Mission, S. 225.

244 So formuliert in Bezug auf das 11. und 12. Jahrhundert Gerd Althoff: „Selig sind, die Verfolgung ausüben.“ Päpste und Gewalt im Hochmittelalter. Darmstadt 2013, S. 188.

245 Vgl. Housley, Contesting the Crusades, S. 88. Ganz abgesehen davon, dass die jüngere Forschung die exorbitant hohen Opferzahlen bei der Erstürmung Jerusalems, von denen sowohl die muslimischen als auch die christlichen mittelalterlichen Quellen berichten, widerlegt hat. Auf beiden Seiten scheint die Brutalität der Kreuzfahrer Gegenstand propagandistischer Ausschmückung gewesen zu sein. Vgl. auch Thomas Scott Asbridge: Die Kreuzzüge. 7. Aufl. Stuttgart 2016, S. 117. 
Christentum eigentlich nicht mehr relevant, sondern anachronistisch sind und im Gegensatz zur theologischen und juristischen Diskussion stehen. ${ }^{246}$

Die Bestimmung der Kreuzzüge als Glaubenskriege bleibt daher ein zwiespältiges Unterfangen. In seiner forschungsgeschichtlich epochalen Arbeit zur „Entstehung des Kreuzzugsgedankens“ unterstreicht Carl Erdmann „die durchgängig defensive Formulierung des Kriegsziels“ in den Äußerungen Urbans II., der damit „korrekt im Rahmen der hergebrachten Doktrin“ geblieben sei:

Die christlichen Brüder oder die Kirchen sollten von der Tyrannei und Bedrückung durch die Heiden befreit werden, so hieß es bei ihm immer wieder. Darin liegt [...] nichts anderes als die Idee einer gemeinsamen Front des Christentums gegen die Heiden. Aber dieser Gedanke hat Urban nicht dazu verleitet, die Bekämpfung der Heiden zum Selbstzweck zu machen. ${ }^{247}$

Der Glaubenskrieg ist bei ihm weder Bestandteil, noch gar Voraussetzung des Kreuzzugsgedankens, ${ }^{248}$ und dieser Grundlegung folgen auch spätere Theoretiker: „Kein Theologe und kein Kirchenrechtler hat jemals explizit den Gedanken geäußert, letztes Ziel der Kreuzzüge sei die Bekehrung der Ungläubigen - notfalls mit dem legitimen Recht, die ,Ungläubigen“ zu töten.“" ${ }^{249}$ Unbestreitbar bleibt demgegenüber aber auch, dass populäre Vorstellungen über die kirchliche Lehre hinausgehen, ja sogar im Widerspruch zu ihr stehen. Riley-Smith ergänzt dann auch seine auf das Wallfahrtswesen konzentrierte Bestimmung des Kreuzzugsgedankens um die Feststellung,

daß die volkstümliche Überzeugung, daß Kreuzzüge Werkzeuge für die Verbreitung des christlichen Glaubens seien, zu stark war, als daß sie hätte ignoriert werden können, und das Verständnis des Kreuzzuges als eines Bekehrungskrieges war während der meisten Zeit als Unterströmung vorhanden. ${ }^{250}$

Auch wenn die Haltung der Kanonisten und Theologen in dieser Hinsicht ablehnend bleibt, kann also eine weniger reflektierte Verhandlung der Diskurse von Heiligkeit und Heidentum und der religiöse Eifer der Laien den Kreuzzug wohl zum ,heiligen Krieg‘ oder zumindest Glaubenskrieg machen, wobei das nicht im Widerspruch zu dessen ursprünglichem Wallfahrtscharakter stehen muss. Eine differenzierte Be-

246 Vgl. Hehl, Heiliger Krieg - eine Schimäre?, S. 335 - 336. Im Gegensatz zu Hehl, der diese Potentiale zur Heiligung des Krieges nur beim Ersten Kreuzzug erläutert, unterstreicht Arnold Angenendt, dass neben der Begründung der Rückeroberung das Motiv der sühnenden Reinigung immer wesentlich gewesen sei, gerade in kirchlich-offiziellen Aufrufen. Vgl. Arnold Angenendt: Die Kreuzzüge. Aufruf zum ,gerechten“ oder zum ,heiligen“ Krieg? In: Krieg und Christentum. Religiöse Gewalttheorien in der Kriegserfahrung des Westens. Hrsg. von Andreas Holzem. Paderborn 2009 (Krieg in der Geschichte. 50), S. 341-367, hier besonders S. 361.

247 Erdmann, Die Entstehung des Kreuzzugsgedankens, S. 321.

248 Vgl. ebd., S. 322.

249 Franco Cardini: Europa und der Islam. Geschichte eines Mißverständnisses. München 2004, S. 96. 250 Riley-Smith, Art. Kreuzzüge, S. 8. 
stimmung des religiösen Charakters der Kreuzzüge als Kriege gegen die Heiden sowie ihr Verhältnis zur Mission ist also nur möglich, wenn man die verschiedenen Ebenen und Kontexte beachtet: Der theologische Diskurs entwirft ein anderes Bild als es die Kreuzzugspredigten bieten, wovon sich ihrerseits die landläufige, laikale Bewertung unterscheiden kann, und selbst innerhalb dieser Gruppen gibt es verschiedene Stimmen. Dazu kommt die zeitliche Entwicklung der mit den Kreuzzügen verbundenen Motive und Vorstellungen. ${ }^{251}$

Angesichts dieser Heterogenität scheint es ratsam, eher von einem Kreuzzugsdiskurs statt von ,der ${ }^{6}$ Kreuzzugsidee zu sprechen, ${ }^{252}$ oder zumindest letztere als weniger statisch und monolithisch wahrzunehmen als gemeinhin üblich. Und das nicht nur hinsichtlich der Heiligkeit des Krieges beziehungsweise der heilbringenden Wirkung des Heidenkampfes für die Kreuzzugsteilnehmer, sondern genauso und insbesondere für den Missionsgedanken. Zwar waren wie gesagt zunächst die Abwehr der islamischen Expansion und die Befreiung der heiligen Stätten, nicht aber die Bekehrung der Gegner das bestimmende Motiv für die Kreuzzüge in den Orient. Doch führen Konversionen, die in ihrem Umfeld stattfinden, dazu, dass sich beide Motive überlagern und ab der Mitte des 12. Jahrhunderts in der Sicht vieler christlicher Zeitgenossen die Bekehrung der Muslime schließlich zum Hauptziel der Kreuzzüge werden kann. ${ }^{253}$

Allerdings führt die Verknüpfung von Kreuzzug und Mission wiederum nicht zu einer konsistenten und unwidersprochen bleibenden Vorstellung eines Bekehrungskrieges unter der Alternative ,Taufe oder Tod'. Eine solche mag zwar im kollektiven Gedächtnis des mittelalterlichen Christentums verankert gewesen sein, ausgehend von der frühmittelalterlichen Missionspraxis, bei der kriegerische Expansion und Verbreitung des christlichen Glaubens eng miteinander verknüpft waren. ${ }^{254}$ Zur Zeit der Kreuzzüge wird diese Zuspitzung vor allem im heldenepischen Erzählen literarisch bearbeitet, doch findet sie sich im theologischen Diskurs selten und dann bezeichnenderweise im Hinblick auf andere Schlachtfelder als das Heilige Land: Wenn im Jahr 1147 Bernhard von Clairvaux, als einer der führenden Kleriker seines Jahrhunderts, und im selben Jahr auch Papst Eugen III. zu einem Kreuzzug aufrufen, um die heidnischen Gegner zu vernichten oder eben zu konvertieren, dann gilt das nicht den Muslimen im Orient, sondern den Wenden im Nordosten. ${ }^{255} \mathrm{Im}$,volkstümlichen“

251 Für den Ersten Kreuzzug beschreibt Norman Housley insgesamt vier Etappen: die Kreuzzugspredigt, die Reaktion der Laien, der Beitrag der Kreuzfahrer selbst und die spätere Bearbeitung der monastischen Chronisten. Als fünfter Schritt wären dem wohl noch die Überlegungen in Theologie und kanonischem Recht hinzuzufügen. Vgl. Housley, Contesting the Crusades, S. 47.

252 Vgl. Skottki, Christen, Muslime und der Erste Kreuzzug, S. 489.

253 Vgl. Benjamin Zeev Kedar: Crusade and Mission. European Approaches toward the Muslims. Princeton 1984, S. 67.

254 Als Beispiel mögen die Sachsenkriege Karls der Großen dienen, wobei dessen Vorgehen, die Unterworfenen zur Taufe zu zwingen, schon bei einigen seiner Zeitgenossen Kritik hervorrief.

255 Vgl. Kedar, Crusade and Mission, S. 70 - 71. 
Verständnis mögen sich solche Differenzierungen verwischen, aber ein Konzept gewaltsamer Mission findet sich weder in theologischen Reflexionen noch im kanonischen Recht ausgearbeitet.

Missionskriege sind für das Christentum trotz gegenteiliger Beispiele immer problematisch geblieben, weil sie der für eine wahre Konversion nötigen Freiheit entgegenstehen. Die eigentliche Schwierigkeit eines Glaubenskrieges gegen die Heiden liegt dabei nicht etwa in einem grundlegenden Gewaltverzicht aus dem Liebesgebot heraus - letztlich fehlt auch in den Evangelien eine ausdrückliche Ablehnung des Krieges -, sondern darin, dass die kriegerische Gewalt dabei schnell in einen Widerspruch zum universalen missionarischen Anspruch gerät. Daher erfolgt die Verknüpfung der Kreuzzugsidee mit dem ihr eigentlich zunächst fremden Missionsgedanken im theologischen Diskurs erst im Nachhinein beziehungsweise im Verlauf der Kreuzzüge, aber nicht als gelungenes Ideal, sondern im Gegenteil im Zeichen kritischer Infragestellung: Die Kreuzzüge werden zunehmend mit der Mission parallelisiert und daran gemessen, inwieweit sie die Bekehrung der Ungläubigen fördern oder nicht. ${ }^{256}$

Das ist eine durchaus neue Perspektive, die jedoch die grundsätzliche Legitimität der Kreuzzüge als kriegerisches Unterfangen gegen die Heiden kaum berührt. Denn die umfassende Begründung des ,gerechten` Krieges durch die Kanonisten erlaubt in dieser Hinsicht keinen Widerspruch mehr:

Von den vier Kriterien des Augustinus - Kriegserklärung durch eine legitime Autorität, gerechtfertigter Kriegsgrund, keine andere Lösungsmöglichkeit und angemessene Formen der Kriegsführung - konnte im Blick auf den Orientkreuzzug [...] nur das dritte zur Erörterung Anlaß geben, ${ }^{257}$

also die Frage, ob Gewalt gerechtfertigt sei oder doch noch friedliche Mittel möglich wären, um das gewünschte Ziel zu erreichen, sei es die Befreiung der heiligen Stätten, der Friede mit den Heiden oder eben ihre Konversion. So verhandelt der vormalige Generalmagister der Dominikaner Humbert von Romans (1200-1277) in seinem Opusculum tripartitum, verfasst als Gutachten im Auftrag des Papstes für das Zweite Konzil von Lyon 1274, unter den zeitgenössischen Einwänden gegen die Kreuzzüge auch den, dass diese die Mission verhindern könnten: alii dicunt quae utilitas est in ista impugnatione Saracenorum? Per hoc enim non provocantur ad conversionem, sed potius provocantur contra fidem Christianam. (Opusculum tripartitum 16) ${ }^{258}$ Darauf antwortet Humbert allerdings mit der gängigen Argumentation, es handele sich bei den

256 Vgl. Cardini, Europa und der Islam, S. 133-134.

257 Hiestand, Die Kreuzzugsidee in der Kritik ihrer Zeit, S. 19.

258 Zitiert nach: Orthuinus Gratius. Fasciculus rerum expetendarum et fugiendarum. Appendix Edwardi Brown. London 1690, S. 185-229, hier S. 196. „Andere sagen: Welcher Nutzen liegt in diesem Angriff auf die Sarazenen? Denn sie werden dadurch nicht zur Konversion angeregt, sondern gegen den christlichen Glauben aufgebracht.“ (Übersetzung F. P.) 
Kreuzzügen ja um legitime und gar notwendige Verteidigungskriege zur Abwehr einer Bedrohung der Christen durch die Heiden: Saraceni habent tantam militiam contra Christianos, quod omnes Christianos interfecissent ubique, sicut in multis locis fecerunt, nisi fuissent repressi a Christianis eis resistentibus. ${ }^{259}$ Im Sonstigen folgt Humbert ganz der theologischen Auffassung, die Gewalt im Zusammenhang mit Mission nicht ausschließt, solange nur die Bekehrung freiwillig erfolge, so wie er auch sonst keinen Zweifel an der Berechtigung eines offensiv geführten Krieges gegen die Heiden aufkommen lässt. ${ }^{260}$

Erkennbar kritisch äußert sich hingegen der franziskanische Philosoph Roger Bacon (um 1220 - nach 1292) in den 1260er Jahren in seinem Opus maius, wenn er den militärischen Orden vorwirft, sie würden durch ihr beständiges Kriegsführen im Kampf um die vollständige Herrschaft die Konversion von Muslimen behindern. In dieser Hinsicht kann er dann auch grundsätzliche Kritik an den Kreuzzügen üben, die letztlich allzu oft erfolglos blieben. Wenn sie überhaupt siegreich seien, dann bleibe keiner mehr, um das Land zu bewirtschaften, und Muslime, die christliche Angriffe überleben, seien kaum geneigt, die feindliche Religion anzunehmen: Unde Saraceni propter hoc in multis mundi partibus fiunt impossibiles conversioni [...] Praterea fides ingressa non est in hunc mundum per arma sed per simplicitatem praedictionis, ut manifestum est. (Opus maius 3, 13) ${ }^{261}$ Er schließt damit aber wiederum nicht aus, dass Gewalt ein legitimes Mittel zur Verteidigung des Heiligen Landes sei, wenn sie mit der Verkündigung des christlichen Glaubens einhergeht. ${ }^{262}$

Das kanonische Recht geht angesichts der Verknüpfung von Kreuzzug und Mission beziehungsweise der kritischen Kontrastierung beider daher einen Mittelweg, wenn es sich immer wieder an der Feststellung abarbeitet, dass wohl die Möglichkeit zur freien Predigt nötigenfalls gewaltsam durchgesetzt werden dürfe, nicht aber die Konversion der Muslime. ${ }^{263}$ In dieser Perspektive sollen die Kreuzzüge die Grundlage und den Rahmen für die Mission schaffen, aber nicht im eigentlichen Sinn erzwingen. ${ }^{264}$ Insofern die Kreuzzüge nicht als Konversionszüge erscheinen, bleibt auch kein ideeller Widerspruch zur Mission, und so sind es gerade die Franziskaner und Do-

259 Ebd. „Die Sarazenen haben so viel Krieg gegen die Christen geführt, dass sie alle Christen getötet haben, überall und an vielen Orten, wenn sie nicht von den Christen, die ihnen Widerstand leisteten, zurückgedrängt wurden.“ (Übersetzung F. P.)

260 Vgl. dazu Hiestand, Die Kreuzzugsidee in der Kritik ihrer Zeit, S. 30 - 33.

261 Zitiert nach: Roger Bacon: Opus maius, Bd. 3. Hrsg. von John Henry Bridges, Oxford 1900, S. 121-122. „Deshalb werden die Sarazenen in vielen Teilen der Welt dadurch unmöglich bekehrt [...] Außerdem kann der Glaube nicht durch Waffengewalt in diese Welt gelangen, sondern durch die Frömmigkeit der Predigt, wie offensichtlich ist.“ (Übersetzung F. P.)

262 Vgl. dazu Alan John Forey: The military orders and the conversion of Muslims in the twelfth and thirteenth centuries. In: Journal of Medieval History 28 (2002), S. 1-22, hier S. 18-19.

263 Vgl. Benjamin Zeev Kedar: Muslim conversion in canon law. In: Ders.: The Franks in the Levant, 11th to 14th centuries. Aldershot [u. a.] 1993 (Variorum Collected Studies Series. 423), S. 321-332.

264 Vgl. dazu grundlegend bei Kedar, Crusade and Mission das Kap. 5: „A contested Linkage: Crusading for the Advancement of Missions“ (S. 159-203). 
minikaner, die einerseits die Impulsgeber und Träger der sich im 13. Jahrhundert neu entfaltenden Mission sind, andererseits aber eben auch in päpstlichem Auftrag den Kreuzzug predigen. ${ }^{265}$

Mit dem Abschluss der Bekehrung Europas im 10. Jahrhundert hatte die Mission eine funktionale Ausdifferenzierung erfahren. Sie war schon lange nicht mehr als Auftrag an alle Glieder der Kirche wahrgenommen worden und bedeutete nun allenfalls noch die Bekehrung von politisch-militärisch unterworfenen ,Ungläubigen“ in eroberten Gebieten, unter dem Schutz weltlicher Gewalt und den damit verbundenen Möglichkeiten mehr oder weniger direkter und offener Ausübung von Druck zur Konversion, so bei den Heiden im Nordosten. ${ }^{266}$ Der weltmissionarische Impuls der Bettelorden stellt demgegenüber einen echten Neuanfang dar, denn er zielt alsbald auf die Mission unter den Muslimen außerhalb christlicher Herrschaftsgebiete, als freie Verkündigung unabhängig von weltlicher Absicherung. Die Frage nach den Formen von Mission wie ihrer institutionellen Organisation wird daher in dieser Zeit neu diskutiert, obwohl oder auch gerade weil der Erfolg der missionarischen Bemühungen ausbleibt.

Die Hoffnung, die Muslime bekehren zu können, löst dabei die Kreuzzugsidee nicht einfach ab, auch wenn sich angesichts der sich im 12. Jahrhundert fortsetzenden militärischen Niederlagen im Orient eine gewisse Ernüchterung hinsichtlich der Erfolgsaussichten der Kreuzzüge eingestellt haben mag. Vielmehr zeigt sich, „that crusaders and missionaries were rarely competitors, but often partners, in the dual process of winning or defending the Holy Land and of defeating Islam“. ${ }^{267}$ Sowohl Kreuzzug als auch Mission bleiben in dieser Hinsicht letztlich erfolglos und begegnen zunehmenden Schwierigkeiten, wie nachlassender Unterstützung für die Kreuzzüge, organisatorischen Problemen und den sehr eingeschränkten Möglichkeiten für eine freie Predigt unter Muslimen, dennoch werden beide gleichermaßen fortgesetzt. ${ }^{268}$ Ein grundsätzlicher Gegensatz beider Konzepte ist daher weder theoretisch noch in Bezug auf die Protagonisten ihrer Umsetzung festzustellen.

Im Kontrast zu den Missionskriegen und Zwangskonvertierungen der vorhergehenden Jahrhunderte, die im 13. Jahrhundert in der Konfrontation mit den Wenden fortleben, kann sich in Bezug auf die Muslime aber immerhin die Idee einer gleichsam „irenischen Missionsmethode“ entfalten, die in der „Überzeugung durch rationale Argumente im friedlichen Dialog“ die ideale Form der Mission sieht. ${ }^{269}$ Die Möglichkeit der Verhandlung von Glaubensgegensätzen und die Überwindung der anderen

265 Vgl. Elizabeth Siberry: Missionaries and Crusaders, 1095-1274. Opponents or Allies? In: Studies in Church History 20 (1983), S. 103-110.

266 Vgl. hierzu und speziell zum Neuansatz der Mission unter den Muslimen im 13. Jahrhundert Fritz Blanke: Die Mohammedanermission im Mittelalter. In: Ders.: Missionsprobleme des Mittelalter und der Neuzeit. Zürich/Stuttgart 1966, S. 77-87.

267 Housley, The crusades and Islam, S. 193.

268 Vgl. ebd.

269 Sievernich, Die christliche Mission, S. 120. 
Religionen im Diskurs schlägt sich in der schon älteren literarischen Form des Religionsdialoges nieder, die im 13. Jahrhundert auf vielfältige Weise aktualisiert und bearbeitet wird ${ }^{270}$ - wiederum trotzdem oder gerade weil die Vision einer friedlichen Bekehrung aller Ungläubigen in dialogischem Einvernehmen reine Utopie bleibt. Die Kreuzzugsidee kommt häufig genau an dieser Stelle wieder zur Geltung, wie sich am Beispiel des mallorquinischen Philosophen und Theologen Ramon Llull (um 12321316) verdeutlichen lässt, in dessen Biographie sich „Kreuzzugs- und Missionierungsgedanke, Märtyrersehnsucht und Hoffnung auf Bekehrung aller Völker zu Christus“ mehrfach abwechseln und doch als Ausdruck ein- und desselben Glaubenseifers erscheinen. ${ }^{271}$

Nach einer Christusvision, die Llull im Jahr 1263 empfangen haben will, gibt er in einer radikalen Konversion sein höfisch-weltliches Leben als Prinzenerzieher und Troubadour auf, um sich in franziskanischem Geiste fortan einem Leben aus der Liebe zu Christus und der Mission zu widmen. Er bereist den gesamten Mittelmeerraum, lernt Arabisch und drängt kirchliche und weltliche Würdenträger, Schulen für Missionare zu gründen, die Kenntnisse über die Sprachen wie die Religion der Muslime vermitteln. Gleichzeitig will er die Irrtümer der Ungläubigen auf philosophische Weise widerlegen. Seine Missionstheorie entwickelt er 1275 in einem fiktiven Religionsdialog, dem Llibre del gentil e dels tres savis (Buch vom Heiden und den drei Weisen), der vorführt, wie sich Überzeugung allein auf Grundlage der Vernunft, ohne Rückbezug auf religiöse Autoritäten, vollziehen könne. In seinem an Papst Nikolaus IV. gerichteten Tractatus de modo convertendi infideles (Über die Bekehrung der Ungläubigen) entwirft er 1292 andererseits einen umfassenden Plan, der vor die eigentliche Missionsarbeit den Krieg gegen die Ungläubigen setzt, und gegen Ende seines Lebens befürwortet er durchaus auch eine erzwungene Mission der Muslime. Sein vom Sufismus beeinflusstes Llibre d'amic e amat (Das Buch vom Freunde und vom Geliebten) von 1288 wiederum spricht die Sprache mystischer Christusfrömmigkeit.

Und immer wieder treibt es Llull, selbst zu den Muslimen aufzubrechen; auf einer Reise nach Nordafrika soll er 1315 von einer aufgebrachten Menge gesteinigt worden und auf der Rückfahrt nach Mallorca an den Folgen gestorben sein. Daher gilt er in der volkstümlichen Verehrung als Märtyrer, gleichwohl er von der Kirche nie offiziell als solcher anerkannt worden ist. Llull steht damit exemplarisch für die zeitgenössische Frömmigkeitspraxis ebenso wie für die theologische Reflektion der widersprüchlichen Dynamik von Kreuzzugsidee und Missionshoffnung, wie sie sich im Laufe des 13. Jahrhunderts herausbildete. Typologisch-strukturell lässt sich das als Nebeneinander gegensätzlicher Heils- und Heiligkeitsmodelle verstehen, die im Zusammenhang stehen mit den unterschiedlichen Optionen des Diskurses um das Heidentum sowie die Grenzen und Möglichkeiten verschiedenen Formen religiösen Kulturkon-

270 Vgl. dazu ausführlicher unten in Kap. 5 Adversus Judaeos, S. 307-320.

271 Cardini, Europa und der Islam, S. 134. Zu Biographie und Wirken Ramon Llulls im Folgenden vgl. Sievernich, Die christliche Mission, S. 119-122. 
taktes. Kreuzzug und Mission werden unter diesen Gesichtspunkten zum Gegenstand diskursiver und narrativer literarischer Bearbeitung, wobei beide Konzepte in einem komplexeren und sich historisch wandelnden Verhältnis stehen; weder schließen sie sich gegenseitig und im Blick auf die Legitimität von Gewaltanwendung aus, noch fügen sie sich problemlos im Sinne einer ,Taufe durch das Schwert` ineinander. 